\title{
Cold Field Emission in Microreactors to Perform Chemical Reactions
}

Mattia Morassutto 


\section{Graduation committee}

Chairman and secretary

Prof. Dr. Ir. J. W. M. Hilgenkamp

Universiteit Twente

Promotor:

Prof. Dr. J.G.E. Gardeniers

Universiteit Twente

Assistant promotor:

Dr. Ir. R. M. Tiggelaar

Universiteit Twente

\section{Members:}

Prof. Dr. H. J. M. Zandvliet

Universiteit Twente

Prof. Dr. ir. J. E. ten Elshof

Universiteit Twente

Prof. Dr. . A. Monzón Bescós

Universidad Zaragoza

Dr. T. Noël

Technische Universiteit Eindhoven

Dr. W. Verboom

Universiteit Twente

The research described in this thesis has been carried out in the Mesoscale Chemical Systems group at the $\mathrm{MESA}^{+}$Institute for Nanotechnology, University of Twente, Enschede, The Netherlands. The work was financially supported by the Netherlands' Organization for Scientific Research (NWO), within the NWONano program, project no. 11411.

Cover is designed by Mattia Morassutto

Cold Field Emission in Microreactors to Perform Chemical Reactions

ISBN: 978-90-365-4071-1

DOI: $10.3990 / 1.9789036540711$

URL: http://dx.doi.org/10.3990/1.9789036540711

Printed by Gildeprint - The Netherlands

Copyright (C) 2016 by Mattia Morassutto, Enschede, The Netherlands. 


\title{
COLD FIELD EMISSION IN MICROREACTORS TO PERFORM CHEMICAL REACTIONS
}

\author{
DISSERTATION
}

to obtain

the degree of doctor at the University of Twente, on the authority of the rector magnificus, prof. dr. H. Brinksma,

on account of the decision of the graduation committee,

to the publicly defended

on Friday, 26 February 2016 at 12:45

by

Mattia Morassutto

born on 7 October 1985

in Udine (UD), Italy 
This dissertation has been approved by:

Prof. Dr. J. G. E. Gardeniers

Dr. Ir. R. M. Tiggelaar
Universiteit Twente (promotor)

Universiteit Twente (assistant promotor) 


\section{Contents}

1 Introduction 1

2 Solvated electrons: background and applications $\quad 5$

2.1 Solvated electrons: properties and models $\quad 6$

$\begin{array}{ll}2.2 \text { Generation of solvated electrons } & 7\end{array}$

2.2.1 Photoionization: $\gamma$-wave and x-ray radiation $\quad 7$

2.2.2 Chemical generation $\quad 7$

$\begin{array}{ll}2.2 .3 \text { Electrochemical generation } & 7\end{array}$

2.3 Solvated electrons in organic chemistry $\quad 8$

2.4 Alternative process to Birch reduction 9

$\begin{array}{ll}2.5 \text { Cold field emission } & 10\end{array}$

$\begin{array}{ll}2.6 \text { References } & 12\end{array}$

3 Optimization of Fe-catalyzed chemical vapor deposition of vertically aligned $\begin{array}{ll}\text { carbon nanotube field emitter arrays } & 17\end{array}$

3.1 Introduction 19

$\begin{array}{ll}3.2 \text { Experimental } & 19\end{array}$

3.2.1 Sample preparation $\quad 19$

3.2.2 Substrate pretreatment and synthesis of (VA)CNTs 20

3.2.3 Analysis of (VA)CNTs $\quad 22$

3.3 Results and discussion $\quad 23$

3.3.1 Growth of VACNTs 23

3.3.2 Influence of Fe thickness, reaction temperature and reaction time on aligned growth of CNTs 25

3.3.3 Synthesis stage: effects of adhesion layer and support 31

3.3.4 Electrical conductivity of VACNTs $\quad 34$

3.3.5 Field electron emission from VACNTs 36

$\begin{array}{ll}3.4 \text { Conclusion } & 37\end{array}$

3.5 References 38

Supporting Information $\quad 42$

4 Cold field emission in liquids in a microreactor with an integrated planar microstructured electrode: modeling and experimental results 47

4.1 Introduction 49

4.2 Theory: design and modeling $\quad 49$

$\begin{array}{ll}\text { 4.2.1 Microreactor design } & 49\end{array}$ 
4.2.2 Microreactor modeling $\quad 50$

4.3 Experimental $\quad 52$

4.3.1 CFE microreactor fabrication $\quad 52$

4.3.2 Field emission experiments in CFE microreactor 54

4.3.3 Chemical reaction in CFE microreactors $\quad 54$

4.4 Results and discussion $\quad 54$

4.4.1 Model results $\quad 54$

4.4.2 Electrical characterization $\quad 55$

4.4.3 Chemical reactions in CFE microreactors $\quad 58$

$\begin{array}{ll}4.5 \text { Conclusions } & 60\end{array}$

4.6 References 61

$\begin{array}{ll}\text { Supporting Information } & 63\end{array}$

5 Flow chemistry using field electron emission from silicon nanowires integrated into a microreactor $\quad 65$

5.1 Introduction $\quad 67$

5.2 Experimental $\quad 68$

5.2.1 Microreactor fabrication $\quad 68$

$\begin{array}{ll}5.2 .2 \text { Electrical measurements } & 70\end{array}$

$\begin{array}{ll}\text { 5.2.3 Chemical reactions } & 70\end{array}$

$\begin{array}{ll}5.3 \text { Results and discussion } & 72\end{array}$

5.3.1 Apolar solvents $\quad 72$

$\begin{array}{ll}\text { 5.3.2 Polar solvents } & 74\end{array}$

$\begin{array}{ll}\text { 5.3.3 Aromatic reduction } & 74\end{array}$

$\begin{array}{ll}5.4 \text { Conclusions } & 77\end{array}$

$\begin{array}{ll}5.5 \text { References } & 78\end{array}$

$\begin{array}{lr}\text { Supporting Information } & 80\end{array}$

6 Birch-type reduction of polycyclic aromatic hydrocarbons in alcohols using

$\begin{array}{lr}\text { field electron emission in a microreactor } & 87\end{array}$

6.1 Introduction $\quad 89$

6.2 Experimental $\quad 89$

$\begin{array}{ll}6.3 \text { Results and discussion } & 90\end{array}$

$\begin{array}{ll}\text { 6.3.1 Reduction of anthracene } & 90\end{array}$

6.3.2 Reduction of naphthalene $\quad 94$

6.3.3 Reduction of benzophenone $\quad 95$

6.4 Conclusions $\quad 96$

$\begin{array}{ll}6.5 \text { References } & 97\end{array}$ 
Supporting Information

7 Conclusions and Outlook

7.1 Conclusions

7.2 Outlook

Summary

107

Samenvatting

109

Acknowledgements 
Chapter

\section{Introduction}


The phrase "solvated electrons" means an excess of electrons in a liquid medium where the electrons are in a spatially localized state instead of in a conduction band of the solvent ${ }^{[1]}$. The physical and chemical properties of solvated electrons are strictly related to the electron-solvent interactions. In 1864 the term solvated electron appeared for the first time in a published report ${ }^{[2]}$, although they had already been observed in 1807 by Sir Humphry Davy ${ }^{[3]}$.

Solvated electrons were considered to be a too exotic topic for a long time, until 1944, when Arthur Birch reported a series of organic reactions - including the partial reduction of aromatic hydrocarbons - using solvated electrons generated by dissolving alkali metals in liquid ammonia ${ }^{[4]}$. The application of solvated electrons in organic chemistry and the advances in radiation chemistry generated new knowledge on the nature and properties of solvated electrons starting from the $60 \mathrm{~s}^{[5]}$. Numerous theoretical and experimental studies based on light absorption, magnetic resonance and kinetics of solvated electrons were carried out by using radiation and electrochemistry. Since the $60 \mathrm{~s}$ electrochemical methods were proposed to partially reduce aromatic hydrocarbons. The majority of the proposed processes were based on the generation of solvated electrons by using alkali salts dissolved in an amine solvent, or by using a mercury electrode and a tetrabutylammonium salt as the electrolyte ${ }^{[6,7,8]}$. Cold field emission (CFE) is another method by means of which solvated electrons may be generated and does not require the use of radiation beams or reduction of alkali salts, as reported by Krivenko et al. and Agiral et al. ${ }^{[9,10]}$. In detail, Agiral et al. have reported the generation of solvated electrons in n-hexane at ambient temperature using carbon nanofibers as emitters. In Chapter 2 all details regarding properties of solvated electrons, the methods to generate them, including their pro's and cons, are discussed, and a state-of-the-art overview of applications of solvated electrons is provided.

In order to achieve a sustainable and green process to perform Birch-like reduction reactions, the use of field emission in combination with microreactor technology is presented in this thesis. The proposed approach consists of the use of microtips or arrays of fabricated nanoneedles integrated in a microfluidic system to enhance field emission in a continuous flow of dielectric solvents with reactants. The main premise of this approach is that solvated electrons generated by field emission from micro- or nano-tips can be used for chemical purposes due to the small-scale of the system, despite the limited lifetime of solvated electrons. In order to have a sufficient supply of solvated electrons, dense arrays of nanotips are preferred, where the tips should have a small radius of curvature to achieve electrical field enhancement, which ensures that a lower voltage is required for field emission. Carbon nanotubes (CNTs) are ideal nanostructures for the emission of electrons, due to their well-suited electrical properties and the possibility of growing them on a lithographically patterned metallic film. In order to acquire knowledge about how to create electrodes formed by a 
dense array of vertically aligned carbon nanotubes, synthesis conditions and the electrical performance of grown arrays of CNTs is studied in Chapter 3.

Another crucial parameter for field emission in dielectric liquids by applying a relatively low voltage between the electrodes (less than $50 \mathrm{~V}$ ), as reported by Agiral et al. ${ }^{[10]}$, is the distance between the two electrodes. A theoretical and experimental study on microreactors with micro-tip-based platinum electrodes with various tip-to-plane spacings is presented in Chapter 4.

Nowadays, silicon nanowires (SiNWs) are widely used, such as in the design of solar cells. SiNWs can be seen as an alternative for the arrays of vertically aligned CNTs. In Chapter 5 their application for field emission and integration in a microfluidic device is described. Integration of electrodes formed by highly doped SiNWs indeed enhances field emission in a continuous flow microreactor, and can be applied for the partial reduction of anthracene in polar and nonpolar solvents if a proton donator is present in the reactants.

The generation of solvated electrons directly in alcohol opens the way to carry out the reduction of polycyclic aromatic hydrocarbons without the addition of any electrolyte or toxic solvent, thereby creating a green process that eventually can be an alternative to the actually used alkali-based processes. The performance of a SiNW-based microdevice for soft reduction processes is given in Chapter 6.

Finally, in Chapter 7 general conclusions of this thesis are given, as well as an outlook for future research. 


\section{References}

[1] A. L. Nichols III and D. Chandler, "Excess electrons in simple fluids IV: real time behavior", J. Chem. Phys., 87, 6671-6681, 1987.

[2] W. Weyl, "Uber metallammonium-verbindungen", Annalen der Physik, 197, 601-612, 1864.

[3] M. Chiesa, M. C. Paganini, E. Giamello, D. M. Murphy, C. di Valentin and G. Pacchiani, “Excess electrons stabilized on ionic oxide surfaces”, Acc. Chem. Res., 39, 861-867, 2006.

[4] A. J. Birch, "Reduction by dissolving metals. Part 1", J. Chem. Soc., 430-436, 1944.

[5] N. R. Kestner, "Theory of the solvated electron" in: Radiation Chemistry: Principles and Applications (eds. Farhataziz and M.A.J. Rodgers), VCH Verlagsgesellschaft GmbH, Weinheim, 237-262, 1987.

[6] H. W. Sternberg, R. Markby and I. Wender, "Electrochemical reduction of the benzene ring”, J. Electrochem. Soc., 110, 425-429, 1963.

[7] T. Asahara, M. Seno and H. Kaneko, "Electrolytic reduction of naphthalene in various alcohol-hexamethylphosphoramide systems”, Bul. Chem. Soc. Jpn., 41, 2985-2989, 1968.

[8] E. Kariv-Miller, K. E. Swenson, G. K. Lehman and R. Andruzzi, "Selective cathodic Birch reductions", J. Org. Chem., 50, 556-560, 1985.

[9] A. G. Krivenko, N. S. Komarova and N. P. Piven, "Electrochemical generation of solvated electrons from nanostructured carbon”, Electrochem. Commun., 9, 2364-2369, 2007.

[10] A. Agiral, H. B. Eral, D. van den Ende and J. G. E. Gardeniers, "Charge injection from carbon nanofibers into hexane under ambient conditions", IEEE Trans. Electron Dev., 58, 3514-3518, 2011. 


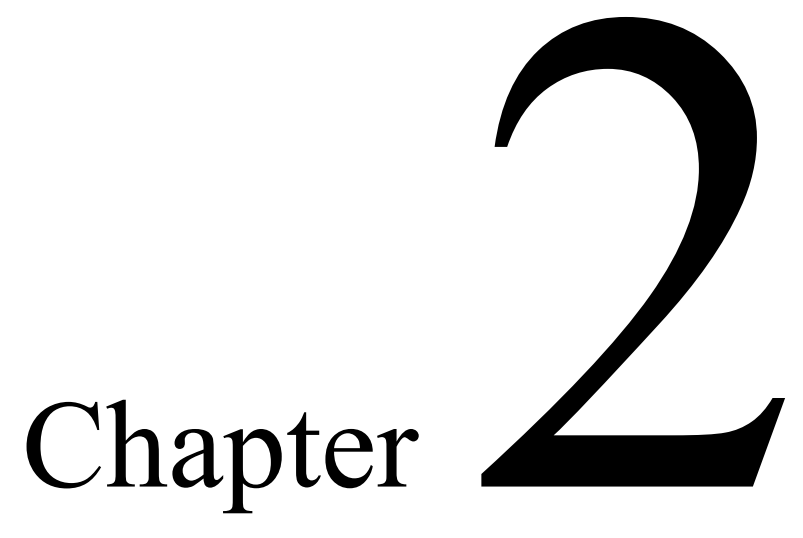

Solvated electrons: background and applications 
In this chapter details are provided regarding the origin of solvated electrons and how they can be generated. In addition, a literature overview of their applications in organic chemistry is given.

\subsection{Solvated electrons: properties and models}

A solvated electron $\left(\mathrm{e}_{\mathrm{sol}}^{-}\right)$can be defined as the smallest anion in solution, with exceptional physical and chemical properties. At the beginning of the $19^{\text {th }}$ century, it was discovered that by dissolving an alkali metal in liquid ammonia a blue solution with strong reducing properties could be obtained ${ }^{[1]}$. In 1908, Kraus carried out a migration experiment, by applying a potential difference between two platinum electrodes in a solution of sodium in liquid ammonia, during which he observed that the colour and the reducing properties were due to the formation of solvated electrons from the dissociation of the alkali metal in a cation $\left(\mathrm{Na}^{+}\right)$and an anion $\left(\mathrm{e}^{-}\right)^{[2]}$. The existence of solvated electrons was also reported for other liquid media, including water. In 1962 Hart and Boag observed the presence of an excess electron in water by analysing the absorption spectra of water and aqueous solutions after applying an electron pulse of $1.8 \mathrm{MeV}$. They observed a lower intensity of the peak, related to the $\mathrm{e}_{\text {sol }}^{-}$, in the absorption spectra of solutions containing contaminants, such as $\mathrm{O}_{2}, \mathrm{CO}_{2}$ or $\mathrm{N}_{2} \mathrm{O}$, than in solutions containing only alkali metals ${ }^{[3]}$. After this discovery, theoretical and experimental studies of electrons in liquid media intensified and it became an active research area. Solvated electrons were also observed in other solvents, such as methanol, hexamethylphosphoramide (HMPA), urea, and hexane ${ }^{[4,5,6,7]}$. Experiments carried out using different solvents showed a correlation between the lifetime of the $\mathrm{e}_{\text {sol }}^{-}$and the type of the solvent: in amine and amide solvents $\mathrm{e}^{-}$ sol have a longer lifetime (i.e. $\mathrm{e}_{\text {sol }}^{-}$are stable for days in $\mathrm{NH}_{3}$, hours in HMPA and ethylamine, and only microseconds in urea) than in polar protic solvents (i.e. a few femtoseconds in water, and picoseconds in alcohols such as methanol, ethanol and 1-propanol ${ }^{[8]}$ ).

Most of the models developed to describe the $\mathrm{e}_{\text {sol }}^{-}$are based on the ammonia-electron system and describe the $\mathrm{e}_{\text {sol }}^{-}$as a particle-in-a-box, where the excess electron is trapped in a cage of solvent molecules ${ }^{[9,10]}$. Recently, Shkrob proposed a more complex theory, which considers also the solvent dynamics. His theory describes the $\mathrm{e}_{\text {sol }}^{-}$as a radical anion stabilized by the solvent, in which most of the excess electron density resides in the external orbitals of $\mathrm{N}$ atoms in the ammonia molecules. The repulsion between the negatively charged ammonia molecules creates a cavity were the electron is trapped. An analogous model was suggested to occur in the case of $\mathrm{e}_{\text {sol }}^{-}$in aprotic solvents other than ammonia $^{[11]}$. 


\subsection{Generation of solvated electrons}

The generation of $\mathrm{e}_{\text {sol }}^{-}$in liquid media can be accomplished by various methods, which will be discussed in the following subsections in detail: i) by photoionization or high energy radiation, ii) by means of a chemical method, and iii) by using electrical or electrochemical methods.

\subsubsection{Photoionization, $\gamma$-wave and x-ray radiation}

Photons can excite electrons and by providing photons with sufficient energy to overcome the band gap, it is possible to generate $\mathrm{e}_{\text {sol. }}^{-}$. Similarly an electron can be excited by using $\gamma$-wave and $\mathrm{x}$-ray radiation $^{[12,13,14]}$.

\subsubsection{Chemical generation}

By dissolving an alkali metal (such as lithium or sodium) in a simple amine, due to the spontaneous dissociation of the alkali metal in a cation $\left(\mathrm{M}^{+}\right)$and an anion $\left(\mathrm{e}^{-}\right)$, solvated electrons can be obtained and their stability is related to the nature and purity of the solvent ${ }^{[15]}$.

\subsubsection{Electrochemical generation}

Another method to generate $\mathrm{e}_{\text {sol }}^{-}$consists of transfer of a charge from the electrode to an acceptor (electrolyte) by applying a potential difference or a current to a solution. The transfer typology can be of first or second order: in case of first order the electron is immediately transferred in the solution, whereas in case of second order ions of opposite electrical charges come together in the solution, thereby forming distinct chemical entities (ion-pair mechanism) ${ }^{[16,17]}$. Usually, for the electrochemical generation of $\mathrm{e}_{\text {sol }}^{-}$, an alkali salt is used as electrolyte, but its role during the reaction is still not totally clarified. At present time, two theories are postulated: i) the alkali salt serves only as electrolyte (current carrier) and the solvated electron is directly generated in the solution, ii) the solvated electron is generated upon re-oxidation of the metal after its reduction to the metal state (ion-pair mechanism). Electron spin resonance (ESR) experiments have clarified the formation mechanism of $\mathrm{e}_{\text {sol }}^{-}$for most of the solvents, and suggest a double function of the alkali metal cation during the reaction, i.e. as current carrier and as generator of $\mathrm{e}_{\text {sol }}^{-}$after reduction to the metal state (ion-pair mechanism). This mechanism is accepted for almost all solvents, except for HMPA. Data obtained by Kanzaki et al. suggest that in the case of HMPA the electrons are directly generated from the electrode in the solution ${ }^{[16]}$. However, this is in contrast with the experimental data of Krishtalik et al., who observed, by using a potential sweep method at high speed scan-rates, two oxidation peaks for the reaction when carried out using HMPA. The latter suggests that, as for all other amine solvents, the formation of $\mathrm{e}_{\text {sol }}^{-}$in HPMA follows the ion-pair mechanism ${ }^{[17]}$. 


\subsection{Solvated electrons in organic chemistry}

As mentioned in section 2.2, alkali metals dissolved in liquid ammonia or amines generate $\mathrm{e}_{\text {sol }}^{-}$and the obtained solution is a powerful reducing agent that may be used to perform organic reduction of aromatic hydrocarbons. This type of reaction, extensively used in the pharmaceutical industry in some synthesis steps of complex molecules (e.g. synthesis of nandrolone, cefradine, epicillin), is commonly known as "Birch reduction",[18].

In addition to an alkali metal and liquid ammonia, the Birch reduction also involves an alcohol and the substrate to be reduced (aromatic compound). The reaction is an alternative process for catalytic hydrogenation and permits to obtain only a partial reduction of the aromatic hydrocarbon. A general overview of the molecular mechanism of the Birch reduction of benzene is shown in Figure 2.1.

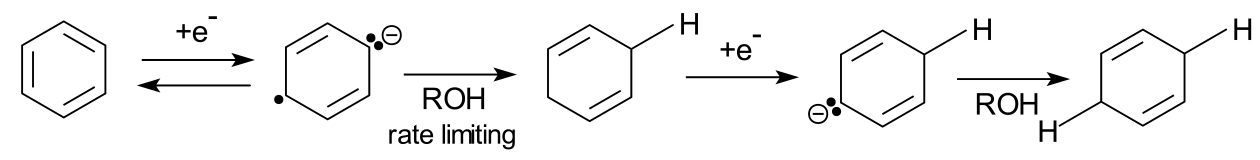

Figure 2.1: Reaction mechanism of the Birch reduction of benzene ${ }^{[19]}$.

The Birch reduction is a radical type reaction and involves the addition of two electrons and two protons to the aromatic ring. A possible mechanism of the reaction was proposed by Krapcho in 1959, identifying the reducing species in the $\mathrm{e}_{\text {sol }}^{-}$generated during the dissociation of the alkali metal in liquid ammonia. The first step is the addition of one electron to the aromatic compound forming a radical anion. This step is followed by the protonation of the radical anion or by re-oxidation to the starting molecule. After protonation of the radical anion another electron is added and followed by protonation ${ }^{[20]}$. The first proton addition to the aromatic ring is considered to be the determining step of the reaction. The regio-selectivity of the reduction depends on the stability of the final product. The second protonation predominantly occurs in para-position with respect to the first protonation. For example, in the case of benzene the competition between 1,2-dihydrohexadine and 1,4dihydrohexadine is favored to 1,4-dihydrohexadine, which is also thermodynamically the most stable product $^{[21]}$. Studies on the charge density of the radical anion confirmed the above mentioned argument, showing that the para-position is the site with the largest negative charge ${ }^{[22]}$. Other less volatile solvents can be used instead of liquid ammonia, like diethylamine or HMPA, however, upon using another solvent the product(s) obtained and their distribution can change ${ }^{[23]}$. 


\subsection{Alternative processes to Birch reduction}

The Birch reduction has some disadvantages, of which the main are the low temperatures (ammonia has to be cooled to temperatures below $-33{ }^{\circ} \mathrm{C}$ to remain liquefied), and the use of corrosive solutions with instable metals (alkali metals react with moisture). In order to avoid these inconveniences, studies on the development of greener and safer processes were carried out. An alternative process was shown by Birch himself, for the reduction of m-methoxytoluene to the corresponding 1,4dihydroderivate ${ }^{[24]}$. A current was applied to a solution of liquid ammonia, ethanol and sodium ethoxide using copper electrodes. This was the first process in which $\mathrm{e}_{\text {sol }}^{-}$were generated using an electrochemical method, although the solvent used was still liquid ammonia at cryogenic conditions.

In 1963, Sternberg et al. showed the reduction of benzene by electrolyzing a solution of ethylamine saturated with lithium chloride ${ }^{[25]}$. Using this process, the reduction of benzene and tetralin to the dihydro-products was achieved, avoiding the use of low temperatures and alkali metals. A similar process was reported by Benkeser et al. using methylamine instead of ethylamine. In this case, the reduction of benzene, toluene, ethylbenzene, cumene and t-butylbenzene was achieved by using divided and undivided electrochemical cells, forming the dihydro-product in the case of a divided cell and the tetrahydro-product upon using an undivided cell ${ }^{[26]}$. Another solvent, HMPA, which has similar properties as liquid ammonia but is in liquid state at ambient temperatures, has become an alternative solvent for Birch-type reactions, which also gives a dark blue color in case of presence of $\mathrm{e}_{\text {sol }}^{-}$in the solution. The use of HMPA permits to carry out reactions at more negative potentials and avoids hydrogen evolution at the cathode surface ${ }^{[27]}$.

An alternative electrochemical process that circumvents the use of low molecular weight amines and HMPA was proposed by Karvin-Miller et al. By using a mercury electrode and tetrabutylammonium solutions in water the reduction of simple aromatic compounds and steroids was achieved ${ }^{[28,29]}$. The possibility to use tetrabutylammonium salts instead of lithium salts without the use of a mercury electrode was investigated by Gagyi Palffy et al. The main advantage of the use of a mercury electrode is suppression of secondary reactions such as the oxidation of the targeted dihydro compound. For this reason, in the case of using tetrabutylammonium salts in water with electrodes composed of other metal types (such as $\mathrm{Mg}, \mathrm{Pt}$ ), the use of a divided cell is recommended in order to reduce the aromatic compounds without oxidation ${ }^{[30]}$.

Recently, greener reduction processes not based on electrochemical reactions were proposed. The partial reduction of polycyclic aromatic hydrocarbons (PAH) was obtained by using alkali metals in silica gel $\left(\mathrm{Na}_{2} \mathrm{~K}-\mathrm{SG}(\mathrm{I})\right)$ in tetrahydrofuran $(\mathrm{THF})$ and water ${ }^{[31]}$. Another approach utilizing ionic liquids was proposed by Adams et al. for the reduction of anthracene ${ }^{[32]}$. A greener approach to reduce benzene using a low-temperature plasma was proposed by $\mathrm{Na}$ et al., although with this gasphase method side reactions occurred, such as oxidation of aromatic compounds ${ }^{[33]}$. 


\subsection{Cold field emission}

Cold field emission (CFE) is the process of discharging electrons from the surface of a material upon exposure to a high electric field. This phenomenon, observed and studied since the beginning of the 20th century, can also be used to inject a current into dielectric solvents and to generate solvated electrons in a liquid ${ }^{[34,35,36]}$. In CFE, electrons should overcome a potential barrier at the emitter surface in order to escape from the material. The potential barrier is expressed by the work-function (Ø) of the material and is defined as the minimum amount of energy required to position an electron in the highest Fermi level at a distance of $10 \mathrm{~nm}$ from the surface ${ }^{[37]}$. In order to enhance the emission of electrons from a surface by means of CFE, two ways are possible: i) lowering the potential barrier and/or ii) increasing the energy of the electrons. The immersion of the electrode in a dielectric liquid decreases the potential barrier that the electrons have to overcome. The formation of a double layer between the electrode and the liquid will change the work function according to the properties of the electrode material and the solvent type.

In 1928 Fowler and Nordheim proposed a relation between theoretically calculated field emission currents and experimentally obtained values. The equation known as Fowler-Nordheim equation permits to calculate the emission current due to electron emission from a metal surface into vacuum $^{[38]}$ (eq. 1$)$

$I=A a \emptyset^{-1} F^{2} \exp \left\{-b \emptyset^{1.5} / F\right\} \equiv R^{e l} F^{2} \exp \left\{S^{e l} / F\right\}$

where $I$ is the current, $A$ is the area of emission, $F$ is the local electric field, $\varnothing$ is the local work function, and $a$ and $b$ are constants $\left(a \equiv e^{3} / 8 \pi h_{p}=1.541434 \times 10^{-6} \mathrm{AeV} V^{-2}, b \equiv \frac{4}{3}\left(2 m_{e}\right)^{\frac{1}{2}} /\right.$ $e \hbar_{p}=6.830888 \times 10^{9} \mathrm{eV} \mathrm{m}^{-1}$ where $m_{e}$ is the electron mass, $e$ is the elementary positive charge, and $\hbar_{p}$ is the Plank's constant divided by $\left.2 \pi\left(\hbar_{p}=h_{p} / 2 \pi\right)\right)$.

This equation was developed assuming that the emitted electrons are into absolute vacuum at a temperature of $0 \mathrm{~K}$. For the emission of electrons into dielectric liquids, instead of vacuum, this Fowler-Nordheim expression has to be modified with several some correction factors (which are in detail discussed in the following chapters of this thesis).

A high melting point, a good mechanical stiffness and a high length/diameter aspect ratio are considered the main criteria to select materials to be used as electron emitter ${ }^{[39]}$. The presence of protrusions - i.e. structures with a high length-to-diameter ratio and a small radius of curvature on the tip - on the surface of an electrode decrease the required electric field to inject an electron into the liquid, due to the re-distribution of the charges on the surface ${ }^{[40]}$. Nowadays nanostructures such as carbon nanotubes and silicon nanowires have gathered interest as electron emitters ${ }^{[41,42,43]}$. The possibility to inject electrons into a commercial grade dielectric liquid was investigated by Agiral et 
al. using carbon nanofibers as emitters and liquid hexane as solvent. They reported the emission of electrons at ambient temperature upon applying low voltages (less than $100 \mathrm{~V}$ ) across a spacing between the electrodes in the micrometer range $(\leq 9 \mu \mathrm{m})$, yielding an electric field of $\sim 100 \mathrm{kV} / \mathrm{cm}^{[44]}$.

In the following chapters it will be shown that, by integrating micro/nano-structured emitter surfaces in microfluidic systems, enhanced field emission can be applied to a continuous flow containing a dielectric solvent and that the generated solvated electrons can be used to reduce PAH in a green and controlled way. 


\subsection{References}

[1] M. Chiesa, M.C. Pagani, E. Giamello, D.M. Murphy, C. Di Valentin and G. Pacchioni, "Excess of electrons stabilized on ionic oxide surfaces", Acc. Chem. Res., 39, 861-867, 2006.

[2] C. A. Kraus, "Solutions of metals in non-metallic solvents; iv. 1. Material effects accompanying the passage of an electrical current through solutions of metals in liquid ammonia. Migration experiments”, J. Am. Chem. Soc., 30, 1323-1344, 1908.

[3] E. J. Hart and J. W. Boag, "Absorption spectrum of hydrated electron in water and in aqueous solutions", J. Am. Chem. Soc., 84, 4090-4095, 1962.

[4] T. Scheidt and R. Laenen, "Ionization of methanol: monitoring the trapping of electrons on the fs time scale", Chem. Phys. Lett., 371, 445-450, 2003.

[5] G. Fraenkel, S. H. Ellis and D. T. Dix, "Hexamethylphosphoramide. An aprotic solvent for active metals", J. Am. Chem. Soc., 87, 1406-1407, 1965.

[6] P. P. Edwards, "From solvated electrons to metal anions: electronic structure and dynamics", J. Solution Chem., 14, 187-208, 1985.

[7] J. H. Baxendale, C. Bell and P. Wardman, "Observations on solvated electrons in aliphatic hydrocarbons at room-temperature by pulse-radiolysis”, J. Chem. Soc., 69, 776-786, 1973.

[8] M. J. Bronskill, R. K. Wolff, and J. W. Hunt, "Picosecond pulse radiolysis studies. I. The solvated electron in aqueous and alcohol solutions”, J. Chem. Phys., 53, 4201-4210, 1970.

[9] D. A. Copeland, N. R. Kestner and J. Jortner, "Excess electrons in polar solvents", J. Chem. Phys., 53, 1189-1216,1970.

[10] W. J. Chase and J.W Hunt, "Solvation time of the electron in polar liquids. Water and Alcohols", J. Phys. Chem., 79, 2835-2845, 1975.

[11] I. A. Shkrob, “Ammoniated electron as a solvent stabilized multimer radical anion”, J. Phys. Chem., 110, 3967-3976, 2006.

[12] H. Aulich, L. Nemec and P. Delahay, "Photoionization spectrum of solvated electrons", J. Chem. Phys., 61, 4235-4241, 1974. 
[13] W. F. Schmidt and A. O. Allen, "Mobility of electrons in dielectric liquids", J. Chem. Phys., 52, 4788-4794, 1970.

[14] M. H. Studier and E. J. Hart, "Reduction of benzene by hydrated electrons in gamma-ray irradiated alkaline solutions", J. Am. Chem. Soc., 91, 4068-4072, 1969.

[15] W. Weyl, "Uber metallammonium-verbindungen", Annalen der Physik, 197, 601-612, 1864.

[16] Y. Kanzaki and S. Aoyagui, "Mechanism of electrode-reaction of solvated electrons in hexamethylphosphoric triamide", J. Electroanal. Chem., 47, 109-114, 1973.

[17] L. I. Krishtalik, "Electrochemistry of solvated electrons in nonaqueous solutions", Electrochim. Acta, 21, 693-699, 1976.

[18] A. J. Birch, "Reduction by dissolving metals: Part I", J. Chem. Soc., 430-436, 1944.

[19] H. E. Zimmerman and P. A. Wang, "Regioselectivity of the Birch reduction", J. Am. Chem. Soc., 112, 1280-1281, 1990.

[20] A. P. Krapcho and A.A.Bothnerby, "Kinetics of the metal-ammonia-alcohol reductions of benzene and substituted benzenes", J. Am. Chem. Soc., 81, 3658-3666, 1959.

[21] P. W. Rabideau and D. J. Huser, "Protonation of anion intermediates in metal-ammonia reduction: 1,2- vs. 1,4-dihydro aromatic products”, J. Org. Chem., 48, 4266-4271, 1983.

[22] H. E. Zimmerman and P.A. Wang, "The regioselectivity of the Birch reduction", J. Am. Chem. Soc., 115, 2205-2216, 1993.

[23] E. M. Kaiser, "A comparison of methods using lithium/amine and Birch reduction systems", Synthesis, 391-415, 1971.

[24] A. J. Birch, "Electrolytic reduction in liquid ammonia", Nature, 158, 60-64, 1946.

[25] H. W. Sternberg, R. Markby and I. Wender, "Electrochemical reduction of the benzene ring”, J. Electrochem. Soc., 110, 425-429, 1963.

[26] R. A. Benkeser and E. M. Kaiser, "An electrochemical method of reducing aromatic compounds selectively to dihydro or tetrahydro products”, J. Am. Chem. Soc., 85, 2858$2859,1963$. 
[27] H. W. Sternberg, R. E. Markby, I. Wender and D. M. Mohilner, "Electrolytic generation of solvated electrons and reduction of the benzene ring in ethanol containing hxamethylphosphoramide”, J. Am. Chem. Soc., 89, 186-187, 1967.

[28] E. Karvin-Miller, K. E. Swenson and D. Zemach, "Cathodic Birch reduction of methoxyaromatics and steroids in aqueous solution”, J. Org. Chem., 48, 4210-4214, 1983.

[29] E. Karvin-Miller, K. E. Swenson, G. K. Lehman and R. Andruzzi, "Selective cathodic Birch reduction”, J. Org. Chem., 50, 556-560, 1985.

[30] E. Gagyi Palffy, P. Starzewski, A. Labani and A. Fontana, "Electrochemical reduction of polyaromatic compounds", J. Appl. Electrochem., 24, 337-343, 1994.

[31] P. Nandi, J. L. Dye and J. E. Jackson, "Birch reductions at room temperature with alkali metals in silica gel (Na2K-SG(I))”, J. Org. Chem., 74, 5790-5792, 2009.

[32] C. J. Adams, M. J. Earle and K. R. Seddon, "Stereoselective hydrogenation reactions in chloroaluminate(III) ionic liquids: a new method for the reduction of aromatic compounds", Chem. Commun., 1043-1044,1999.

[33] N. Na, Y. Xia, Z. Zhu, X. Zhang and R. G. Cooks, "Birch reduction of benzene in a lowtemperature plasma", Angew. Chem. Int. Ed., 48, 2017-2019, 2009.

[34] B. Halpern and R. Gomer, "Field emission in liquids", J. Chem. Phys., 51, 1031-1045, 1969.

[35] K. Dotoku, H. Yamada, S. Sakamoto, S. Noda and H. Yoshida, "Field emission into nonpolar organic liquids", J. Chem. Phys., 69, 1121-1124, 1978.

[36] A. G. Krivenko, N. S. Komarova and N. P. Piven, "Electrochemical generation of solvated electrons from nanostructured carbon”, Electrochem. Commun., 2364-2369, 2007.

[37] P. Bergveld, J. Hendrikse and W. Olthuis, "Theory and application of the material work function for chemical sensors based on the field effect principle”, Meas. Sci. Technol., 9, 1801-1808, 1998.

[38] R. H. Fowler, L. Nordheim, "Electron emission in intense electric fields" Proc. R. Soc. A, 119, 173-181, 1928. 
[39] Z. Li, S. Deng and N. Xu, "Mechanism of field emission from carbon nanotubes", Front. Phys. China, 3, 305-316, 2006.

[40] J. Shrimpton, "Charge injection systems: physical principles, experimental and theoretical work", Springer, 2009.

[41] S. Fan, M. G. Chapline, N. R. Franklin, T. W. Tombler, A. M. Cassell and H. Dai, "Selforiented regular arrays of carbon nanotubes and their field emission properties", Science, 283, 512-514, 1999.

[42] P. G. Collins and A. Zettl, "A simple and robust electron beam source from carbon nanotubes”, Appl. Phys. Lett., 69, 1969-1971, 1996.

[43] F. C. K. Au, K. W. Wong, Y. H. Tang, Y. F. Zhang, I. Bello, and S. T. Lee, "Electron field emission from silicon nanowires", Appl. Phys. Lett., 75, 1700-1702, 1999.

[44] A. Agiral, H. B. Eral, D. van den Ende, J. G. E. Gardeniers, "Charge injection from carbon nanofibers into a dielectric liquid under ambient conditions", IEEE Trans. Electron Devices, 58, 3514-3518, 2011. 
Chapter 2 


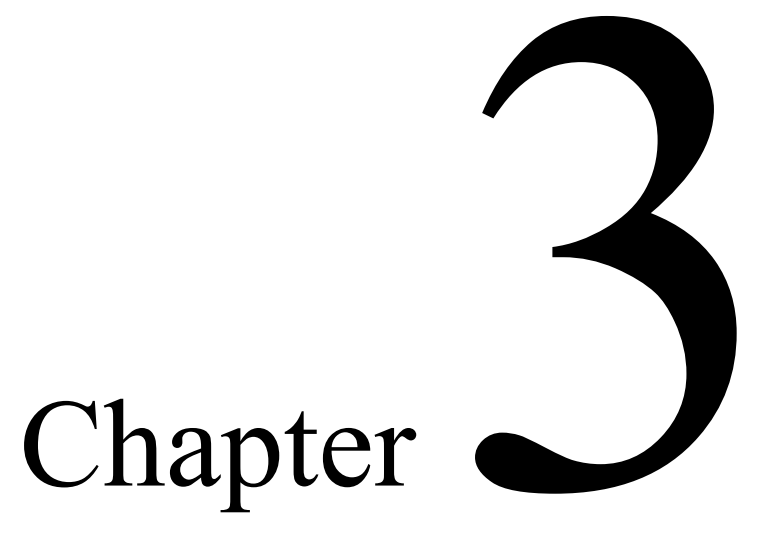

Optimization of Fe-catalyzed chemical vapor deposition of vertically aligned carbon nanotube field emitter arrays

This chapter is submitted to Carbon; M. Morassutto, M.A. Smithers, R.M. Tiggelaar and J.G.E. Gardeniers 


\begin{abstract}
The application of carbon nanotubes and fibers for efficient field emission requires vertically aligned arrays of these elements on an electrically conductive material. In this study, vertically aligned carbon nanotubes are obtained by thermal catalytic chemical vapor deposition using Fe catalyst dispersed on a thin Ta layer, on silicon or fused silica support wafers. The effect of the original Fe layer thickness, a Fe dewetting pretreatment and synthesis conditions on the topography and electrical properties of the nanotubes is analyzed. Either randomly oriented or vertically aligned carbon nanotubes can be obtained by varying the catalyst thickness from 2 to $6 \mathrm{~nm}$ or the synthesis temperature between 680 and $740^{\circ} \mathrm{C}$. A layer of $100 \mathrm{~nm}$ platinum or gold inserted between the Ta layer and the support enhances vertical alignment and electrical conductivity of the nanotubes. It is concluded that the intermediate layer affects the formation of Fe nanoparticles during the pretreatment phase, which directly influences the final nanotube morphology. Optimal growth of dense arrays of vertically aligned nanotubes on different conductive supports is obtained by adjusting the pretreatment time for a given set of parameters of the synthesis stage. Field emission in nitrogen atmosphere is demonstrated, with field enhancement factors of 971 and 2136 for nanotubes grown using $\mathrm{Fe} / \mathrm{Ta}$ catalyst deposited on gold and platinum.
\end{abstract}

Keywords: Vertically aligned carbon nanotubes, Carbon nanotube field emitters, Thermal catalytic chemical vapor deposition 


\subsection{Introduction}

The promising applications of carbon nanotubes (CNTs) in different fields, due to their exceptional mechanical, thermal and electrical properties, has initiated a significant effort of research in the last twenty years ${ }^{[1,2,3]}$. The interest to apply CNTs in nano electronics originates mostly from the possibility to grow them on patterned supports. Methods frequently applied to synthesize vertically aligned CNTs (VACNTs) are thermal catalytic chemical vapor deposition (TCCVD) ${ }^{[4]}$ and plasma enhanced chemical vapor deposition (PECVD) ${ }^{[5]}$, which both permit the formation of dense arrays of VACNTs on different substrates by tuning and control of the synthesis parameters. Due to the simplicity of the required equipment and the large versatility of the method, TCCVD is preferred for large arrays of VACNTs. In this method, a variety of metal catalyst / support combinations have been used, such as $\mathrm{Co}, \mathrm{Ni}$ and $\mathrm{Fe}$ on alumina $\left(\mathrm{Al}_{2} \mathrm{O}_{3}\right)$, silica $\left(\mathrm{SiO}_{2}\right)$ or glass, and oxidized $\mathrm{Si}^{[6,7]}$.

Fe catalyst (with or without $\mathrm{Ta}$ as adhesion layer) has gained attention due to the possibility to form VACNTs on electrically conductive supports ${ }^{[8,9]}$, for which important applications can be found in field emission and vacuum microelectronic devices, since VACNTs belong to the best electron emitters currently available ${ }^{[10,11,12]}$. It is of high relevance to analyze the main TCCVD parameters that affect the alignment of CNTs on a thin film of $\mathrm{Fe} / \mathrm{Ta}$, and to point out correlations between the factors that influence vertical alignment and those that determine the electrical properties. In this work we perform a study of the influence of the hydrocarbon source and synthesis conditions (temperature and time of pretreatment and growth stages) on the vertical alignment of the CNTs and on the electrical properties of the fabricated VACNTs. We will also demonstrate the use of the synthesized CNTs for field emission in atmospheric nitrogen gas.

\subsection{Experimental}

\subsubsection{Sample preparation}

Fe thin films were deposited on wafers of fused silica (UV grade, $100 \mathrm{~mm}$ diameter, $500 \mu \mathrm{m}$ thick; Mark Optics) or Si (p+-type boron doped, (100)-orientation, resistivity 0.01-0.024 $\Omega \mathrm{cm}, 100 \mathrm{~mm}$ diameter, thickness $525 \mu \mathrm{m}$, single side polished; Okmetic, Finland). The supports were cleaned for 10 min. in fuming $100 \%$ nitric acid (UN2031 OM Group) and 15 min. in boiling 69\% nitric acid (51153574 BASF), followed by rinsing in demineralized (DI) water, and spin drying. On the wafers $8 \times 8 \mathrm{~mm}^{2}$ squares, centered with respect to a sample size of $10 \times 10 \mathrm{~mm}^{2}$, were defined in Olin $907-17$ photoresist by standard UV-lithography. Prior to loading in the metal deposition system, silicon supports were immersed for 1 minute in $1 \%$ hydrofluoric acid (D252M Honeywell) to remove the native oxide, followed by DI water rinsing and spin drying. Electron beam evaporation of Fe thin films, with compositions as given in Table 3.1, was done in a Balzers BAK600 system. Metal films were deposited at a pressure below $10^{-5} \mathrm{~Pa}$, and if multiple layers were deposited on the same substrate, this was done without breaking the vacuum. The film thickness was monitored with an in- 
situ quartz crystal monitor. Evaporation material purity was $99.95 \%$ for Ta, $99.95 \%$ for $\mathrm{Fe}, 99.99 \%$ for Pt and $99.999 \%$ for Au. After evaporation, ultrasonic lift-off of the photoresist layer was performed in acetone (20 min; VLSI 51150924, BASF) followed by immersion in isopropanol (10 min; VLSI 51152037, BASF), rinsing in DI water (10 min) and spin drying. A layer of photoresist was spin-coated on the metal surface to protect it from contamination and damage during dicing of $10 \times 10 \mathrm{~mm}^{2}$ samples (Disco DAD-321 dicing machine). After dicing, the photoresist was removed via ultrasonication in acetone.

Table 3.1: Composition of Fe-based thin films on various supports

\section{Reduction of naphthalene in 1-propanol}

\begin{tabular}{cccccc}
\hline $\begin{array}{c}\text { Sample } \\
\text { series }\end{array}$ & $\begin{array}{c}\text { Fe layer } \\
\text { thickness } \\
(\mathbf{n m})\end{array}$ & $\begin{array}{c}\text { Ta layer } \\
\text { thickness } \\
(\mathbf{n m})\end{array}$ & $\begin{array}{c}\text { Underlayer metal } \\
\text { (type, thickness) }\end{array}$ & $\begin{array}{c}\text { Adhesion metal for } \\
\text { underlayer (type, } \\
\text { thickness) }\end{array}$ & $\begin{array}{c}\text { Substrate } \\
\text { (type) }\end{array}$ \\
\hline A1-A8 & 2 & 10 & none & none & $\mathrm{p}+(100)-\mathrm{Si}$ \\
B1-B10 & 4 & 10 & none & none & $\mathrm{p}+(100)-\mathrm{Si}$ \\
$\mathrm{C} 1-\mathrm{C} 4$ & 6 & 10 & none & none & $\mathrm{p}+(100)-\mathrm{Si}$ \\
D1-D13 & 3 & 10 & none & none & $\mathrm{p}+(100)-\mathrm{Si}$ \\
E1-E3 & 3 & 10 & none & none & $\mathrm{Fused} \mathrm{Silica}$ \\
F1-F3 & 3 & 10 & Au, $100 \mathrm{~nm}$ & $\mathrm{Ta}, 10 \mathrm{~nm}$ & $\mathrm{p}+(100)-\mathrm{Si}$ \\
G1-G3 & 3 & 10 & $\mathrm{Pt}, 100 \mathrm{~nm}$ & $\mathrm{Ta}, 10 \mathrm{~nm}$ & $\mathrm{p}+(100)-\mathrm{Si}$
\end{tabular}

\subsubsection{Substrate pretreatment and synthesis of (VA)CNTs}

Samples were positioned flat, with deposited metals facing upwards, in a quartz tube three-zone heated reactor (Elicra Electrowarmte B.V.). This reactor has a flat temperature zone with a variation in temperature of less than $10 \mathrm{~K}$ over ca. $18 \mathrm{~cm}$ of reactor length. In order to guarantee a well-defined and equal temperature at each sample surface, all samples were placed in this zone, with a positional tolerance of $\pm 0.5 \mathrm{~mm}$. No more than 6 samples per run were loaded.

As-deposited continuous Fe thin films were annealed in hydrogen $\left(99.999 \%\right.$, specs $<1 \mathrm{ppm} \mathrm{O}_{2},<3$ ppm $\mathrm{H}_{2} \mathrm{O}$; Indugas/Praxair) at atmospheric pressure to dewet the film, leading to metallic nanoparticles which subsequently act as starting points for VACNT formation. Immediately after the reduction step (to be called "pretreatment stage"), the reaction mixture was adapted to initiate carbon nanostructure formation (the "growth stage"), in which ethylene $\left(\mathrm{C}_{2} \mathrm{H}_{4} ; 99.96 \%\right.$, specs: $<5$ ppm $\mathrm{O}_{2},<$ 
1 ppm $\mathrm{H}_{2} \mathrm{O}$; Praxair) was used as carbon source and nitrogen $\left(\mathrm{N}_{2} ; 99.999 \%\right.$, specs: $<1$ ppm $\mathrm{O}_{2},<3$ ppm $\mathrm{H}_{2} \mathrm{O}$; Praxair) as a diluting inert gas, whereas in a few cases $\mathrm{H}_{2}$ was added. Various settings of temperature and gas flow composition were applied for the growth stage (Table 3.2). All experiments were repeated at least three times. If not mentioned otherwise, presented results are reproducible and shown images are characteristic for the outcome of synthesis experiments at given conditions.

Table 3.2: Conditions of pretreatment and synthesis stage for each sample ${ }^{\mathrm{a}}$ Reduction of naphthalene in 1-propanol

\begin{tabular}{|c|c|c|c|c|c|}
\hline \multirow[b]{2}{*}{ Sample } & \multicolumn{2}{|c|}{ Pretreatment stage } & \multicolumn{3}{|c|}{ Growth stage } \\
\hline & $\begin{array}{c}\text { Temperature } \\
\left({ }^{\circ} \mathrm{C}\right)\end{array}$ & $\begin{array}{l}\text { Time } \\
\text { (min.) }\end{array}$ & $\begin{array}{c}\text { Temperature } \\
\left({ }^{\circ} \mathrm{C}\right)\end{array}$ & $\begin{array}{l}\text { Time } \\
\text { (min.) }\end{array}$ & $\begin{array}{c}\text { Gases (type, flow) } \\
(\mathrm{ml} / \mathrm{min})\end{array}$ \\
\hline $\mathrm{A} 1, \mathrm{~B} 1, \mathrm{C} 1$ & 680 & 180 & 680 & 60 & $\mathrm{~N}_{2}, 100-\mathrm{C}_{2} \mathrm{H}_{4}, 50$ \\
\hline $\mathrm{A} 2, \mathrm{~B} 2, \mathrm{C} 2$ & 680 & 180 & 680 & 60 & $\mathrm{~N}_{2}, 50$ \\
\hline D1 & 720 & 180 & 720 & 60 & $\mathrm{~N}_{2}, 100-\mathrm{C}_{2} \mathrm{H}_{4}, 50$ \\
\hline D2 & 720 & 180 & 720 & 2.5 & $\mathrm{~N}_{2}, 100-\mathrm{C}_{2} \mathrm{H}_{4}, 50$ \\
\hline D3 & 720 & 180 & 720 & 5 & $\mathrm{~N}_{2}, 100-\mathrm{C}_{2} \mathrm{H}_{4}, 50$ \\
\hline D4 & 720 & 180 & 720 & 15 & $\mathrm{~N}_{2}, 100-\mathrm{C}_{2} \mathrm{H}_{4}, 50$ \\
\hline $\mathrm{A} 3, \mathrm{~B} 3, \mathrm{C} 3$ & 720 & 180 & 720 & 60 & $\mathrm{~N}_{2}, 50$ \\
\hline $\mathrm{A} 4, \mathrm{~B} 4, \mathrm{C} 4$ & 720 & 180 & 720 & 60 & $\mathrm{~N}_{2}, 100-\mathrm{C}_{2} \mathrm{H}_{4}, 50$ \\
\hline B5 & 680 & 180 & 680 & 60 & $\mathrm{~N}_{2}, 50$ \\
\hline B6 & 680 & 120 & 680 & 60 & $\mathrm{~N}_{2}, 50$ \\
\hline B7 & 680 & 60 & 680 & 60 & $\mathrm{~N}_{2}, 50$ \\
\hline B8 & 680 & 180 & 680 & 60 & $\mathrm{~N}_{2}, 100-\mathrm{C}_{2} \mathrm{H}_{4}, 50$ \\
\hline B9 & 680 & 120 & 680 & 60 & $\mathrm{~N}_{2}, 100-\mathrm{C}_{2} \mathrm{H}_{4}, 50$ \\
\hline $\mathrm{B} 10$ & 680 & 60 & 680 & 60 & $\mathrm{~N}_{2}, 100-\mathrm{C}_{2} \mathrm{H}_{4}, 50$ \\
\hline A5 & 680 & 180 & 680 & 60 & $\mathrm{~N}_{2}, 50$ \\
\hline A6 & 700 & 180 & 700 & 60 & $\mathrm{~N}_{2}, 50$ \\
\hline
\end{tabular}




\begin{tabular}{|c|c|c|c|c|c|}
\hline A7 & 720 & 180 & 720 & 60 & $\mathrm{~N}_{2}, 50$ \\
\hline A8 & 740 & 180 & 740 & 60 & $\mathrm{~N}_{2}, 50$ \\
\hline $\begin{array}{l}\text { E1, D5, F1, } \\
\quad \text { G1 }\end{array}$ & 720 & 180 & 720 & 60 & $\mathrm{~N}_{2}, 100-\mathrm{C}_{2} \mathrm{H}_{4}, 50$ \\
\hline $\begin{array}{l}\text { E2, D6, F2, } \\
\text { G2 }\end{array}$ & 720 & 180 & 720 & 60 & $\mathrm{~N}_{2}, 50$ \\
\hline E3 & 720 & 120 & 720 & 60 & $\mathrm{~N}_{2}, 100-\mathrm{C}_{2} \mathrm{H}_{4}, 50$ \\
\hline D7 & 720 & 180 & 720 & 60 & $\mathrm{~N}_{2}, 100-\mathrm{C}_{2} \mathrm{H}_{4}, 50$ \\
\hline $\mathrm{F} 3$ & 720 & 150 & 720 & 60 & $\mathrm{~N}_{2}, 100-\mathrm{C}_{2} \mathrm{H}_{4}, 50$ \\
\hline G3 & 720 & 110 & 720 & 60 & $\mathrm{~N}_{2}, 100-\mathrm{C}_{2} \mathrm{H}_{4}, 50$ \\
\hline D8 & 720 & 180 & 720 & 30 & $\mathrm{~N}_{2}, 100-\mathrm{C}_{2} \mathrm{H}_{4}, 50$ \\
\hline D9 & 720 & 180 & 720 & 30 & $\mathrm{~N}_{2}, 100-\mathrm{C}_{2} \mathrm{H}_{4}, 50-\mathrm{H}_{2}, 10$ \\
\hline D10 & 720 & 180 & 720 & 30 & $\begin{array}{c}\mathrm{N}_{2}, 100-\mathrm{C}_{2} \mathrm{H}_{4}, 50 \text { - after } \\
\text { 5min. } \mathrm{H}_{2}, 10\end{array}$ \\
\hline D11 & 720 & 180 & 720 & 30 & $\mathrm{~N}_{2}, 100-\mathrm{C}_{2} \mathrm{H}_{4}, 50-\mathrm{H}_{2}, 10$ \\
\hline D12 & 720 & 180 & 720 & 30 & $\mathrm{~N}_{2}, 50-\mathrm{C}_{2} \mathrm{H}_{4}, 50-\mathrm{H}_{2}, 50$ \\
\hline D13 & 720 & 180 & 720 & 30 & $\mathrm{C}_{2} \mathrm{H}_{4}, 50-\mathrm{H}_{2}, 100$ \\
\hline
\end{tabular}

${ }^{\text {a }}$ Pretreatment stage: heating-up rate $10^{\circ} \mathrm{C} / \mathrm{min}$ in $\mathrm{N}_{2} / \mathrm{H}_{2}\left(\mathrm{~N}_{2} 40 \mathrm{ml} / \mathrm{min}\right.$ and $\left.\mathrm{H}_{2} 10 \mathrm{ml} / \mathrm{min}\right)$ is included in the indicated time. Post to growth stage: cooling down at $10^{\circ} \mathrm{C} / \mathrm{min}$ in $\mathrm{N}_{2}$.

\subsubsection{Analysis of (VA)CNTs}

The morphology of grown CNTs was investigated using high-resolution scanning electron microscopy (HR-SEM; Zeiss, Merlin). Samples with catalyst particles after the pretreatment stage were analyzed with SEM. In order to determine the size distribution of nanoparticles (NPs) formed on a sample surface after the pretreatment stage, top view SEM images were analyzed with ImageJ software (using the toolbox "analyze particles"). Of each SEM-image, with a magnification of $50.000 \mathrm{X}$, five areas of $1 \mu \mathrm{m} \times 1 \mu \mathrm{m}$ were considered. These areas were converted to gray scale values (8-bit), followed by binarization, thresholding, and identification of the edges of particles and discretization, in order to obtain particle size and size distribution.

The electrical resistance of samples with VACNTs was measured with a source measurement unit (2410, Keithley). Contact pads to samples with VACNTs were created via sputtering of a $100 \mathrm{~nm}$ 
thick $\mathrm{Au}$ layer on the backside of the silicon (this deposition was already done prior to CNTsynthesis), and via gluing a copper wire to the VACNTs, with conductive paste (CW2400 Circuitworks) applied as a $2.5 \mathrm{~mm}$ diameter dot. This glue was also used to contact the backside $\mathrm{Au}$ patch with a copper wire. After electrical analysis the conductive epoxy glue was removed in order to verify that it did not penetrate through the CNT-film, which would have resulted in a direct electrical path to the Ta and substrate underneath the VACNTs. During removal of the glue consistently the CNTs were torn of the sample, while the metal remained on the sample surface, which proves that the epoxy glue drop was sufficiently viscous to penetrate only into the top of the VACNT array.

Field emission from VACNTs in $\mathrm{N}_{2}$ atmosphere (overall pressure: 1 bar) was tested for three different sample configurations (samples ID's: D7, F3 and G3), where each sample was placed at 500 $\mu \mathrm{m}$ from a flat stainless steel (AISI 316L) anode. The required electric field was generated using the source measurement unit mentioned above, and data were recorded by a customized Labview program.

\subsection{Results and Discussion}

\subsubsection{Growth of VACNTs}

In order to understand if the initial phase of the synthesis procedure affects vertical alignment, CNTs were grown on $3 \mathrm{~nm} \mathrm{Fe}$ on $\mathrm{Ta}$ on $\mathrm{Si}$, at $720^{\circ} \mathrm{C}$ for various synthesis times (samples D1, D2, D3, D4, Tables 3.1 and 3.2). The results in Figure 3.1 indicate a random orientation of CNTs for growth times up to 15 minutes. Especially for the shortest growth times, 2.5 and $5 \mathrm{~min}$, not all $\mathrm{Fe}$ particles have been active in forming CNTs, which points out an incubation time for CNT growth. This could be related either to incomplete breaking up of the original continuous Fe film into active nanoparticles, but more likely is the presence of a thin oxide shell on the particles, which renders them temporarily inactive, a mechanism proposed by Nessim et $\mathrm{al}^{[13]}$. The iron oxide may be reduced by hydrogen atoms generated through decomposition of ethylene, or, as was proposed by Bayer et al. ${ }^{[14]}$, by Ta acting as a solid-state reducing agent. 


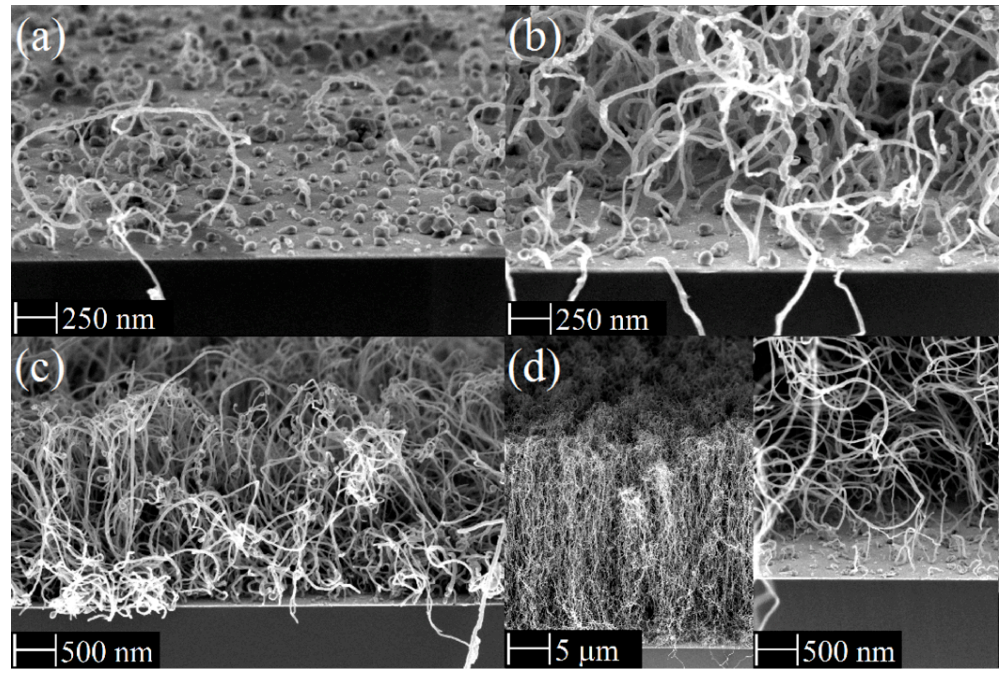

Figure 3.1: CNTs synthesized on $3 \mathrm{~nm} \mathrm{Fe} / 10 \mathrm{~nm}$ Ta thin films on silicon supports at $720{ }^{\circ} \mathrm{C}$ at various growth times: a) $2.5 \min$ (sample D2), b) 5 min (sample D3), c) 15min (sample D4), d) 1h (sample D1).

In another study by Bayer et al. ${ }^{[9]}$ a correlation between synthesis temperature and vertical alignment of CNTs was established, with the best aligned CNTs at temperatures of $550^{\circ} \mathrm{C}$ and less alignment at temperatures above $600{ }^{\circ} \mathrm{C}$. The two main processes involved are the oxidation of $\mathrm{Ta}$ to $\mathrm{Ta}_{2} \mathrm{O}_{5}$, which is promoted by $\mathrm{Fe}$, and the reduction of $\mathrm{Fe}$, enhanced by Ta. Due to diffusion of $\mathrm{Fe}$ via grain boundaries in the $\mathrm{Ta}_{2} \mathrm{O}_{5}$ that forms at higher temperatures, $\mathrm{Fe}$ is removed from the surface and less dense, and therewith less aligned, CNT arrays are formed. The oxygen needed for $\mathrm{Ta}_{2} \mathrm{O}_{5}$ formation originates from residual $\mathrm{O}_{2}$ in the background gases and from exposure to air in-between film depositions (in Bayer's case Ta was sputtered and Fe evaporated in different vacuum systems). In our study we have taken care to deposit the Ta and Fe film combinations in one system without breaking the vacuum. However, the metal films have to be exposed to atmospheric air conditions during transfer to the TCCVD reactor for CNT deposition, which will lead to oxide formation on the outer Fe layer. It is less likely that the Ta layer, which is entirely covered by Fe, will form an oxide during this transfer at room temperature. During the TCCVD of CNTs residual oxygen-containing species are present in ppm concentrations, originating from the used process gases (see section 3.2.2), and together with the much higher solid-state diffusion rates at CNT growth temperatures, this will certainly lead to Ta oxidation, similar to Bayer's case; In fact, it was proven that a crystalline $\mathrm{Ta}_{2} \mathrm{O}_{5}$ phase is formed under such conditions ${ }^{[9]}$, which we did not further verify in our work. It is noteworthy that we obtain good CNT alignment at temperatures significantly higher than Bayer et al., which we attribute to a different oxygen partial pressure in our system (lower than in Bayer's 
systems), leading to a different (higher) temperature at which oxide layer formation and oxide reduction are in equilibrium.

As is seen in Figure 3.1, the tendency towards vertical alignment increases for increasing growth times, until for a sufficiently long synthesis time (1h) the CNTs exhibit aligned growth. This result confirms that alignment of CNTs, grown by TCCVD, arises from the crowding effect of neighboring CNTs.

A novel aspect in our study compared to previous work is a study of the influence of the as-deposited Fe film thickness on VACNTs growth, which we consider relevant for alignment: different Fe film thicknesses are expected to result in different nanoparticle size and surface density after dewetting, which may affect the degree of CNT crowding. With the aim to achieve the highest density of active sites for the formation of CNTs, we therefore have investigated the three main parameters (film thickness, reaction temperature, reaction time) that are expected to affect catalyst nanoparticle formation.

\subsubsection{Influence of Fe thickness, reaction temperature and reaction time on aligned growth of} CNTs

The Fe layer thickness was studied by exposing samples with 2, 4 and $6 \mathrm{~nm}$ of Fe (sample IDs A1, $\mathrm{B} 1$ and $\mathrm{C} 1$ in Table 3.1) to identical reaction conditions, i.e. a $3 \mathrm{~h}$ pretreatment step at $680^{\circ} \mathrm{C}$ under a reducing atmosphere, followed by $1 \mathrm{~h}$ growth at $680^{\circ} \mathrm{C}$ (see Table 3.2).

Figures 3.2a, c and e indicate that an increase in the Fe layer thickness is beneficial for the formation of VACNTs. However, the effect of Fe layer thickness cannot be analyzed without considering pretreatment and growth conditions and the influence of the support onto which the catalyst film is deposited. During pretreatment in a reducing atmosphere, morphology, size and composition of catalytic Fe-NPs will change due to three subsequent processes: i) $\mathrm{Fe}_{2} \mathrm{O}_{3}$ present on the film surface is reduced to metallic $\mathrm{Fe}$ by the $\mathrm{H}_{2}$ atmosphere; ii) because of surface energy minimization, the $\mathrm{Fe}$ film dewets and forms NPs; and iii) the formed NPs agglomerate to larger particles by Ostwald ripening. This last process is also driven by surface energy minimization, but is kinetically limited by diffusion of Fe atoms over the surface of the sample ${ }^{[15]}$. The increase of NP size by agglomeration evidently leads to a decrease in the number and therewith to a lower surface density of Fe-NPs. For equal pretreatment conditions, an originally thicker Fe layer gives a higher surface NP density, with consequently a smaller gap between the agglomerated NPs. The SEM images of the samples, after annealing but before growth, show an increase in the NP density for the case where a transition to vertical alignment of the CNTs occurs (Fig. 3.2b, 3.2d and 3.2f). Particle size analysis highlights an increase of NPs with diameters between 8 to $30 \mathrm{~nm}$ for the thicker Fe layers (Fig. 3.2g). Based on the diameter of our synthesized CNTs (10 to $15 \mathrm{~nm}$ ) and the results obtained by Kukovitsky ${ }^{[16]}$, who established a correlation between CNT diameter and Ni catalyst particle size after pretreatment, we 
conclude that NPs with a diameter $<30 \mathrm{~nm}$ are the active sites in the formation of CNTs. This is supported by the presence of inactive Fe clusters larger than $30 \mathrm{~nm}$ at the bottom of the CNTs after the growth phase (see Fig. 3.1).
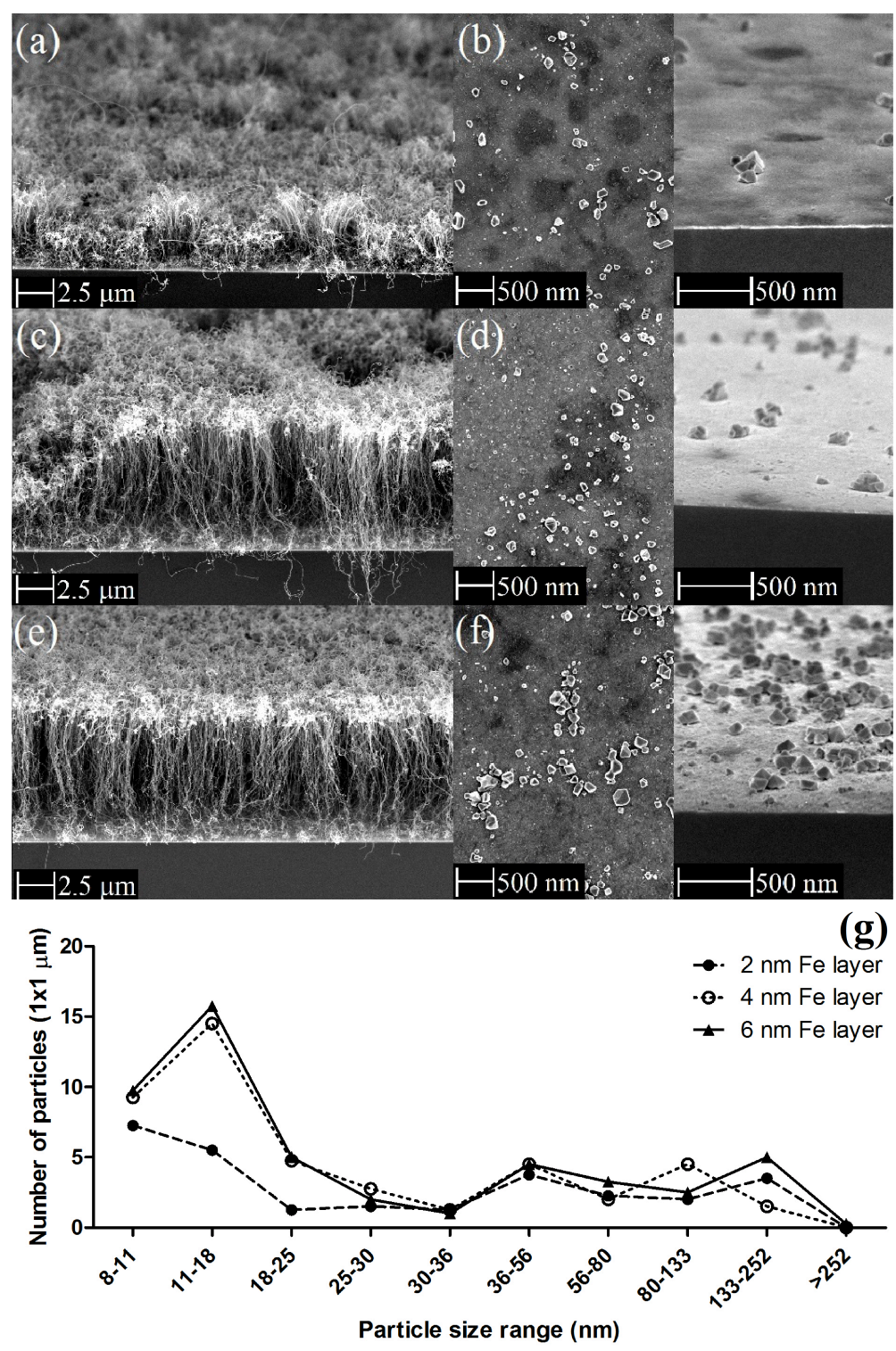

Figure 3.2: a-c-e) CNTs synthesized on Fe-based thin films on silicon supports at $680{ }^{\circ} \mathrm{C} / 1 \mathrm{~h}$ (samples A1, B1, C1); b-d-f: Fe/Ta films on silicon pretreated at $680{ }^{\circ} \mathrm{C} / 3 \mathrm{~h}$ (samples A2, B2, C2); a/b) $2 \mathrm{~nm} \mathrm{Fe} \mathrm{on} 10 \mathrm{~nm} \mathrm{Ta}$, c/d) 4 $\mathrm{nm} \mathrm{Fe}$ on $10 \mathrm{~nm} \mathrm{Ta}$, e/f) $6 \mathrm{~nm}$ Fe on $10 \mathrm{~nm}$ Ta; g) Size distribution of Fe-NPs on $1 \mu \mathrm{m} \times 1 \mu \mathrm{m}$ footprint on silicon upon $680^{\circ} \mathrm{C} / 3 \mathrm{~h}$ pretreatment. 
Experiments were carried out for a $2 \mathrm{~nm}$ Fe layer thickness and $3 \mathrm{~h}$ pretreatment time with different pretreatment temperatures. If the temperature is increased from 680 to $740^{\circ} \mathrm{C}$, the surface density of particles increases, due to the faster formation of grains on the Fe layer, and bigger particles are formed on the surface due to an agglomeration effect (Fig. 3.3e).
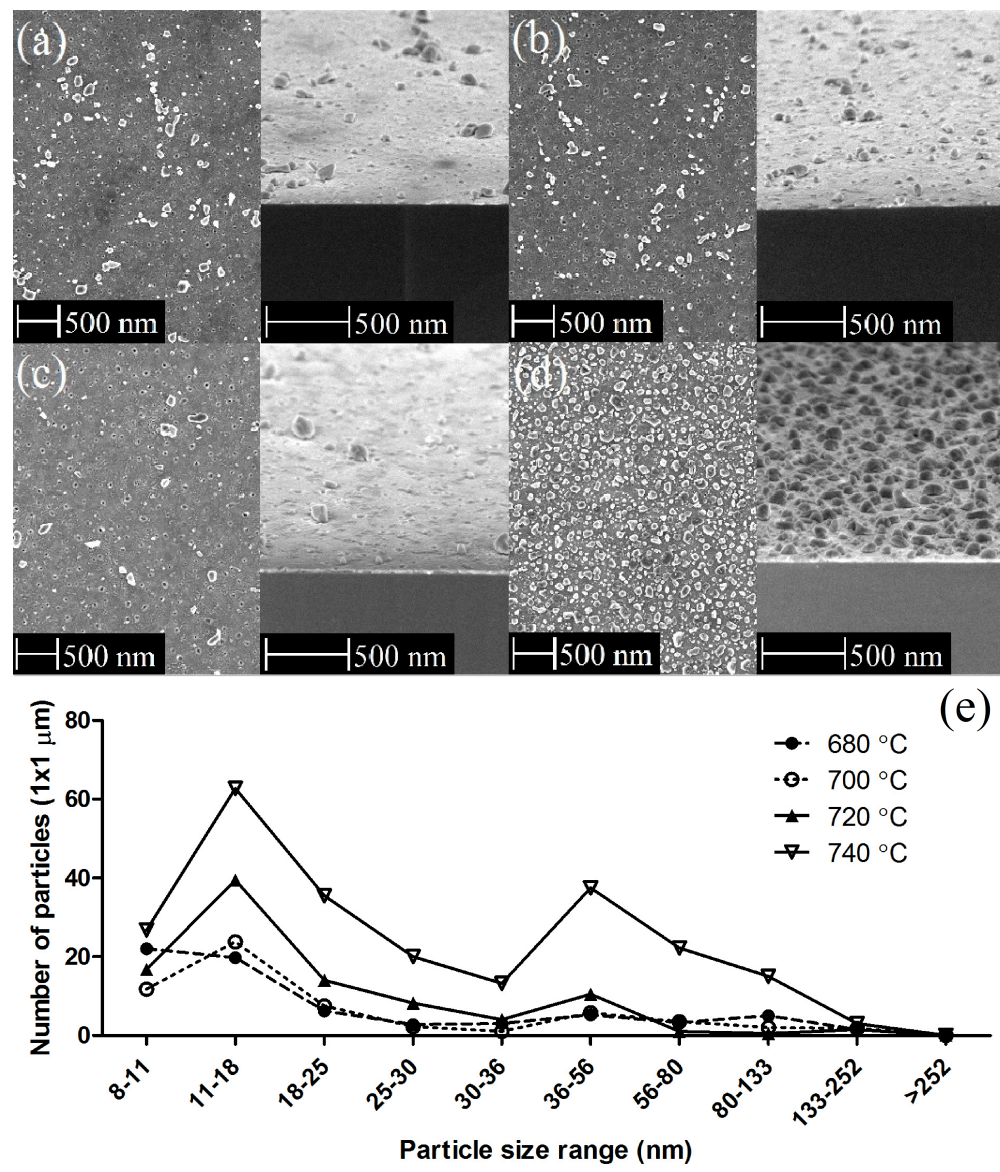

Figure 3.3: Pretreated $2 \mathrm{~nm} \mathrm{Fe} / 10 \mathrm{~nm}$ Ta films on silicon for $3 \mathrm{~h}$ : a) $680{ }^{\circ} \mathrm{C}$ (sample A5), b) $700{ }^{\circ} \mathrm{C}$ (sample A6), c) $720{ }^{\circ} \mathrm{C}$ (sample A7), d) $740{ }^{\circ} \mathrm{C}$ (sample A8) e) Size distribution of Fe-NPs on $1 \mu \mathrm{m} \times 1 \mu \mathrm{m}$ footprint on silicon upon pretreatment at various temperatures; f) Size distribution on $1 \mu \mathrm{m} \times 1 \mu \mathrm{m}$ footprint of the particles on silicon upon pretreatment at various temperatures for 3 hours.

Also for 4 and $6 \mathrm{~nm} \mathrm{Fe}$ layers an increase of the pretreatment temperature from $680^{\circ} \mathrm{C}$ to $720^{\circ} \mathrm{C}$ was observed to create a higher density of NPs. One would expect this to lead to better alignment of the CNTs, which is indeed the case for the 2 and $4 \mathrm{~nm}$ films (Fig. 3.2a/c vs. 3.4a/c), but not for the $6 \mathrm{~nm}$ film (Fig. 3.2e vs. 3.4e). Despite the presence of particles with a diameter $<30 \mathrm{~nm}$, for the $6 \mathrm{~nm}$ film the formation of a large amount of particles $>30 \mathrm{~nm}$ during pretreatment creates Fe-free areas on the 


\section{Chapter 3}

sample surface, nullifying the effect of a higher density of particles and obtaining a result similar to that achieved at $680^{\circ} \mathrm{C}$.

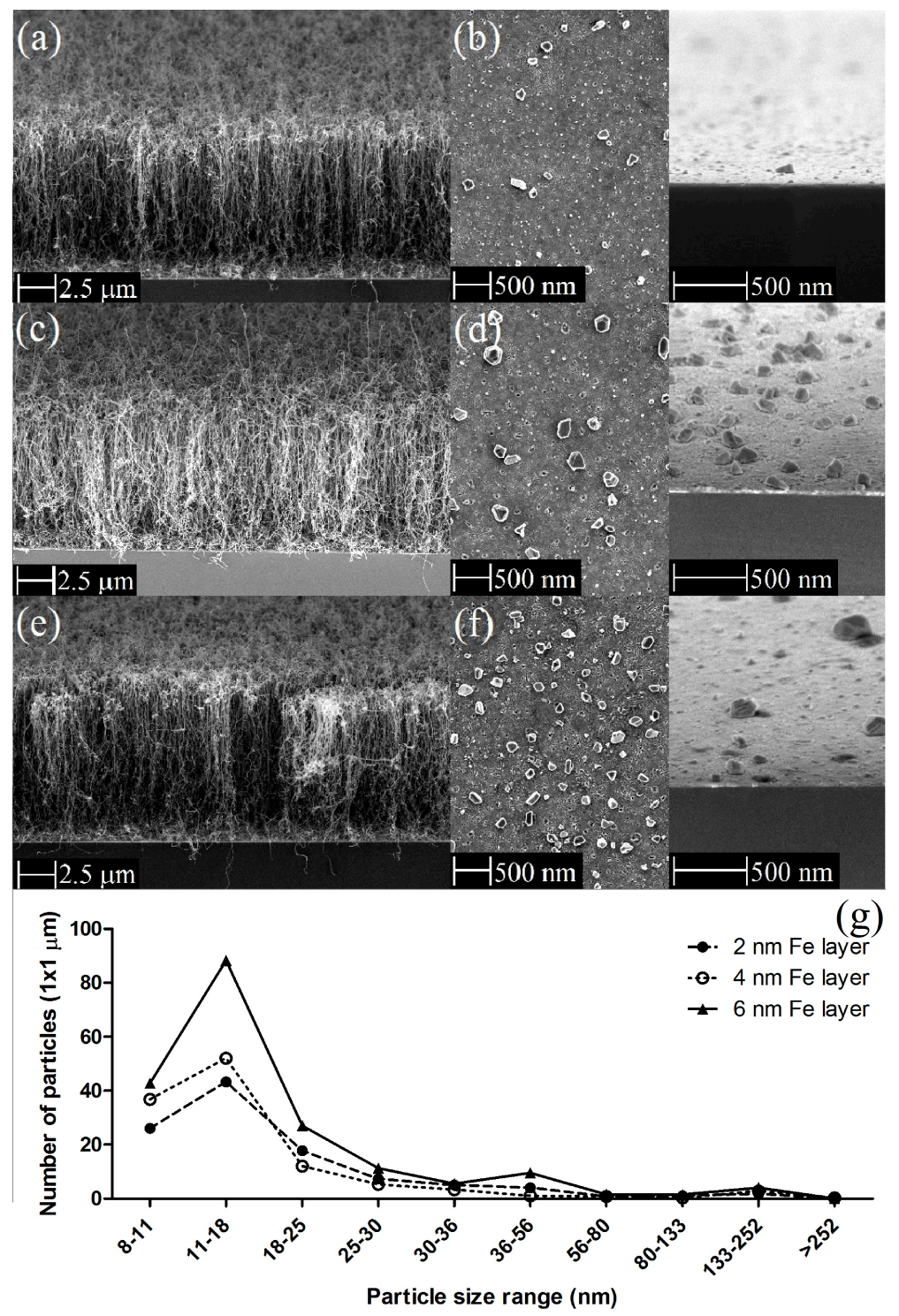

Figure 3.4: a-c-e) CNTs synthesized on Fe-based thin films on silicon supports at $720{ }^{\circ} \mathrm{C} / 1 \mathrm{~h}$ (samples A4, B4, C4); b-d-f: Fe/Ta films on silicon pretreated at $720{ }^{\circ} \mathrm{C} / 3 \mathrm{~h}$ (samples A3, B3, C3); a/b) $2 \mathrm{~nm} \mathrm{Fe} \mathrm{on} 10 \mathrm{~nm} \mathrm{Ta}$, c/d) 4 $\mathrm{nm} \mathrm{Fe}$ on $10 \mathrm{~nm} \mathrm{Ta}$, e/f) $6 \mathrm{~nm} \mathrm{Fe}$ on $10 \mathrm{~nm} \mathrm{Ta}$; g) Size distribution of Fe-NPs on $1 \mu \mathrm{m} \times 1 \mu \mathrm{m}$ footprint on silicon upon $720^{\circ} \mathrm{C} / 3 \mathrm{~h}$ pretreatment. 
Besides pretreatment temperature, pretreatment time also has an effect on NP formation. Nessim et $\mathrm{al}^{[13]}$ demonstrate that the initial rate of NP formation is low due to the fact that $\mathrm{Fe}_{2} \mathrm{O}_{3}$ present on the surface of the Fe film blocks the dewetting process. After reduction to the metal state, there is a substantial increase in the coarsening rate, which in time decreases again when, after ca. 25 min annealing at $770^{\circ} \mathrm{C}$, an equilibrium particle size (particle height of ca. $4 \mathrm{~nm}$, measured by AFM) is reached. The original Fe film thickness was $1.2 \mathrm{~nm}$ on a $10 \mathrm{~nm} \mathrm{Al}_{2} \mathrm{O}_{3}$ underlayer. In Figure 3.5 SEM images are shown of samples with a $4 \mathrm{~nm}$ Fe layer, pretreated for $1 \mathrm{~h}, 2 \mathrm{~h}$ or $3 \mathrm{~h}$ at $680^{\circ} \mathrm{C}$ in a $\mathrm{H}_{2} / \mathrm{N}_{2}$ atmosphere. The NP size distribution (Fig. 3.5g) continues to change with pretreatment time, indicating that an equilibrium as described by Nessim has not been reached even after $3 \mathrm{~h}$ annealing. Comparison with Nessim's work remains difficult, because we have used a lower pretreatment temperature (which may mean different $\mathrm{Fe}$ oxidation state ${ }^{[17]}$ ), a thicker Fe film, and a different substrate (different surface tension which may lead to different de-wetting behavior).

VACNTs are formed at $680^{\circ} \mathrm{C}$ only for a pretreatment time of 3 hours (Fig. 3.5e), in all the other cases randomly oriented CNTs are found. For $1 \mathrm{~h}$ pretreatment a carbonaceous layer is observed below the randomly oriented CNTs (Fig. 3.5a), which was not observed for a 2nm Fe layer (synthesis at $680{ }^{\circ} \mathrm{C}$ with $3 \mathrm{~h}$ pretreatment, Figure 3.2 ) that gave roughly the same amount of particles on the surface. This indicates that the presence of the carbon layer is not related to NP size or density, and another factor must play a role during the initial CNT formation. Nessim et al. reported that the absence of hydrogen during synthesis negatively affects the formation rate of CNTs as a consequence of carbide layer deposition ${ }^{[13]}$. Others have considered the presence of water in the gas phase as a possible means to keep the catalyst surface free of amorphous carbon ${ }^{[18]}$. Furthermore, oxygen and hydroxyl species originating from the water reduce catalyst atom surface diffusion (on $\mathrm{Al}_{2} \mathrm{O}_{3}$ ) and therewith inhibit catalyst agglomeration ${ }^{[19,20]}$.

The affinity of Ta for gases like $\mathrm{H}_{2}$ and $\mathrm{O}_{2}$ is a well-studied topic. Shleifman et al. demonstrated that (in an ultrahigh vacuum chamber) a thin film of Ta absorbs $\mathrm{H}_{2}{ }^{[21]}$, and Uchida et al. demonstrated that a Ta layer also absorbs $\mathrm{H}_{2}$ when its surface is covered with a Fe film ${ }^{[22]}$. As an explanation for the phenomena observed in Figure 3.5, we therefore propose that during pretreatment absorption of $\mathrm{H}_{2}$ by the Ta layer occurs. This $\mathrm{H}_{2}$ impedes carbide deposition on the Fe-NPs. A too low amount of absorbed $\mathrm{H}_{2}$ available for the Fe-NPs decreases the number of active sites for nucleation and growth of CNTs, resulting in a lower density of CNTs, which then will have random growth directions due to absence of steric impedance. A pretreatment time of $1 \mathrm{~h}$ at $680{ }^{\circ} \mathrm{C}$ seems not sufficient to absorb enough $\mathrm{H}_{2}$. 


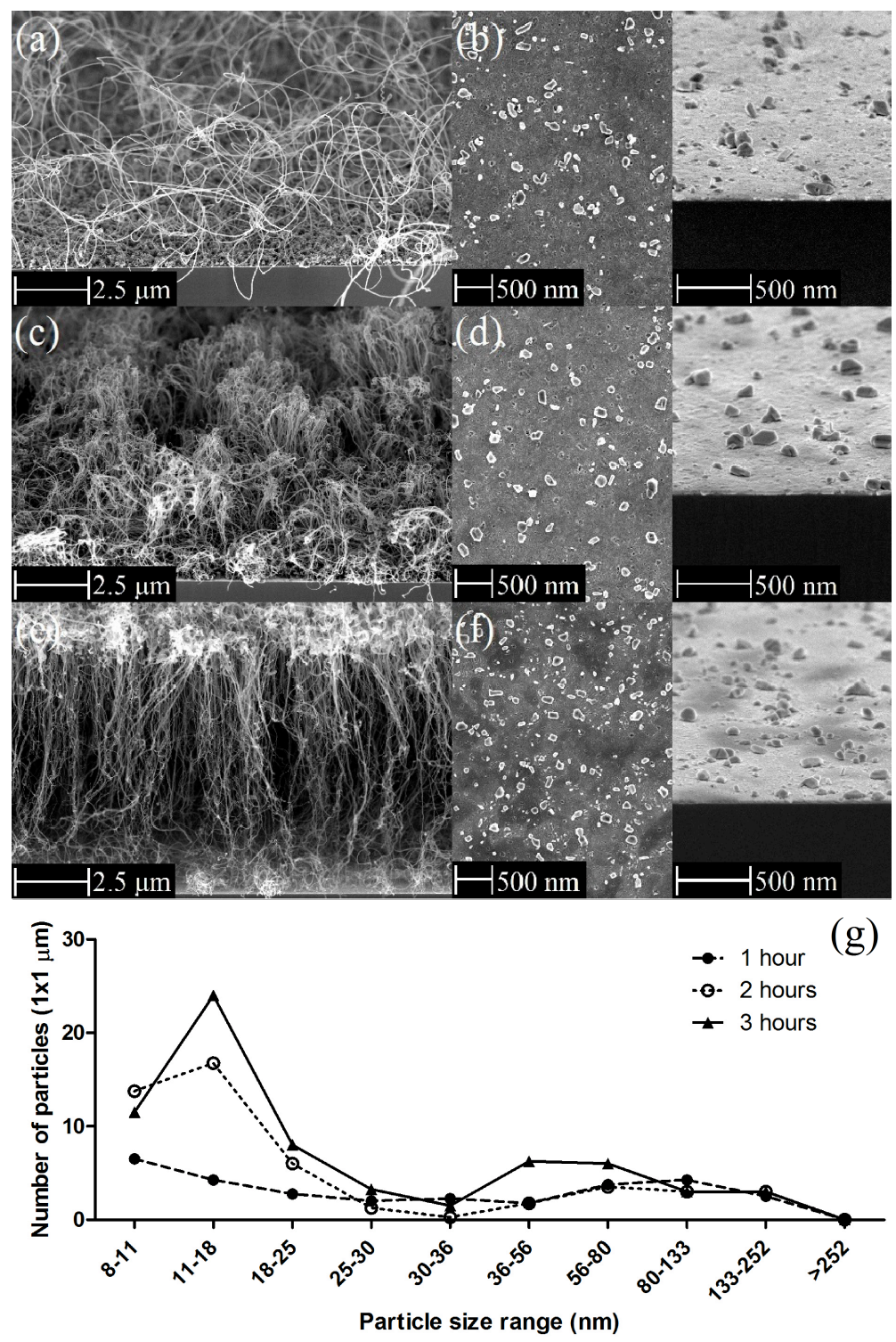

Figure 3.5: a-c-e) CNTs synthesized on $4 \mathrm{~nm} \mathrm{Fe} / 10 \mathrm{~nm}$ Ta thin films on silicon supports at $680{ }^{\circ} \mathrm{C} / 1 \mathrm{~h}$ (samples B8, B9, B10); b-d-f: $4 \mathrm{~nm} \mathrm{Fe} / 10 \mathrm{~nm}$ Ta films on silicon pretreated at $680{ }^{\circ} \mathrm{C}$ (samples B5, B6, B7); a/b) 1h pretreatment, c/d) $2 \mathrm{~h}$ pretreatment, e/f) $3 \mathrm{~h}$ pretreatment; g) Size distribution of Fe-NPs on $1 \mu \mathrm{m} \times 1 \mu \mathrm{m}$ footprint on silicon upon pretreatment at $680^{\circ} \mathrm{C}$ for different times. 
We conclude that, for a given Fe film thickness, increasing the pretreatment time from $1 \mathrm{~h}$ to $3 \mathrm{~h}$ at fixed temperature shifts the size distribution towards larger particles more than increasing the pretreatment temperature from $680{ }^{\circ} \mathrm{C}$ to $720{ }^{\circ} \mathrm{C}$ with fixed annealing time. Our observations are in agreement with reported data on Fe surface mobility ${ }^{[23]}$ and Ni/Ta dewetting ${ }^{[24]}$. The latter authors state that the presence of Ta favors dewetting of Ni coatings, compared to Ni directly on oxidized silicon supports, and it is very likely that a similar effect occurs for Fe coatings on Ta. This notion motivates our investigations on the influence of the support and the composition of Fe-based metallic thin films on the synthesis of VACNTs, to be discussed in the next section.

\subsubsection{Synthesis stage: effects of adhesion layer and support}

A combinatorial approach was used by $\mathrm{Ng}$ et al. to analyze the influence of various adhesion metals underneath thin layers of $\mathrm{Fe}, \mathrm{Ni}, \mathrm{Co}$ and $\mathrm{Fe} / \mathrm{Ni}$ alloy catalysts ${ }^{[25]}$. These authors conclude that the type of intermediate layer influences the appearance of grown CNTs, which are vertically aligned for $\mathrm{Fe} / \mathrm{Ni}$ catalyst on $\mathrm{Al}$ and randomly oriented in the other cases. Nessim et al. employed SEM analysis to investigate the effect of palladium (Pd) as adhesion layer for $\mathrm{Ni}$ catalyst and $\mathrm{Ta}$ as adhesion promoter for $\mathrm{Fe}^{[26]}$, and found that $\mathrm{Ta}$, independent of its layer thickness, is the more stable underlayer because it does not exhibit grain boundary mobility, in contrast to Pd with substantial grain growth, leading to more $\mathrm{Ni}$ incorporation, the thicker the Pd film. Burt et al. studied CNT growth on Ni/Al films deposited on bare and oxidized silicon supports with $\mathrm{SEM}^{[27]}$, whereas Tiggelaar et al. and Thakur et al. investigated CNT-growth and pretreatment effects of Ni/Ta and $\mathrm{Ni} / \mathrm{Ti}$ thin films on oxidized silicon and fused silica supports ${ }^{[24,28]}$ by means of HR-SEM and Raman spectroscopy. Common conclusion of this literature is that the adhesion layer influences catalyst particle size and distribution, by affecting both the surface and the sub-surface mobility of the catalytic metal upon reduction pretreatment.

Since good adhesion of synthesized CNTs is a necessity to obtain proper electrical contact, we have maintained a $10 \mathrm{~nm}$ thick Ta underlayer in all subsequent experiments. Fe/Ta $(3 \mathrm{~nm} / 10 \mathrm{~nm})$ was deposited onto silicon, fused silica, and silicon coated with $100 \mathrm{~nm} \mathrm{Au}$ or Pt, which both also had a $10 \mathrm{~nm}$ Ta adhesion layer underneath. Samples of each configuration were exposed to $\mathrm{N}_{2} / \mathrm{H}_{2}$ for $3 \mathrm{~h}$, followed by $1 \mathrm{~h}$ CNT growth, all at a temperature of $720^{\circ} \mathrm{C}$. Results of these experiments are shown in Figure 3.6. 


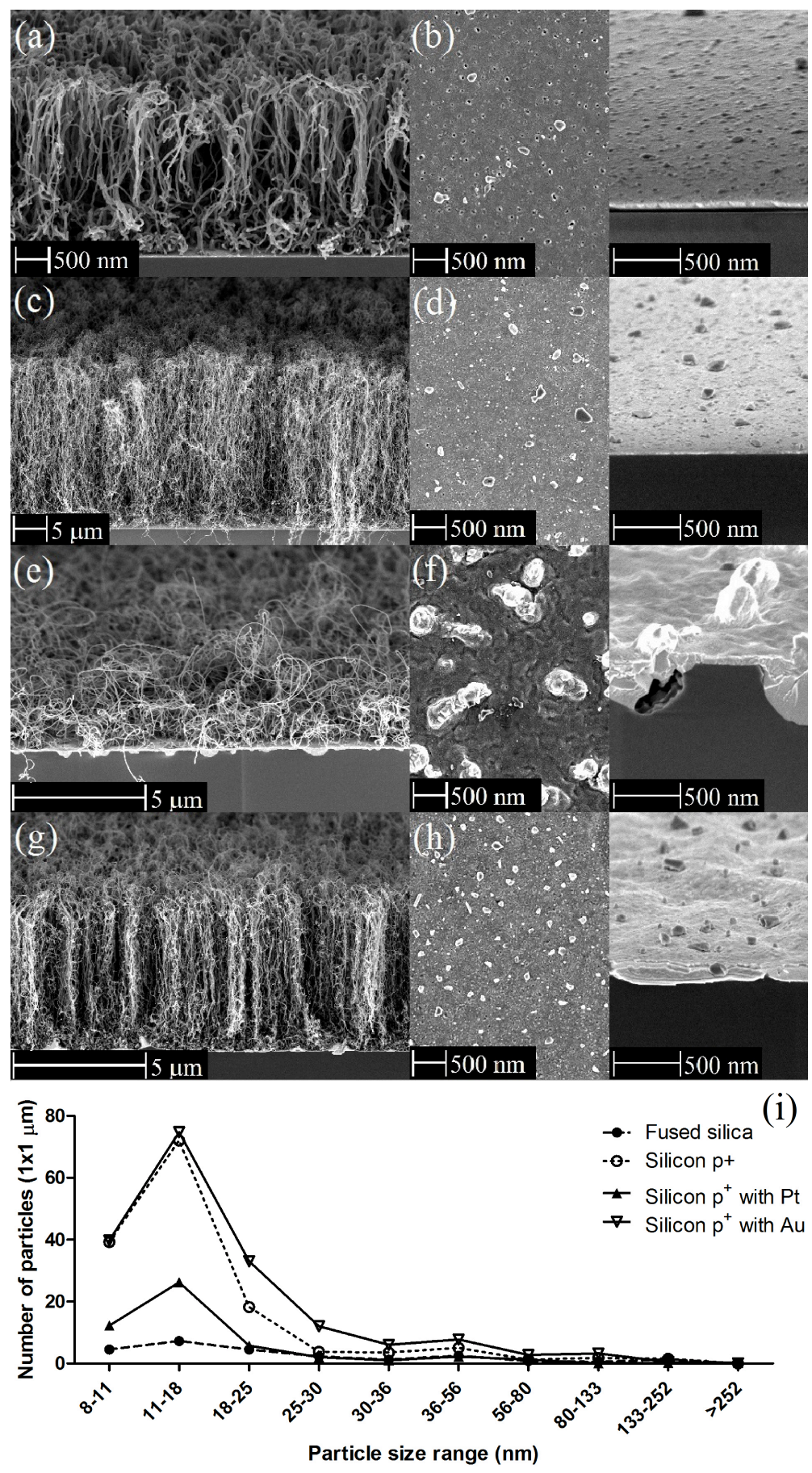


Figure 3.6: a-c-e-g) CNTs synthesized on $3 \mathrm{~nm} \mathrm{Fe} / 10 \mathrm{~nm}$ thin films on various supports at $720^{\circ} \mathrm{C} / 1 \mathrm{~h}$ (samples E1, D5, G1, F1); b-d-f-h: $3 \mathrm{~nm} \mathrm{Fe} / 10 \mathrm{~nm}$ Ta films on various supports pretreated at $720{ }^{\circ} \mathrm{C} / 3 \mathrm{~h}$ (samples E2, D6, G2, F2); a/b) fused silica substrate, c/d) silicon substrate, e/f) silicon coated with $100 \mathrm{~nm} \mathrm{Pt,} \mathrm{g/h)} \mathrm{silicon} \mathrm{coated}$ with $100 \mathrm{~nm} \mathrm{Au}$; i) Size distribution of Fe-NPs on $1 \mu \mathrm{m} \times 1 \mu \mathrm{m}$ footprint on various supports upon $720^{\circ} \mathrm{C} / 3 \mathrm{~h}$ pretreatment.

Clearly, alignment is reasonably good for $\mathrm{Fe} / \mathrm{Ta}$ and $\mathrm{Fe} / \mathrm{Ta} / \mathrm{Au} / \mathrm{Ta}$ films on $\mathrm{Si}$ (Figures 3.6c, 3.6g), but poor for $\mathrm{Fe} / \mathrm{Ta}$ on fused silica and $\mathrm{Fe} / \mathrm{Ta} / \mathrm{Pt} / \mathrm{Ta}$ on $\mathrm{Si}$ (Figures 3.6a, 3.6e). SEM-images of pretreated samples show that identical $\mathrm{Fe} / \mathrm{Ta}$ films on silicon and fused silica dewet differently upon identical pretreatment conditions (Fig. 3.6b, 3.6d), which is confirmed by the size distribution (Fig. 3.6i). Fe on $\mathrm{Au}$ gives results similar to $\mathrm{Fe}$ on $\mathrm{Si}$, whereas in the case of $\mathrm{Fe}$ on $\mathrm{Pt}$ a much lower amount of particles is found (Fig. 3.6i). Although the support clearly affects Fe film dewetting, as long as a sufficient amount of small-sized NPs is present, VACNTs can be grown. Note that the Au layer below the Fe/Ta becomes irregular in thickness due to the $\mathrm{Au}-\mathrm{Si}$ eutectic melting at $363{ }^{\circ} \mathrm{C}$ during synthesis ${ }^{[29]}$. Similarly, platinum silicide is formed at $440{ }^{\circ} \mathrm{C}^{[30]}$, resulting in the formation of depressions in the silicon. The presence of a Ta barrier layer between the Si and the Pt and Au layers should in principle avoid these phenomena, but possibly the formation of a porous Ta layer, as was observed by Tiggelaar et al. at temperatures above $500^{\circ} \mathrm{C}^{[24]}$, renders the Ta inefficient as blocking layer.

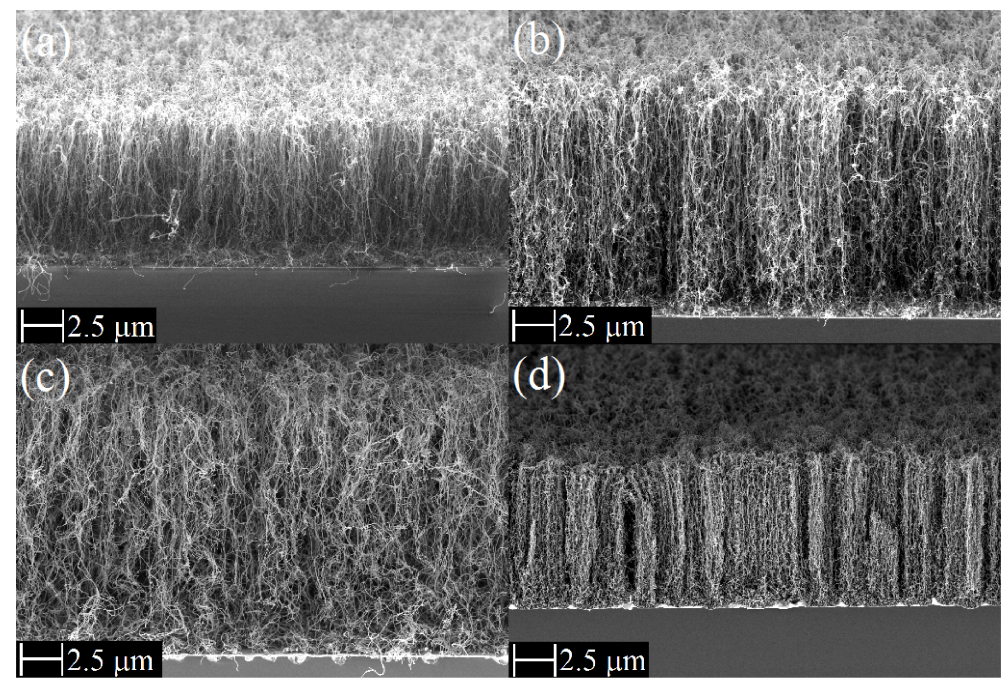

Figure 3.7: CNTs synthesized on $3 \mathrm{~nm} \mathrm{Fe} / 10 \mathrm{~nm}$ Ta thin films on various supports at $720{ }^{\circ} \mathrm{C} / 1 \mathrm{~h}$, pretreatment conditions: a) fused silica $120 \mathrm{~min} / 720{ }^{\circ} \mathrm{C}$ (sample E3), b) silicon $180 \mathrm{~min} / 720{ }^{\circ} \mathrm{C}$ (sample D7), c) $100 \mathrm{~nm} \mathrm{Pt}$ on silicon $110 \mathrm{~min} / 720^{\circ} \mathrm{C}$ (sample G3), d) $100 \mathrm{~nm} \mathrm{Au}$ on silicon $150 \mathrm{~min} / 720^{\circ} \mathrm{C}$ (sample F3). 
By tuning the pretreatment time, it is possible to obtain VACNTs at growth conditions of $1 \mathrm{~h} / 720^{\circ} \mathrm{C}$ for $3 \mathrm{~nm} \mathrm{Fe} / 10 \mathrm{~nm} \mathrm{Ta}$ on different supports, exemplifying our control of dewetting of Fe-based thin films and subsequent CNT-growth on various supports. For example, Fig. 7a shows VACNTs on $3 \mathrm{~nm} \mathrm{Fe} / 10 \mathrm{~nm} \mathrm{Ta}$ on fused silica pretreated at $720{ }^{\circ} \mathrm{C}$ for $2 \mathrm{~h}$, whereas on a silicon support a pretreatment time of $3 \mathrm{~h}$ is required to obtain such VACNTs (Fig. 3.7b). When a $\mathrm{Au} / \mathrm{Ta}$ or Pt/Ta layer is implemented on the silicon support, a pretreatment time of respectively $110 \mathrm{~min}(\mathrm{Fe} / \mathrm{Ta} / \mathrm{Pt} / \mathrm{Ta}$, Fig. $3.7 \mathrm{c})$ or $2.5 \mathrm{~h}(\mathrm{Fe} / \mathrm{Ta} / \mathrm{Au} / \mathrm{Ta}$, Fig. 3.7d) results in VACNTs.

\subsubsection{Electrical conductivity of VACNTs}

The electrical resistance of the samples with the best vertically aligned CNTs (synthesized at 720 ${ }^{\circ} \mathrm{C} / 1 \mathrm{~h}$ on $3 \mathrm{~nm} \mathrm{Fe} / 10 \mathrm{~nm}$ Ta on various supports) was measured, which is a series resistance combined of the resistances of thousands of VACNTs in parallel, the silicon substrate and (if applicable) the intermediate $\mathrm{Au} / \mathrm{Ta}$ or Pt/Ta film. Table 3.3 and Figure 3.8 show that low Ohmic resistance is found for samples containing a metal layer underneath the Fe/Ta catalyst system, in contrast to samples where the $\mathrm{Fe} / \mathrm{Ta}$ is directly deposited onto silicon, which show a high resistance and slight nonlinearity over the investigated voltage range. We attribute this high resistance to a Schottky barrier, because the temperature most likely has not been high enough to form the lowresistivity $\alpha-\mathrm{FeSi}_{2}$ alloy $^{[31]}$.

Table 3.3: Electrical resistance of samples with VACNTs grown at $720^{\circ} \mathrm{C} / 1 \mathrm{~h}$

\begin{tabular}{ccc}
\hline Sample configuration & Resistance $(\mathbf{O h m})$ & $\begin{array}{c}\text { Standard deviation } \\
\text { (Ohm) }\end{array}$ \\
\hline $3 \mathrm{~nm} \mathrm{Fe} / 10 \mathrm{~nm} \mathrm{Ta}$ & 36.2 & \pm 19.26 \\
$3 \mathrm{~nm} \mathrm{Fe} / 10 \mathrm{~nm} \mathrm{Ta} / 100 \mathrm{~nm} \mathrm{Au} / 10 \mathrm{~nm} \mathrm{Ta}$ & 1.7 & \pm 1.04 \\
$3 \mathrm{~nm} \mathrm{Fe} / 10 \mathrm{~nm} \mathrm{Ta} / 100 \mathrm{~nm} \mathrm{Pt} / 10 \mathrm{~nm} \mathrm{Ta}$ & 1.4 & \pm 0.91
\end{tabular}




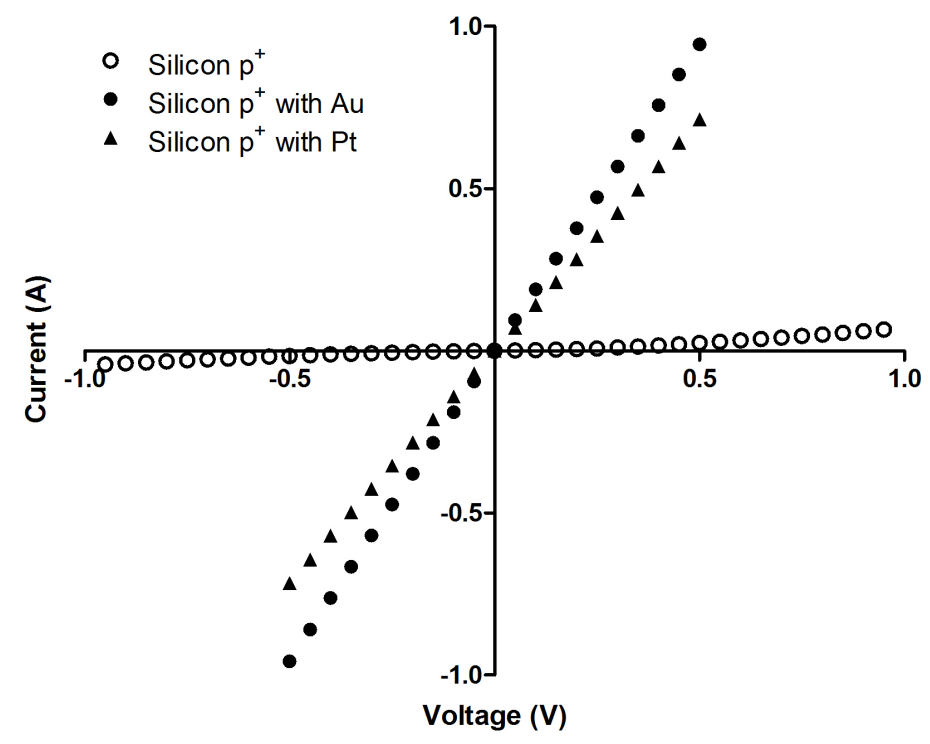

Figure 3.8: Current-voltage curves for CNTs synthesized on $3 \mathrm{~nm} \mathrm{Fe} / 10 \mathrm{~nm}$ Ta thin films on various supports at $720{ }^{\circ} \mathrm{C} / 1 \mathrm{~h}$, pretreatment conditions: i) silicon $180 \mathrm{~min} / 720^{\circ} \mathrm{C}$ (sample D7), ii) $100 \mathrm{~nm}$ Pt on silicon $110 \mathrm{~min} / 720$ ${ }^{\circ} \mathrm{C}$ (sample G3), iii) $100 \mathrm{~nm} \mathrm{Au}$ on silicon $150 \mathrm{~min} / 720^{\circ} \mathrm{C}$ (sample F3).

The average conductivity of samples with Au or Pt underneath the VACNTs is at least 30 times lower than that of samples without such metals, with no significant difference between Au or Pt. The measured lower resistance in our work compared to that of Bayer et al. is due to the diffusion barrier formed by $\mathrm{Pt}$ and $\mathrm{Au}$ in our case, which prevents oxidation of the Ta layer on Si, whereas in Bayer's case for $\mathrm{Fe} / \mathrm{Ta}$ on silicon during synthesis at temperatures above $600^{\circ} \mathrm{C}$ the Ta layer oxidized to the insulating $\mathrm{Ta}_{2} \mathrm{O}_{5}{ }^{[9]}$.

The measured resistance is an average of at least thousands of VACNT electrically addressed in parallel, and an estimation of the resistance of an individual nanotube is virtually impossible due to the multitude of electrical interconnections between neighbouring wires and the unknown contact resistances present in the system (wire tip to epoxy glue, Si to Au, Au to epoxy glue etc.). Therefore our data cannot be compared with reported data based on AFM probing, a method by means of which only a single CNT (or a few CNTs) may be electrically characterized ${ }^{[8,9,25]}$. 


\subsubsection{Field electron emission from VACNTs}

Field emission from VACNTs to a flat steel electrode was performed in $\mathrm{N}_{2}$ gas at 1 atmosphere with an electrode distance of $500 \mu \mathrm{m}$. The characteristic field emission currents (Figure 3.9) shows a steep increase when the voltage reaches 560 and $620 \mathrm{~V}$ respectively, in the case of VACNTs grown with the introduction of $\mathrm{Au}$ and $\mathrm{Pt}$ as metal intermediate layer.

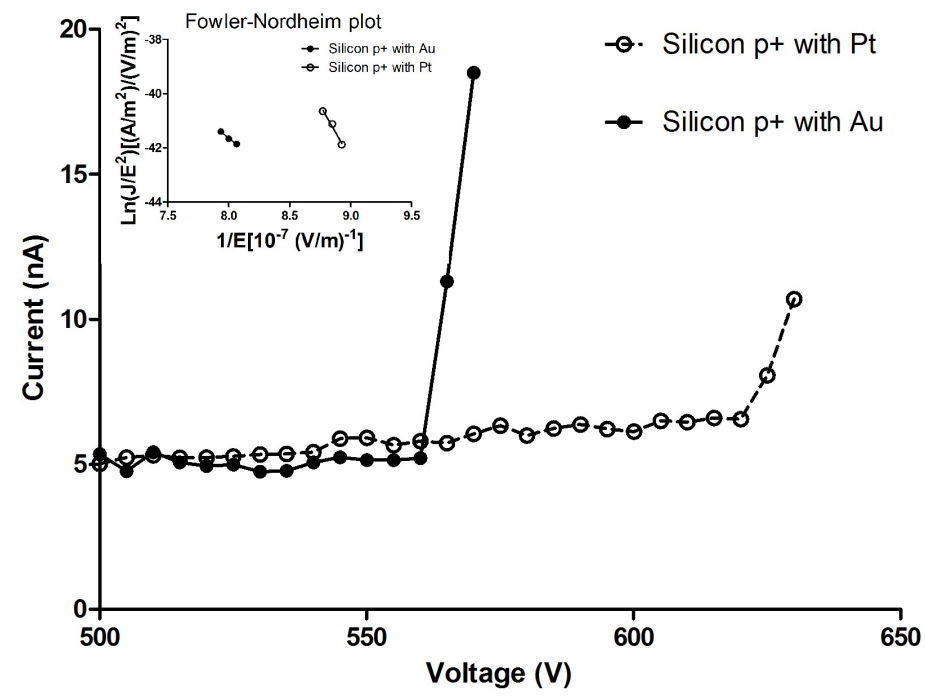

Figure 3.9: Field emission test for 2 samples with VACNTs synthesized on $3 \mathrm{~nm} \mathrm{Fe} / 10 \mathrm{~nm}$ Ta thin films on various supports at $720^{\circ} \mathrm{C} / 1 \mathrm{~h}$. Pretreatment conditions are $110 \mathrm{~min}$ at $720^{\circ} \mathrm{C}$ for $100 \mathrm{~nm} \mathrm{Pt}$ on silicon (sample G3), and $150 \mathrm{~min}$ at $720^{\circ} \mathrm{C}$ for $100 \mathrm{~nm} \mathrm{Au}$ on silicon (sample F3). The inset shows the same data in a FowlerNordheim plot, where $\mathrm{J}$ is current density (measured current divided by CNT array area) and E is electric field (applied voltage divided by electrode gap).

A rapid increase in current at voltages above $800 \mathrm{~V}$ was also observed for samples with CNTs grown without the introduction of a metal layer between the Ta and the silicon, but in this case it was not possible to record reproducibly the current due to the high instability of the VACNTs at the applied experimental conditions. The observed current-voltage curves in Fig. 3.9 are re-plotted in the insert and indicate a linear relation in agreement with Fowler-Nordheim theory. As was reported in literature ${ }^{[32]}$, the presence of $\mathrm{N}_{2}$ in the experimental environment does not influence the field emission current, therefore the obtained iV-curves were analyzed using the standard Fowler-Nordheim theory for field emission in vacuum ${ }^{[33]}$. Enhancement factors of 971 and 2136 are found for arrays of nanotubes grown using $\mathrm{Fe} / \mathrm{Ta}$ catalyst deposited on platinum and gold, respectively. The measurement shown in Figure 3.9 could not be repeated on the same samples due to burnout of the 
CNTs during the measurement. SEM images of samples after emission experiments are shown in Fig 3.10 .

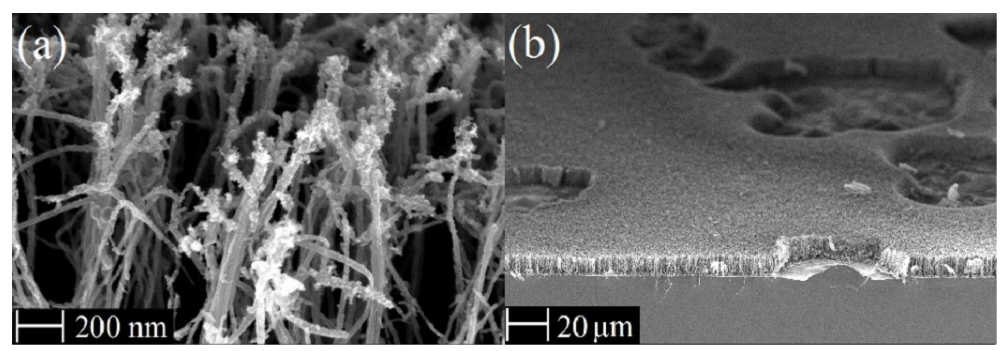

Figure 3.10: SEM images of the samples after field emission in 1 atm $\mathrm{N}_{2}:$ a) View of the top part of the CNTs, b) Sample surface after the experiment.

During the measurements the upper part of the CNTs becomes modified (Fig. 3.10a), whereas the formation of local hot-spots is observed to have generated holes in the CNTs carpet (Fig 3.10b).

\subsection{Conclusions}

In this work we analyzed the main processing parameters that characterize the synthesis of aligned CNTs using Fe catalyst on Ta and ethylene as carbon source. The size of catalyst particles before the introduction of ethylene in the reaction chamber is dominant in the formation of VACNTs. For the applied growth method only particles smaller than $30 \mathrm{~nm}$ seem active in the formation of CNTs, and random orientation or vertical alignment of the CNTs is strictly related to the density of this size particles. Particle size distribution and density are determined by the pretreatment time and temperature, and the surface onto which the Ta layer is deposited. The increase in pretreatment time from $1 \mathrm{~h}$ to $3 \mathrm{~h}$ affects particle size distribution more than increasing the pretreatment temperature from $680{ }^{\circ} \mathrm{C}$ to $720^{\circ} \mathrm{C}$, or changing the thickness of the catalyst layer from 2 to $6 \mathrm{~nm}$. The nature of the substrate under the Ta layer has an important effect on catalyst dewetting during pretreatment. Introduction of an $\mathrm{Au}$ or $\mathrm{Pt}$ metal layer between the silicon and the Ta significantly improves the overall conductivity of the sample. The preferred method to grow VACNTs on silicon, fused silica, with or without the introduction of a metal layer between the adhesion layer and the support is found by adjusting the pretreatment time for a fixed catalyst layer thickness $(3 \mathrm{~nm})$, and fixed temperature $\left(720{ }^{\circ} \mathrm{C}\right)$ and gas mixture composition during pretreatment $\left(4: 1 \mathrm{~N}_{2} / \mathrm{H}_{2}\right)$ and growth $\left(2: 1 \mathrm{~N}_{2} / \mathrm{C}_{2} \mathrm{H}_{4}\right)$ phases. This method permits creation of VACNTs with a low Ohmic resistance, suitable for field emission applications. Field enhancement factors up to 2136 are found for VACNTs synthesized on $\mathrm{Fe} / \mathrm{Ta}$. 


\subsection{References}

[1] V. Meunier, M. Buongiorno Nardelli, C. Roland, and J. Bernholc, "Structural and electronic properties of carbon nanotube tapers”, Phys. Rev. B, 64, 195-419, 2001.

[2] R. S. Ruoff and D.C. Lorents, "Mechanical and thermal properties of carbon nanotubes", Carbon, 33, 925-930, 1995.

[3] J. P. Salvetat, J.-M. Bonard, N.H. Thomson, A.J. Kulik, L. Forró, W. Benoit and L. Zuppiroli, "Mechanical properties of carbon nanotubes", Appl. Phys. A, 69, 255-260, 1999.

[4] Z. W. Pan, S. S. Xie, B. H. Chang, C. Y. Wang, L. Lu, W. Liu, W. Y. Zhou, W. Z. Li, and L. X. Qian, "Very long carbon nanotubes”, Nature, 394, 631-632, 1998.

[5] Z. P. Huang, J. W. Xu, Z. F. Ren, J .H. Wang, M. P. Siegal and P. N. Provencio, "Growth of highly oriented carbon nanotubes by plasma-enhanced hot filament chemical vapor deposition", Appl. Phys. Lett., 73, 3845-3847, 1998.

[6] N. Nagaraju, A. Fonseca, Z. Konya and J. B. Nagy, "Alumina and silica supported metal catalysts for the production of carbon nanotubes", J. Mol. Cat. A-Chem., 181, 57-62, 2002.

[7] C. J. Lee, J. Park and J. A. Yu, "Catalyst effect on carbon nanotubes synthesized by thermal chemical vapor deposition”, Chem. Phys. Lett., 360, 250-255, 2002.

[8] G. D. Nessim, M. Seita, K. P. O’Brien, A. J. Hart, R. K. Bonaparte, R. R. Mitchell and C. V. Thompson, "Low temperature synthesis of vertically aligned carbon nanotubes with electrical contact to metallic substrates enabled by thermal decomposition of the carbon feedstock", Nano Lett., 9, 3398-3405, 2009.

[9] B. C. Bayer, S. Hofmann, C. Castellarin-Cudia, R. Blume, C. Baehtz, S. Esconjauregui, C. T. Wirth, R. A. Oliver, C. Ducati, A. Knop-Gericke, R. Schlögl, A. Goldoni, C. Cepek and J. Robertson, "Support-catalyst-gas interactions during carbon nanotube growth on metallic Ta films", J. Phys. Chem. C, 115, 4359-4369, 2011.

[10] W. A. de Heer, A. Chatelaine and D. Ugarte, "A Carbon Nanotube Field-Emission Electron Source", Science, 270, 1179-1180, 1995.

[11] J.M. Bonard, J.P. Salvetat, T. Stockli, L. Forro and A. Chatelain, "Field emission from carbon nanotubes: perspectives for applications and clues to the emission mechanism", Appl. Phys. A., 69, 245-254, 1999. 
[12] W. Zhu, C. Bower, O. Zhou, G. Kochanski and S. Jin, "Large current density from carbon nanotube field emitters", Appl. Phys. Lett., 75, 873-875, 1999.

[13] G. D. Nessim, A. J. Hart, J. S. Kim, D. Acquaviva, J. H. Oh, C. D. Morgan, M. Seita, J. S. Leib and C. V. Thompson, "Tuning of vertically-aligned carbon nanotube diameter and areal density through catalyst pre-treatment”, Nano Lett., 8, 3587-3593, 2008.

[14] B.C. Bayer, M. Fouquet, R. Blume, C.T. Wirth, R.S. Weatherup, K. Ogata, A. KnopGericke, R. Schlögl, S. Hofmann and J. Robertson, "Co-catalytic solid-state reduction applied to carbon nanotube growth”, J. Phys. Chem C, 116, 1107-1113, 2012.

[15] C V. Thompson and R. Carel, "Stress and grain growth in thin films", J. Mech. Phys. Solids, 44, 657-673, 1996.

[16] E. F. Kukovitsky, S. G. L’vov, N. A. Sainov and L. A. Chemozatonskii, "Correlation between metal catalyst particle size and carbon nanotube growth", Chem. Phys. Lett., 355, 497-503, 2002.

[17] E. Teblum, Y. Gofer, C.L. Pint, G.D. Nessim, "Role of catalyst oxidation state in the growth of vertically aligned carbon nanotubes”, J. Phys. Chem. C, 116, 24522-24528, 2012.

[18] K. Hata, D. N. Futaba, K. Mizuno, T. Namai, M. Yumura and S. Iijima, "Water-assisted highly efficient synthesis of impurity-free single-walled carbon nanotubes", Science 306, 1362-1364, 2004.

[19] P. B. Amama, C. L. Pint, S. M. Kim, L. McJilton, K. G. Eyink, E. A. Stach, R. H. Hauge and B. Maruyama, "Influence of alumina type on the evolution and activity of aluminasupported Fe catalysts in single-walled carbon nanotube carpet growth", ACS Nano, 4, 895904, 2010.

[20] G. D. Nessim, A. Al-Obeidi, H. Grisaru, E. S. Polsen, C. R. Oliver, T. Zimrin, A. J. Hart, D. Aurbach, and C. V. Thompson, "Synthesis of tall carpets of vertically aligned carbon nanotubes by in situ generation of water vapor through preheating of added oxygen", Carbon, 50, 4002-4009, 2012.

[21] D.E. Shleifman, D. Shaltiel and I.T. Steinberger, "Thermally stimulated hydrogen desorption from zirconium and tantalum”, J. Alloys Comp., 81-86, 1995. 
[22] H. Uchida and E. Fromm, "Effect of palladium and oxygen layers on the hydrogen absorption rate of tantalum films at $300 \mathrm{~K}$ ", J. Less Comm. Metals, 95, 139-146, 1983.

[23] C. E. Krill III, L. Helfen, D. Michels, H. Natter, A. Fitch, O. Masson and R. Birringer, "Size-dependent grain-growth kinetics observed in nanocrystalline Fe", Phys. Rev. Lett., $86,842-845,2001$.

[24] R. M. Tiggelaar, D. B. Thakur, H. Nair, L. Lefferts, K. Seshan and J. G. E. Gardeniers, "Influence of thin film nickel pretreatment on catalytic thermal chemical vapor deposition of carbon nanofibers", Thin Solid Films, 534, 341-347, 2013.

[25] H. T. Ng, B. Chen, J. E. Koehne, A. M. Cassell, J. Li, J. Han and M. Meyyappan, "Growth of carbon nanotubes: a combinatorial method to study the effects of catalysts and underlayers”, J. Phys. Chem. B., 107, 8484-8489, 2003.

[26] G. D. Nessim, D. Acquaviva, M. Seita, K. P. O’Brien and C. V. Thompson, "The critical role of the underlayer material and thickness in growing vertically aligned carbon nanotubes and nanofibers on metallic substrates by chemical vapor deposition", Adv. Funct. Mater., 20, 1306-1312, 2010.

[27] D. P. Burt, W. M. Whyte, J. M. R. Weaver, A. Glidle, J. P. Edgeworth, J. V. Macpherson and P. S. Dobson, "Effects of metal underlayer grain size on carbon nanotube growth", J. Phys. Chem. C, 113, 15133-15139, 2009.

[28] D. B. Thakur, R. M. Tiggelaar, J. G. E. Gardeniers, L. Lefferts and K. Seshan, "Growth of carbon nanofiber coatings on nickel thin films on fused silica by catalytic thermal chemical vapor deposition: On the use of titanium, titanium-tungsten and tantalum as adhesion layers”, Surf. Coat. Technol., 203, 3435-3441, 2009.

[29] H. Okamoto and T. B. Massalski, "The Au-Si (Gold-Silicon) system”, Bulletin of Alloy Phase Diagrams, 4, 190-198, 1983.

[30] H. Okamoto, “O-Ti (Oxygen-Titanium)”, J. Phase Equilib. Diff., 32, 394, 2011.

[31] J. Zhang, Q. Xie, P. Yu, Q. Xiao, Y. Zhang, Z. Yang and Y. Liang, "Preparation of $\alpha-F e S i$ 2 by laser annealing”, Thin Solid Films, 516, 8625-8628, 2008. 
[32] C. Kim, Y. S. Choi, S. M. Lee, J. T. Park, B. Kim and Y. H. Lee, "The effect of gas adsorption on the field emission mechanism of carbon nanotubes", J. Am. Chem. Soc., 124, 9906-9911, 2002.

[33] R. H. Fowler and L. Nordheim, "Electron emission in intense electric fields", Proc. R. Soc. A, 119, 173-181, 1928. 


\section{SUPPORTING INFORMATION}

\section{Effects of synthesis temperature and gas composition}

For the investigated range of $680-720{ }^{\circ} \mathrm{C}$, the temperature of the gas mixture did not have a major impact on the appearance of synthesized CNTs: vertical alignment was obtained for proper pretreatment settings. The temperature only slightly influenced the growth rate, i.e. for a higher synthesis temperature the formation rate of VACNTs increased a little. In contrast, addition of $\mathrm{H}_{2}$ to $\mathrm{C}_{2} \mathrm{H}_{4}$ significantly affects the orientation of CNTs as well as their formation rate. Moreover, the amount of added $\mathrm{H}_{2}$ to the hydrocarbon source and the time-scale at which $\mathrm{H}_{2}$-addition occurs (with respect to the time-length that $\mathrm{C}_{2} \mathrm{H}_{4}$ is fed in the reactor) also influences the outcome of the synthesis process, including the number of walls in multi-walled CNTs.

In Figure SI-1 synthesis results as obtained without and with (delayed) hydrogen addition to the ethylene/nitrogen mixture are shown. Transmission electron microscopy (TEM) was done on a Philips system (CM300ST). It can be observed that, after a $3 \mathrm{~h}$ pretreatment stage at $720{ }^{\circ} \mathrm{C}$ with $\mathrm{H}_{2} / \mathrm{N}_{2}$, the verticality of CNTs decreases upon addition of $\mathrm{H}_{2}$ (Figure SI-1c) compared to $\mathrm{C}_{2} \mathrm{H}_{4} / \mathrm{N}_{2}$ as hydrocarbon source (Figure SI-1a). Feeding of $\mathrm{H}_{2}$ to $\mathrm{C}_{2} \mathrm{H}_{4}$ increases the formation rate of CNTs (in agreement with Thakur et. al. ${ }^{[1]}$ ), and also causes a decrease in the number of sheets of the CNT (Figure SI-1b vs. Figure SI-1d). When hydrogen is added with a delay to the gas mixture - i.e. the first 5 minutes of a synthesis stage $\mathrm{N}_{2} / \mathrm{C}_{2} \mathrm{H}_{4}$ is used, followed by $25 \mathrm{~min}$ of feeding a mixture of $\mathrm{N}_{2} / \mathrm{C}_{2} \mathrm{H}_{4} / \mathrm{H}_{2}$ to the system - an even stronger enhancement of the formation rate of CNTs is found, whereas this does not largely benefit the verticality of CNTs (Figure SI-1e) nor influences the amount of planes of a CNT (Figure SI-1f). Another negative aspect of $\mathrm{H}_{2}$ is that it results in non-uniformities in the thickness of the CNT-film, which is not desirable if VACNTs are to be used for electron emission. The presented results regarding addition of hydrogen to the hydrocarbon source are in agreement with data reported by Nessim et al., although it has to be noted that these researchers did not apply a pretreatment protocol ${ }^{[2]}$. 


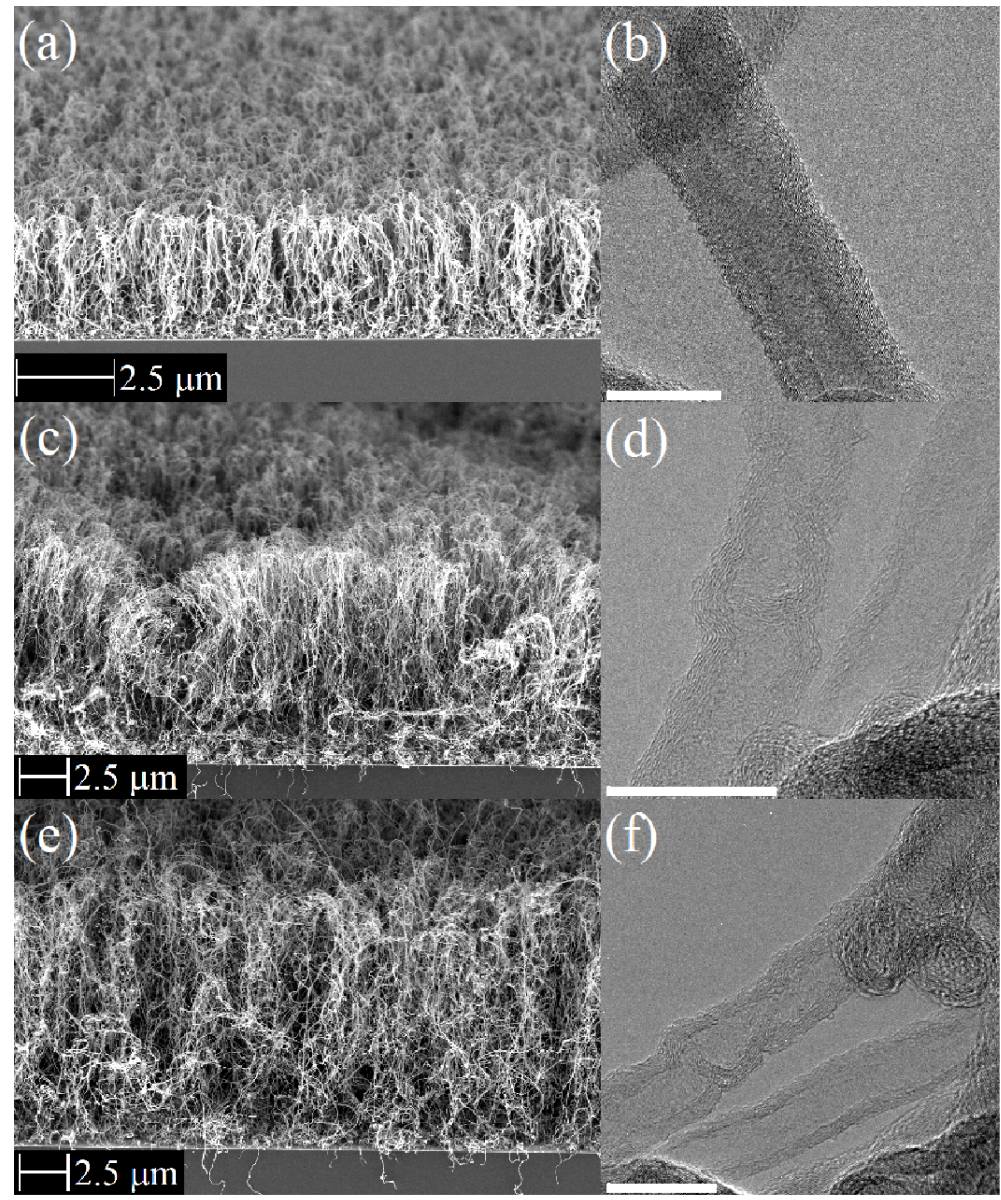

Figure SI-1: SEM and TEM images of CNTs synthesized on $3 \mathrm{~nm} \mathrm{Fe} / 10 \mathrm{~nm}$ Ta thin films on silicon at $720{ }^{\circ} \mathrm{C}$ : a/b) No $\mathrm{H}_{2}$ during growth phase, $30 \mathrm{~min} . \mathrm{N}_{2} / \mathrm{C}_{2} \mathrm{H}_{4}$ (sample D8); c/d) 10ml/min $\mathrm{H}_{2}$ during growth phase, 30min. $\mathrm{N}_{2} / \mathrm{C}_{2} \mathrm{H}_{4} / \mathrm{H}_{2}$ (sample D9); e/f) $10 \mathrm{ml} / \mathrm{min} \mathrm{H}_{2}$ added 5 min after the starting of the growth phase, $5 \mathrm{~min} . \mathrm{N}_{2} / \mathrm{C}_{2} \mathrm{H}_{4}$ and $25 \min . \mathrm{N}_{2} / \mathrm{C}_{2} \mathrm{H}_{4} / \mathrm{H}_{2}$ (sample D10).

Increasing the hydrogen content of the $\mathrm{N}_{2} / \mathrm{C}_{2} \mathrm{H}_{4} / \mathrm{H}_{2}$ mixture (either directly added to the $\mathrm{N}_{2} / \mathrm{C}_{2} \mathrm{H}_{4}$ stream or with a time-delay), does not always enhance the formation rate: in fact, a hydrogen concentration above $20 \%$ of the total gas flow has an opposite effect. Experiments in which increasing amounts of $\mathrm{H}_{2}$ were introduced in the reactor, ranging from $6.5 \mathrm{vol} \%$ to $66 \mathrm{vol} \%$, demonstrate a decrease in the CNT formation velocity (Fig. SI-2), as well as negatively affect the verticality of CNTs. 


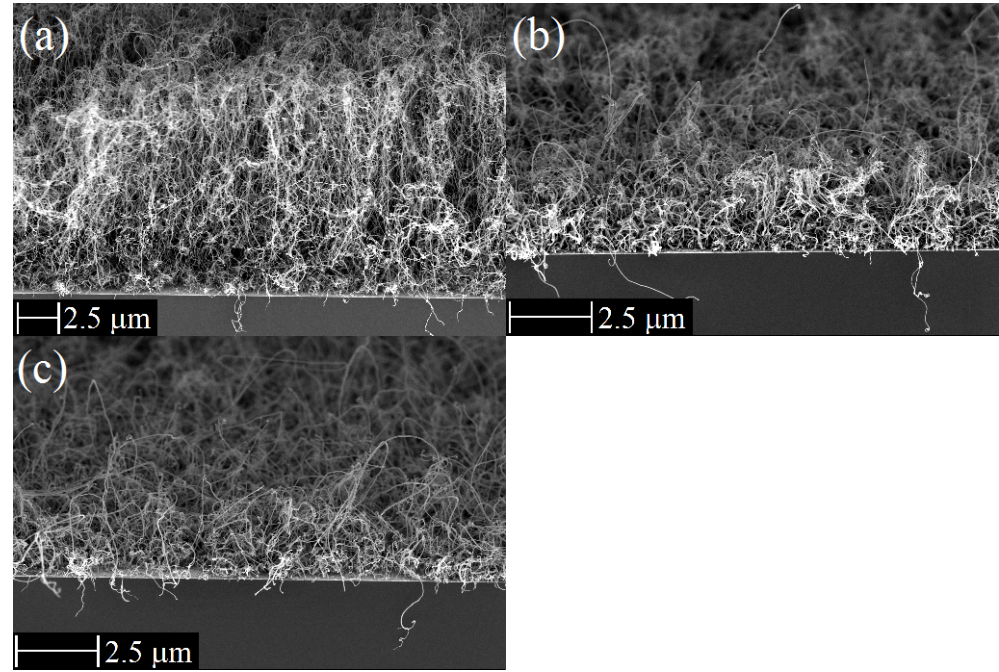

Figure SI-2: SEM images of CNTs synthesized on $3 \mathrm{~nm} \mathrm{Fe} / 10 \mathrm{~nm}$ Ta thin films on silicon at $720^{\circ} \mathrm{C}$ with various $\mathrm{H}_{2}$ contents: a) $10 \mathrm{ml} / \mathrm{min} \mathrm{H}_{2}$ during growth phase, $5 \mathrm{~min} . \mathrm{N}_{2} / \mathrm{C}_{2} \mathrm{H}_{4}$ and $25 \mathrm{~min} . \mathrm{N}_{2} / \mathrm{C}_{2} \mathrm{H}_{4} / \mathrm{H}_{2}$ (sample D11); b) $50 \mathrm{ml} / \mathrm{min} \mathrm{H}_{2}$ during growth phase $5 \mathrm{~min} . \mathrm{N}_{2} / \mathrm{C}_{2} \mathrm{H}_{4}$ and $25 \mathrm{~min} . \mathrm{N}_{2} / \mathrm{C}_{2} \mathrm{H}_{4} / \mathrm{H}_{2}$ (sample D12); c) 100ml/min $\mathrm{H}_{2}$ during growth phase $5 \mathrm{~min} . \mathrm{N}_{2} / \mathrm{C}_{2} \mathrm{H}_{4}$ and $25 \mathrm{~min} . \mathrm{C}_{2} \mathrm{H}_{4} / \mathrm{H}_{2}$ (sample D13).

The presence of $\mathrm{H}_{2}$ in the reaction environment is necessary for the formation of (VA)CNTs on Fe clusters, since hydrogen maintains the metallic state of Fe clusters during synthesis and thus preserves their catalytic function. However, since $\mathrm{H}_{2}$ is one of the products formed during the decomposition of $\mathrm{C}_{2} \mathrm{H}_{4}$ and subsequent deposition of carbon on the Fe clusters, addition of $\mathrm{H}_{2}$ to the feedstock gas shifts the equilibrium of the CNT formation reaction (resulting in randomly oriented CNTs and/or lower formation velocities, rather than VACNTs). This is for example the case when the amount of $\mathrm{H}_{2}$ exceeds $20 \%$ of the gas composition, above which VACNT formation is hampered. Another to take into consideration when $\mathrm{H}_{2}$ is added during the synthesis of CNTs is the presence of contaminants in the reaction chamber. In et al. demonstrated that the presence of $\mathrm{O}_{2}$ in the reaction environment when a higher amount of $\mathrm{H}_{2}$ is added decreases the growth of $\mathrm{CNTs}^{[3]}$.

Overall, for $\mathrm{Fe} / \mathrm{Ta}$ thin films on silicon the investigated settings of synthesis temperature and feedstock composition with hydrogen addition did not affect the generation of VACNTs, and optimal results were found for a growth temperature of $720^{\circ} \mathrm{C}$ upon $1 \mathrm{~h}$ feeding of $\mathrm{N}_{2} / \mathrm{C}_{2} \mathrm{H}_{4}$. 


\section{References}

[1] D. B. Thakur, R. M. Tiggelaar, J. G. E. Gardeniers, L. Lefferts and K. Seshan, "Carbon nanofiber based catalyst supports to be used in microreactors: Synthesis and characterization”, Chem. Eng. J., 160, 899-908, 2010.

[2] G. D. Nessim, A. J. Hart, J. S. Kim, D. Acquaviva, J. H. Oh, C. D. Morgan, M. Seita, J. S. Leib and C. V. Thompson, "Tuning of vertically-aligned carbon nanotube diameter and areal density through catalyst pre-treatment", Nano Lett., 8, 3587-3593, 2008.

[3] J. B. In, C. P. Grigoropoulos, A. A. Chernov and A. Noy, "Growth kinetics of vertically aligned carbon nanotube arrays in clean oxygen-free conditions", ACS Nano, 5, 9602-9610, 2011. 
Chapter 3 


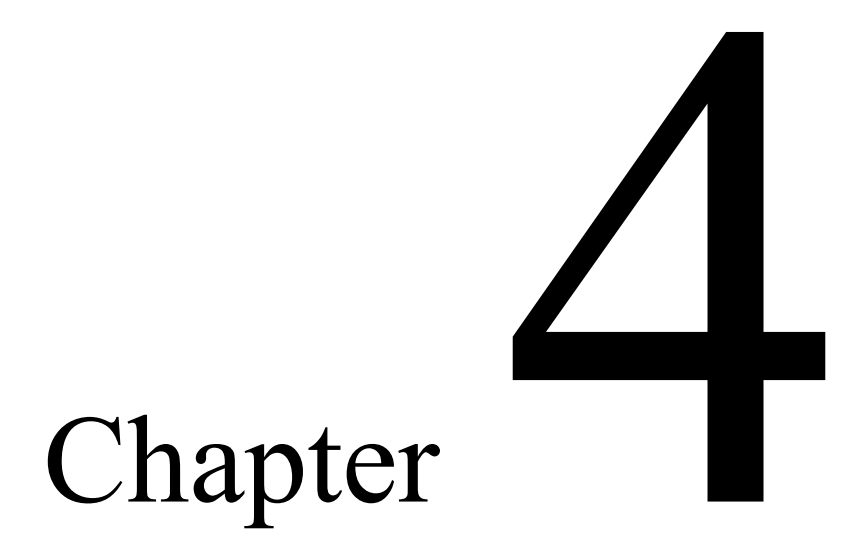

Cold field emission in liquids in a microreactor with an integrated planar microstructured electrode: modeling and experimental results 


\title{
Chapter 4
}

\begin{abstract}
In this work we report a novel microreactor with a photolithographically defined integrated planar electrode containing micro tips that serve as emission points for solvated electrons into liquid nhexane flow in a microchannel. Cold field emission into dielectric liquids from electrodes with sharp tips permits the use of low voltages to overcome the potential barrier necessary to extract electrons from the electrode material. The electric field distribution in the gap between a linear microtip array and a flat electrode is analyzed by a computational model. Cold field emission using these microdevices is experimentally verified, and the reaction of anthracene with solvated electrons emitted in solutions with or without ethanol in n-hexane is demonstrated.
\end{abstract}

Keywords: Cold field emission, microreactor, Fowler-Nordheim, solvated electrons, reduction of anthracene 


\subsection{Introduction}

Solvated electrons have been observed for the first time in 1807 by Sir Humphry Davy and are mentioned in a scientific report in 1864 by $\mathrm{Wey}^{[1,2]}$. In more recent days, in particular the nature of the solvated electron in water, the hydrated electron, with its typical characteristics of a short lifetime (nanoseconds), exceptionally high diffusion rate and high reactivity, has been extensively studied ${ }^{[3]}$. The enormous reducing power of solvated electrons has been noted early on, like in the groundbreaking work of Birch, who investigated, amongst other topices, the partial reduction of polycyclic aromatic hydrocarbons (PAH) using solvated electrons generated by dissolving an alkali metal in liquid ammonia ${ }^{[4]}$. More recent studies have focused on the development of greener processes, avoiding the use of alkali metals or liquid ammonia, and electrochemical methods or plasma sources, to generate solvated electrons were proposed ${ }^{[5,6,7]}$.

Following the original studies on field emission into liquids ${ }^{[8,9]}$, the possibility to generate solvated electrons by cold field emission (CFE) was proposed by Krivenko et al. and Agiral et al. ${ }^{[10,11]}$. The latter authors show the possibility to inject electrons directly into liquid hexane by using carbon nanofibers and a defined small interspace between the carbon nanofibers and a counter electrode. The micrometer range electrode gap and the nanometer scale radius of curvature of the structures on the cathode surface facilitate the emission of electrons by creating a high electric field with only a relatively low potential difference.

State of the art microfabrication technology permits the creation of integrated electrodes with a defined geometry and dimensions, by means of which microreactors suitable to generate CFE in a liquid flow can be made. In this work, using physical vapor deposition (PVD) of a metal film in combination with photolithography, microreactors have been achieved which are suitable to perform CFE in liquid n-hexane. In this work, the theory on field enhancement is considered and modeled, electrical analysis of the proposed microreactors is performed and the chemical performance of the system for the reduction of anthracene is evaluated.

\subsection{Theory: design and modeling}

\subsubsection{Microreactor design}

The microreactors are composed of glass and silicon and have two platinum $(\mathrm{Pt})$ electrodes, oriented in a horizontal planar configuration, positioned at the edges of the flow channel. In order to locally increase the electric field, which enhances the emission of electrons from the metal surface, one of the two electrodes contains lithographically defined microtips with a triangular shape. The distance (d) between the two electrodes is varied between 1,2,3,5, 10 and $20 \mu \mathrm{m}$. The electrode with triangular emitters, the cathode, is formed by a series of isosceles triangles $(10 \mu \mathrm{m}$ height and $10 \mu \mathrm{m}$ length $)$ that are connected by means of a straight line of $6 \mathrm{~mm}$ length and $100 \mu \mathrm{m}$ width. The thickness of the electrode is $100 \mathrm{~nm}$. The anode has a flat surface and is $6 \mathrm{~mm}$ in length, $100 \mu \mathrm{m}$ in width and $100 \mathrm{~nm}$ 


\section{Chapter 4}

thick. Both electrodes are placed at the bottom of the flow channel which is $150 \mu \mathrm{m}$ wide and $25 \mu \mathrm{m}$ deep $(0.05 \mu \mathrm{L}$ volume of the channel). In Figure 4.1 schematic representations of the CFE microreactor are given.

a)

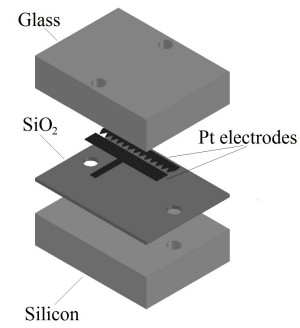

c) b)

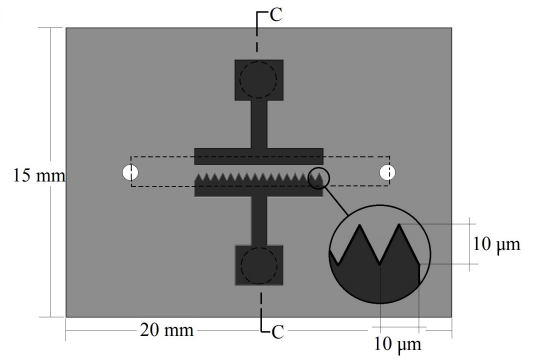

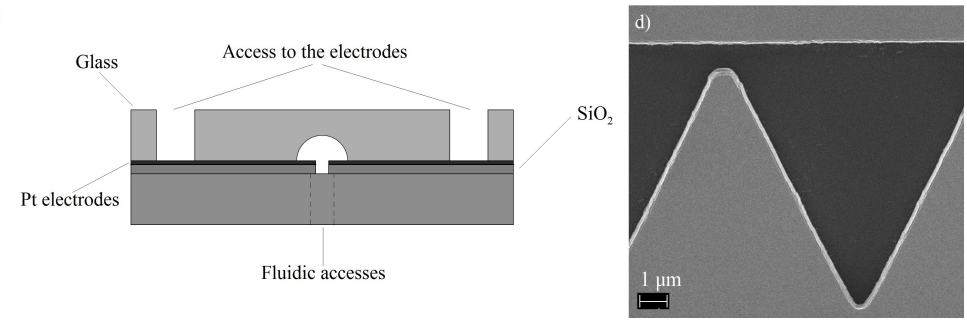

Figure 4.1. Microreactor with photolithographically defined microtips: a) 3D model of the microdevice, b) top view scheme, c) cross section scheme, d) SEM image of microtip shape for $1 \mu \mathrm{m}$ gap.

\subsubsection{Microreactor modeling}

In order to study the local field enhancement at the microtips, an electrostatic model of the distribution of the electric field distribution upon applying a potential between the flat anode and the microtips on the cathode surface is created. Below, first the electrostatic theory is introduced, which is subsequently inserted into a model in Comsol Multiphysics Software. The proposed model and all relative electrostatic derivations are based on Griffiths' work $^{[12]}$.

Two electrical point charges in a space have repulsive as well as attractive mutual interactions. The force $(F)$ exerted between the two point charges can be calculated by using Coulomb's law ${ }^{[13]}$ :

$F=\frac{1}{4 \varepsilon_{r} \pi} \frac{q Q}{r^{2}} \vec{r}$

where $\varepsilon_{r}$ is the permittivity in vacuum, $q$ the source charge, $Q$ the test charge, $r$ the magnitude of the separation vector between the two charges and $\vec{r}$ the direction of the separation vector. In the case of $n$ charges, the total electrostatic force becomes:

$F=\sum_{i=1}^{n} F_{i}=\frac{1}{4 \varepsilon_{r} \pi} \sum_{i=1}^{n} \frac{q_{i} Q}{r_{i}^{2}} r_{i}^{\prime}$

Introducing the electric field $\mathrm{E}$ and considering a uniform distribution of the charge in the considered region $F=Q E$, the electric field can be expressed as:

$E=\frac{1}{4 \varepsilon_{r} \pi} \int \frac{1}{r^{2}} \vec{r} d q$ 
If a surface area $(S)$ is considered, the electric field can be expressed as:

$E=\frac{1}{4 \varepsilon_{r} \pi} \int_{0}^{S} \frac{\sigma\left(r^{\prime}\right)}{r^{2}} \vec{r} d a^{\prime}$

The flux through a surface area $(S)$ can be described as:

$\emptyset_{E} \equiv \int_{0}^{S} E d a$

with $d a$ defined as an infinitely small area element. By considering a surface area $S$, equation (5) can be written into [6]:

$\oint E d a=\sum_{i=1}^{n}\left(\int E_{i} d a\right)=\sum_{i=1}^{n} \frac{1}{\varepsilon_{0}} q_{i}=\oint E d a_{s}=\frac{1}{\varepsilon_{0}} Q_{\text {enc }}$

with $Q_{e n c}$ the charge enclosed in the surface $S$. The surface charge and volume charge for our geometries were computed using equation (6).

The formation of an electric field depends on material properties as well as the electrical charges present on the surface. The electric field distribution can be visualized by electric field lines and vector plots. Gauss' law relates the electrostatic scalar potential with the static electric field:

$\Phi_{E}=\frac{Q}{\varepsilon_{0}}$

with $\Phi_{\mathrm{E}}$ the electrical flux through a closed surface, $Q$ the charge enclosed in the surface and $\varepsilon_{0}$ the permittivity in vacuum. The following formulas can be derived from Gauss' law ${ }^{[14]}$ :

$E=\nabla V$

$\nabla \varepsilon E=\rho$

where $\varepsilon$ is the absolute permittivity $\left(\varepsilon=\varepsilon_{r} * \varepsilon_{0}\right)$, E the static electric field, $\rho$ the charge and $\mathrm{V}$ the electric potential. The considered dielectric constants $\left(\varepsilon_{r}\right)$ in the model are 1 and 2.2 for the platinum electrode and n-hexane, respectively.

Equations (8) and (9) were used to numerically calculate the electrostatic field between an electrode with triangular emitters and a flat counter-electrode, using Comsol 4.3a. The model considers the case of a cathode placed at $3 \mu \mathrm{m}$ from the anode. The volume between the electrodes is filled with nhexane. The overall dimension of the model is set at $50 \mu \mathrm{m}$ width (x-direction), $33 \mu \mathrm{m}$ depth (ydirection) and $2 \mu \mathrm{m}$ height (z-direction). These dimensions represent a characteristic part of the microreactor. In Figure 4.2a the overall modeled geometry is given. 
a)

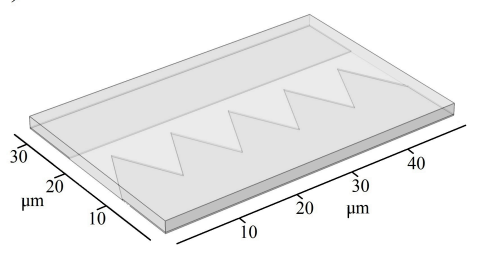

c)

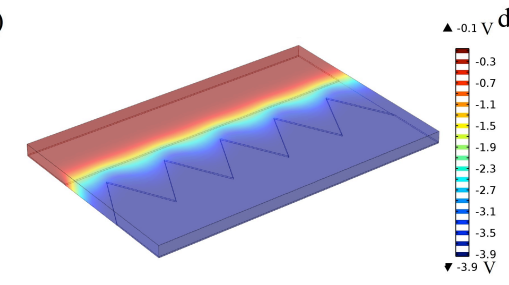

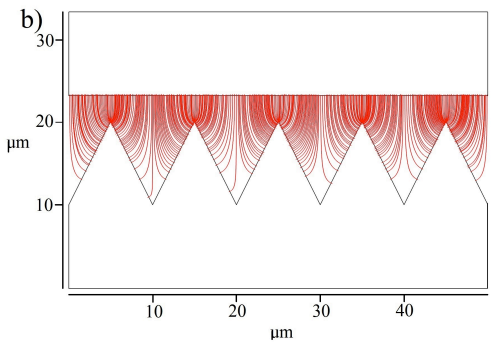

$.0 .1 \mathrm{~V} d)$

Figure 4.2. a) Overall model geometry, b) 2D streamline plot of the electric field, c) contour potential plot of the electric field, d) arrow line plot of the electric field.

The mesh for the geometry was set as follows: maximum element size $128 \mathrm{~nm}$, minimum element size $23 \mathrm{~nm}$, maximum element growth rate 1.5, resolution of curvature 0.6 and resolution of the narrow regions 0.5 . The initial values of all structures were set to a potential of 0 Volt, apart from the cathode potential which was set to $-4 \mathrm{~V}$. The temperature was set at $293.25 \mathrm{~K}$. The stationary solver was set with its tolerance at 0.001 and an algebraic multigrid was selected.

\subsection{Experimental}

\subsubsection{CFE microreactor fabrication}

CFE microreactors with various gaps between the microstructured cathode and the anode were made for silicon and glass by the following sequence of process steps: silicon (100) substrates (p-type boron doped, resistivity 5-10 $\Omega \mathrm{cm}, 100 \mathrm{~mm}$ diameter, $525 \mu \mathrm{m}$ thickness, single side polished; Okmetic, Finland) were cleaned by immersion in fuming 100\% nitric acid (UN2031 OM Group) for 10 min, in boiling 69\% nitric acid (BASF, 51153574) for $15 \mathrm{~min}$., rinsed in demineralized water, and immersed in $1 \%$ aqueous HF (D252M Honeywell) for $1 \mathrm{~min}$., followed by rinsing in demineralized water and spin drying. $1 \mu \mathrm{m}$ of $\mathrm{SiO}_{2}$ was deposited on the substrates in a furnace, using wet oxidation (Tempress, $\mathrm{H}_{2} \mathrm{O}+\mathrm{N}_{2}$ bubbler, $\mathrm{N}_{2}$ flow 2 liter $/ \mathrm{min}, 1150^{\circ} \mathrm{C}$ ). Electrode structures were photolithographically defined in photoresist (standard UV-lithography, photoresist Olin 907-17). They are centered with respect to a microreactor footprint-size of $20 \times 15 \mathrm{~mm}$. In the lithographically defined areas $150 \mathrm{~nm}$ of $\mathrm{SiO}_{2}$ was removed by immersion in buffered HF solution (BHF; Honeywell, 10188624), followed by rinsing in demineralized water and spin drying. A layer of $100 \mathrm{~nm}$ Pt with 10 $\mathrm{nm}$ Ta as adhesion layer was sputtered (homemade PVD machine, Ar plasma 200W, 6.66 $10^{-3} \mathrm{mbar}$, 
$145 \mathrm{sccm}$ Ar flow rate). After the lift-off process by ultrasonication in acetone (VLSI 51150924, BASF) for 10 min., the substrates were washed with isopropanol (VLSI 51152037, BASF) followed by rinsing in demineralized water and spin drying. The flow channel of the microreactor $(15 \mathrm{~mm}$ long with a variable width due to the various electrode spacings) was lithographically defined in photoresist (standard UV-lithography, photoresist Olin 907-17). By means of ion beam etching (15 min. IBE etching Oxford i300, current 50mA, voltage 300V, generator power $300 \mathrm{~W}$ ) followed by 2.5 min. of reactive ion etching (Adixen DE, 20/15/150 sccm flow of $\mathrm{C}_{4} \mathrm{~F}_{8} / \mathrm{CH}_{4} / \mathrm{He}, 8.5 \cdot 10^{-3} \mathrm{mbar}$, 2800 W ICP, $350 \mathrm{~W}$ CCP) the $\mathrm{SiO}_{2}$ between the electrodes was removed. On the non-polished backside of the silicon substrate fluidic access holes to the flow channel were created via plasma etching (Adixen SE, $\mathrm{T}=-40^{\circ} \mathrm{C}, 175 / 500 \mathrm{sccm}$ flow rate $\mathrm{C}_{4} \mathrm{~F}_{8} / \mathrm{SF}_{6}, 2500 \mathrm{~W}$ ICP, $20 \mathrm{~W} \mathrm{CCP}$ ) after standard UVlithography (photoresist Olin 908-35), after which the remaining photoresist was removed with $\mathrm{O}_{2}$ plasma (Tepla 300).

On glass substrates (Mempax, $100 \mathrm{~mm}$ diameter, thickness $500 \mu \mathrm{m}$, Mark Optics, USA), after immersion in fuming 100\% nitric acid (UN2031 OM Group) for $10 \mathrm{~min}$. followed by rinsing in demineralized water and spin drying, a layer of $100 \mathrm{~nm} \mathrm{Au}$ with $10 \mathrm{~nm} \mathrm{Cr}$ as adhesion layer was sputtered (homemade PVD machine, Ar plasma $200 \mathrm{~W}, 6.66 \cdot 10^{-3} \mathrm{mbar}, 145 \mathrm{sccm}$ flow rate). This metallic layer served as a masking layer during the fabrication of the flow channel. A $15 \mathrm{~mm}$ long straight channel was lithographically defined in photoresist (standard UV-lithography, photoresist Olin 907-17). After ozone exposure ((Surf Ozone UV PRS 100 reactor, $300 \mathrm{sec}$.), in order to improve the wetting of the photoresist for proper metal etching, the $\mathrm{Au}$ and $\mathrm{Cr}$ were removed in the patterned areas by wet etching in a solution of $\mathrm{KI}: \mathrm{I}_{2}: \mathrm{H}_{2} \mathrm{O}(4: 1: 40)$ for 1 min. followed by a solution of chromium etchant (BASF) for $20 \mathrm{sec}$. Both etch steps were followed by rinsing in demineralized water and spin drying. The flow channel was subsequently created by immersion in a $25 \%_{\mathrm{vol}} \mathrm{HF}$ solution (BASF, 51151083) for $25 \mathrm{~min}$, followed by rinsing in demineralized water and spin drying. The cross section of the obtained channel is $150 \mu \mathrm{m}$ wide and $25 \mu \mathrm{m}$ deep. The photoresist and the $\mathrm{Au} / \mathrm{Cr}$ mask were removed using 99\% nitric acid (UN2031 OM Group) and with a solution of $\mathrm{KI}: \mathrm{I}_{2}: \mathrm{H}_{2} \mathrm{O}(4: 1: 40)$ and a solution of chromium etchant (BASF), respectively. Access holes to the metallic electrodes were created via powder blasting ${ }^{[15]}$.

After cleaning in piranha solution for $30 \mathrm{~min}$., processed silicon and glass wafers were thermally bonded (Heraeus, temperature $600{ }^{\circ} \mathrm{C}$ for $1 \mathrm{~h}$.) and individual microreactors of $20 \mathrm{~mm}$ by $15 \mathrm{~mm}$ were cut out of the stack with a dicing machine (Disco DAD-321). 


\subsubsection{Field emission experiments in CFE microreactors}

In the fabricated microreactors cold field emission was studied in n-hexane, which is an apolar aprotic solvent (n-hexane 95\% from Sigma-Aldrich). Using a source measurement unit (Keithley, 2410) the required electrical field was generated by applying a negative potential to the cathode, with the anode grounded. Current-voltage curves (i/V curves) were recorded via a custom made Labview program. The two electrodes were connected to the source measurement unit via spring connectors (MCS004, Mill Max), which ensure proper electrical contact between the microreactor and the rest of the setup. By using a Harvard pump (Harvard Apparatus, PHD 2000) and a $2.5 \mathrm{ml}$ syringe (Hamilton Gastight) the solvent was flushed into and through the microdevice. Current-voltage measurements were done for continuous (from 1 to $10 \mu \mathrm{l} / \mathrm{min}$ ) and stopped flow. Before and after each measurement fresh solvent was flushed through the microreactor (approx. $100 \mu 1$ ). Recorded characteristic currentvoltage curves, obtained by applying a negative potential to the cathode with the microtips, are shown below in Figure 4.3. Electrical measurements were carried out at least three times in different microreactors (different gaps) and show very reproducible behavior, within experimental error.

\subsubsection{Chemical reaction in CFE microreactors}

In order to prove the possibility of cold field emission for the generation of solvated electrons and their application in chemical synthesis, the microreactors were used for the partial reduction of anthracene. Solutions of $5 \mathrm{mM}$ of anthracene (Sigma-Aldrich, 97\%) in n-hexane (Sigma-Aldrich, $95 \%$ ) or in $n$-hexane $+25 \%$ vol of ethanol (VWR 99\%, 10009831000) were fed in continuous flow $(1 \mu 1 / \mathrm{min})$ upon applying a constant current of $5 \mu \mathrm{A}$. For each electrode spacing a total of $1 \mathrm{ml}$ of reactant was collected in a vial and analyzed with a GC-MS (Agilent Technologies, GC 7890A MS 5975C).

\subsection{Results and discussion}

\subsubsection{Model results}

The model results are graphically summarized in Figure $4.2 \mathrm{~b}-\mathrm{d}$. The electric field is represented by a 2D streamline plot in Figure 4.2.b. Clearly, the highest convergence of the streamlines occurs at the tips of the triangular cathode, demonstrating the expected field enhancement at the microtips. The 3D representation of the streamline plot depicted in Figure 4.2.c indicates this as well: the highest potential is reached at the tips. Furthermore, it can be observed that the streamlines mainly originate and terminate at the top of both electrodes, i.e. at the position where the distance between both electrodes is minimal, leading to a higher potential at the tips. The 3D model (Figure 4.2.d) shows an arrow line plot of the electric field along the z-direction of the electrodes: the region with the highest potential is located at the apices of the electrode tips. Thus, the microtips on the cathode clearly lead 
to local enhancement of the electric field which favors emission of solvated electrons into the flow channel between the electrodes.

The electric field distribution between the electrodes is similar for different distances between the electrodes, only the intensity of the electric field (for a fixed applied potential) decreases for an increase of the distance between the cathode and the anode.

\subsubsection{Electrical characterization}

Scanning Electron Microscope (HR-SEM; Zeiss, Merlin) analysis of the metallic electrodes with micro tips on a silicon wafer before bonding revealed that the fabrication process was reproducible and that microtips with different electrode gaps have similar geometry. An example of a realized electrode pattern is shown in Figure 4.1d. The radius of curvature of the tips was measured to be 750 $\pm 50 \mathrm{~nm}$.

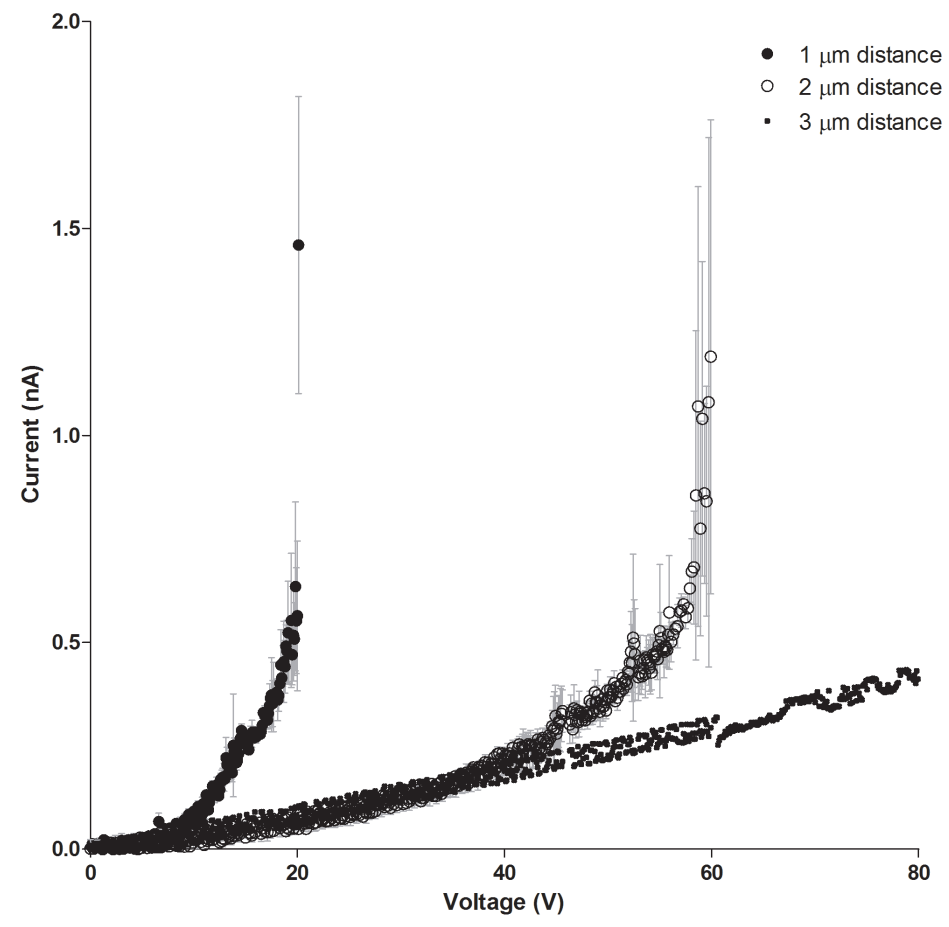

Figure 4.3. Current-voltage curves as measured in microreactors filled with $n$-hexane and with different electrodes gaps. 


\section{Chapter 4}

In Figure 4.3 current-voltage curves are shown of microreactors of which the flow channel is filled with n-hexane and with different distances between the electrodes. Each curve is an average of at least three measurements per chip type. The exponential behavior of the current in relation to the applied potential is characteristic for cold field emission. In Figure 4.4 the data is replotted and evaluated using standard Fowler-Nordheim theory ${ }^{[16]}$, of which the validity for field emission of electrons into dielectric liquids was demonstrated by Forbes et al ${ }^{[17]}$. In Figure 4.4 for the case of a gap of 1 or $2 \mu \mathrm{m}$ a linear trend is observed, which means that field emission indeed has occurred in these microreactors.

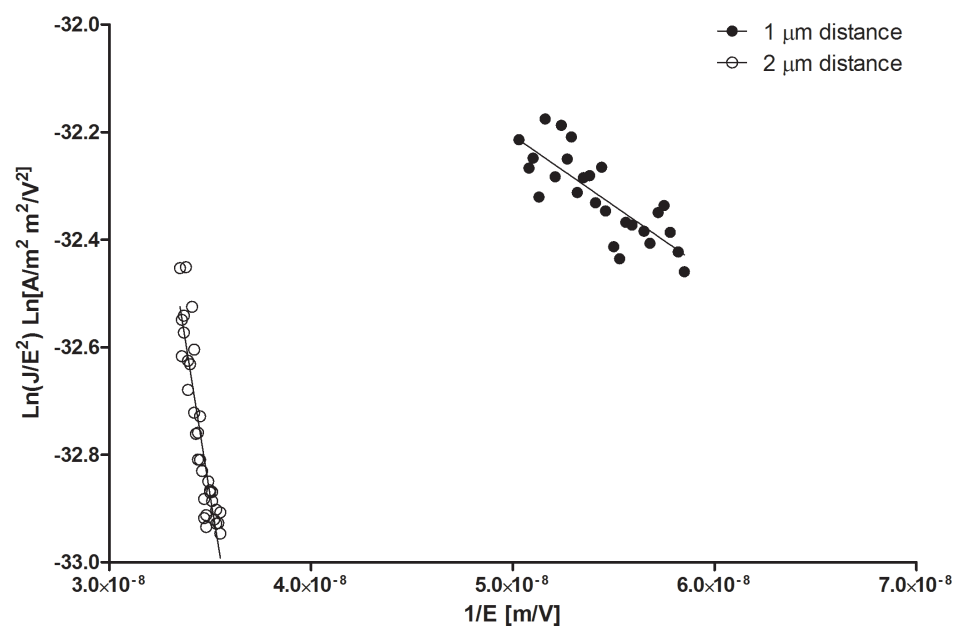

Figure 4.4: Fowler-Nordheim plot for microreactors filled with n-hexane and with $1 \mu \mathrm{m}$ and $2 \mu \mathrm{m}$ electrode gaps.

The field enhancement factor can be calculated from the curves in Figure 4.4 using:

$I=A a \emptyset^{-1} F^{2} \exp \left\{-b \emptyset^{1.5} / F\right\} \equiv R^{e l} F^{2} \exp \left\{S^{e l} / F\right\}$

where $I$ is the current, $A$ is the area of emission, $F$ is the local electric field, $\varnothing$ is the local work function, and $a$ and $b$ are constants $\left(a \equiv e^{3} / 8 \pi h_{p}=1.541434 \times 10^{-6} A e V V^{-2}, b \equiv \frac{4}{3}\left(2 m_{e}\right)^{\frac{1}{2}} /\right.$ $e \hbar_{p}=6.830888 \times 10^{9} \mathrm{eV} \mathrm{m}^{-1}$ where $m_{e}$ is the electron mass, $e$ is the elementary positive charge, and $\hbar_{p}$ is the Plank's constant divided by $\left.2 \pi\left(\hbar_{p}=h_{p} / 2 \pi\right)\right)$.

The standard Fowler-Nordheim theory was developed for CFE in vacuum and has to be adjusted for a dielectric liquid. A dielectric liquid in contact with the electrode decreases the potential barrier that has to be overcome in order to emit an electron from the Pt microstructured cathode into the liquid. Therefore, the work function of the electrode material in the Fowler-Nordheim equation [10] has to be reduced by a factor $1 / \varepsilon_{\mathrm{r}}$ where $\varepsilon_{\mathrm{r}}$ is the dielectric constant of the liquid. 
$\emptyset^{*}=\emptyset-\frac{1}{\varepsilon_{r}}$

The presence of microtips on the emitting surface, as demonstrated in the model, will locally increase the generated electric field. The ratio between the electric field in the case of two flat planar surfaces $\left(F_{M}\right)$ and the electric field obtained using the proposed electrode system (one flat, one microstructured) $(F)$ is defined as enhancement factor $\gamma$ :

$\gamma=\frac{F}{F_{M}}$

Considering a uniform local work-function and assuming that n-hexane behaves as a classic dielectric liquid, for a triangular barrier the slope of the linear fitting line in Fowler-Nordheim plot is equal to:

$M=\frac{-b \emptyset^{* 1.5}}{\gamma}$

The experimental field enhancement factors calculated from the Fowler-Nordheim plots, assuming a work-function of 5.9 for platinum ${ }^{[18]}$, are 3039 and 432 for 1 and $2 \mu \mathrm{m}$ separation, respectively.

The different electrode distances influence the locally generated electric field upon applying a fixed voltage. The electric field scales with the separation distance ( $E=\frac{V}{d}$ ) therefore current-voltage measurements for similar conditions but with different separation distances favor higher currents for smaller electrodes gap. For gaps $\geq 3 \mu \mathrm{m}$ the charge injection mechanism changes from field emission to space charge limited current (Ohmic behavior) which can be observed in Figure 4.3, where for the $3 \mu \mathrm{m}$ gap a straight line is observed instead of an exponential curve. Such transition was also observed by Agiral et al, upon using n-hexane as dielectric liquid and carbon nanofibers as emission points: only for inter electrode distances $\leq 9 \mu \mathrm{m}$ field emission was predominant over space charge ${ }^{[11]}$. In this work it is found that a transition between field emission and space charge currents occurs at $10 \mathrm{~V}$ and $40 \mathrm{~V}$ for electrode distances of 1 and $2 \mu \mathrm{m}$, respectively.

For various continuous flows in the range 1 to $10 \mu \mathrm{l} / \mathrm{min}$ the current-voltage curves for a fixed electrode distance do not show a significant difference. This is due to the geometrical configuration of the microdevices, the main flow in the channel is above the electrodes because the electrodes are placed at the bottom of the flow channel. Due to this configuration the velocity of the liquid in the gap between the electrodes is much lower than in the center of the channel. In fact, although the overall flow velocity might be varied from 1 to $10 \mu \mathrm{l} / \mathrm{min}$, in the proximity of the electrodes the liquid velocity remains constant. 


\section{Chapter 4}

\subsubsection{Chemical reactions in CFE microreactors}

$\mathrm{GC}$ analysis of solutions obtained after the reaction in the microdevices indicate that pure n-hexane is inactive during the partial reduction of anthracene. The limited number of emission points on the electrodes (here we have 600 microtips), the low current (here $\leq 1 \mu \mathrm{A}$ ) that passes through the liquid, the absence of a proton donator in the solution and the geometry of the microfluidic device (the electrodes are placed at the bottom of the flow channel) all can be limiting factors for the reduction reaction. A proton donator is necessary to continue the reduction after the formation of the anthracene radical anion and this can be obtained by the addition of ethanol to the n-hexane and anthracene solution. A $5 \mathrm{mM}$ solution of anthracene in $\mathrm{n}$-hexane containing $25 \%$ vol of ethanol was loaded in the microreactors and a constant current of $5 \mu \mathrm{A}$ or a maximum voltage of $80 \mathrm{~V}$ were applied (higher potentials can lead to a short-circuit in the microreactors due to electrical breakdown of the $\mathrm{SiO}_{2}$ layer below the electrodes) for electrode gaps of 1, 3, 5, 10 and $20 \mu \mathrm{m}$. GC-MS analyses of reacted solutions for various gaps and at a flow velocity of $1 \mu \mathrm{l} / \mathrm{min}$ showed the formation of three different molecules, i.e. 9-ethyl-2-methyl-9,10-dihydroanthracene, 9-ethyl-3-methyl-9,10-dihydroanthracene and 9-ethyl-anthrone, in microreactors with electrode spacing $\leq 10 \mu \mathrm{m}$ (Table 4.1). We hypothesize that the formation of 9-ethyl-2-methyl-9,10-dihydroanthracene and 9-ethyl-3-methyl-9,10dihydroanthracene is due to the addition of ethyl and methyl cations. In detail, the ethyl cation is added, instead of a proton, after the formation of the anthracene radical anion formed by the addition of a solvated electron to the anthracene aromatic ring. After the formation of the 9-ethyl-9,10dihydroanthracene, the alkylation of a methyl cation, present in the solution, occurs at one of the remaining aromatic rings followed by the removal of a proton by a hydroxide anion forming the 9ethyl-2-methyl-9,10-dihydroanthracene and 9-ethyl-3-methyl-9,10-dihydroanthracene. Presumably an ionization process of ethanol occurs during the reaction in the proximity of the electrodes, which together with formed solvated electrons, creates anions and cations that take part in the anthracene reduction.

For the generated electric fields the measured current passing through the liquid during the reaction can be due to two different phenomena: i) direct injection of electrons generating solvated electrons in the liquid medium, and ii) the formation of charge carriers (i.e. methyl and ethyl cations). The formation of 9-ethyl-10-anthrone is probably due to the oxidation of 9-ethyl-9,10-dihydroanthracene at the anode. A similar effect was observed by Fontana et al. for the re-oxidation of the 9,10dihydroanthracene using an undivided electrochemical cell ${ }^{[19]}$. 
Table 4.1: GC-MS analysis of solutions containing $5 \mathrm{mM}$ of anthracene after reaction at ambient temperature in continuous flow $(1 \mu \mathrm{l} / \mathrm{min}$ ) by applying a constant current of $5 \mu \mathrm{A}$ (or a maximum voltage of $80 \mathrm{~V}$ ).

\begin{tabular}{ccccc}
\hline \multicolumn{5}{c}{ Reduction of anthracene in n-hexane + 25\% } \\
Current & ethanol \\
& $\begin{array}{c}\text { Electrode } \\
\text { distance }\end{array}$ & $\begin{array}{c}\text { Conversion } \\
(\%)\end{array}$ & $\begin{array}{c}\text { 9-ethyl-2-methyl-9,10- } \\
\text { dihydroanthracene and 9-ethyl-3- } \\
\text { methyl-9,10-dihydroanthracene (\%) }\end{array}$ & $\begin{array}{c}\text { 9-ethyl-10-anthrone } \\
\text { (\%) }\end{array}$ \\
\hline $5 \mu \mathrm{A}$ & $1 \mu \mathrm{m}$ & 5.6 & 2.5 & 3.1 \\
$5 \mu \mathrm{A}$ & $3 \mu \mathrm{m}$ & 4 & 1.7 & 2.3 \\
$5 \mu \mathrm{A}$ & $5 \mu \mathrm{m}$ & 3.6 & 1.2 & 2.4 \\
$3 \mu \mathrm{A}$ & $10 \mu \mathrm{m}$ & 2 & 0.6 & 1.5 \\
$1 \mu \mathrm{A}$ & $20 \mu \mathrm{m}$ & 0 & 0 & 0
\end{tabular}

The yields obtained by using microreactors with a different space between the electrodes show an increase of the product formation for decreasing gaps. In the case of distances above $5 \mu \mathrm{m}$ the measured current was lower than $5 \mu \mathrm{A}$ (i.e. 3 and $1 \mu \mathrm{A}$ for 10 and $20 \mu \mathrm{m}$ gaps, respectively). For gaps $\leq 5 \mu \mathrm{m}$ the recorded current was constant, however smaller gaps show higher product formation (Table 4.1). This can be explained by the fact that in the case of smaller gaps in the flow channel the density of solvated electrons is higher compared with larger gaps, and this facilitates the reduction of one of the aromatic rings of anthracene forming the radical anion.

The presence of cations and anions in the solution and the higher product formation, in the case of smaller gaps between the electrodes, suggest that the observed current is an equilibrium between two different phenomena, field emission and carrier injection, where with the latter we mean the electrochemical formation of cations and anions directly at the electrode surface. By decreasing the distance between the electrodes a higher density of solvated electrons is formed facilitating the formation of the anthracene radical anion, which increases product formation. 


\section{Chapter 4}

\subsection{Conclusions}

The proposed study confirms the possibility to generate CFE in commercially pure grade n-hexane by using a low potential on electrodes with small electrode gaps and with sharp tips to enhance the electric field between the electrodes. We conclude that for tip-to-flat-electrode distances of less than 3 $\mu \mathrm{m}$ field emission is the prevalent way to introduce charges in liquid n-hexane, whereas for distances higher than $3 \mu \mathrm{m}$ direct charge exchange at the electrode surfaces becomes the prevalent way. Field emission in pure $\mathrm{n}$-hexane with the proposed microreactor does not directly reduce aromatic hydrocarbons, for that the addition of a proton donator is necessary. In this way, in solutions of nhexane and ethanol a mixture of products, identified as 9-ethyl-2-methyl-9,10-dihydroanthracene, 9ethyl-3-methyl-9,10-dihydroanthracene and 9-ethyl-anthrone, is formed, due to the presence of methyl and ethyl cations formed by electrochemical degradation of the alcohol. The knowledge acquired in this work will be useful for future microreactor devices for the partial reduction of polycyclic aromatic hydrocarbons based on cold field emission to inject electrons in liquids. 


\subsection{References}

[1] M. Chiesa, M. C. Paganini, E. Giacomello, D. M. Murphy, C. Di Valentin and G. Pacchioni, "Excess electrons stabilized on ionic oxide surfaces", Acc. Chem. Res., 39, 861-867, 2006.

[2] W. Weyl, "Uber metallammonium-verbindungen", Annalen der Physik, 197, 601-612, 1864.

[3] B. Abel, U. Buck, A. L. Sobolewski and W. Domcke, "On the nature and signatures of the solvated electron in water", Phys. Chem. Chem. Phys., 14, 22-34, 2012.

[4] A. J. Birch, "Reduction by dissolving metals. Part 1", J.Chem. Soc., 430-436, 1944.

[5] H. W. Sternberg, R. Markby and I. Wender, "Electrochemical reduction of benzene ring", J. Electrochem. Soc.,110, 425-429, 1963.

[6] N. Na, Y. Xia, Z. Zhu, X. Zhang and R. G. Cooks, "Birch reduction of benzene in a lowtemperature plasma”, Angew. Chem. Int. Ed., 48, 2017-2019, 2009.

[7] E. Karvin-Miller, K.E. Swenson and D. Zemach, "Cathodic Birch reduction of methoxyaromatics and steroids in aqueous solution”, J. Org. Chem., 48, 4210-4214, 1983.

[8] B. Halpern and R. Gomer, "Field emission in liquids", J. Chem. Phys., 51, 1031-1047, 1969.

[9] K. Dotoku, H. Yamada, S. Sakamoto, S. Noda and H. Yoshida, "Field emission into nonpolar organic liquids”, J. Chem. Phys., 69, 1121-1125, 1978.

[10] A. G. Krivenko, N. S. Komarova and N. P. Piven, "Electrochemical generation of solvated electrons from nanostructured carbon”, Electrochem. Commun., 9, 2364-2369, 2007.

[11] A. Agiral, H. B. Eral, D. van den Ende, J. G. E. Gardeniers, "Charge injection from carbon nanofibers into a dielectric liquid under ambient conditions", Trans. Electron Devices, 58, 3514-3518, 2011.

[12] D. J. Griffiths, “Introduction to electrodynamics", Prentice hall, 3rd edition, 1999.

[13] A. Coulomb, Memories de l'Academie Royale des Science, 569-577, 1785.

[14] I. S. Grant and W. R. Philips, "Electromagnetism”, 2nd Ed., Manchestern Physics, John Willey \& Sons, 1990. 


\section{Chapter 4}

[15] H. Wensink, H. V. Jansen, J. W. Berenschot and M. C. Elwenspoek, "Mask materials for powder blasting”, J. Micromech. Microeng., 10, 175-180, 2000.

[16] R. H. Fowler, L. Nordheim, "Electron emission in intense electric field", Proc. R. Soc. A, 119, 173-181, 1928.

[17] R.G. Forbes and J.H.B. Deane, "Reformulation of the standard theory of Fowler-Nordheim: tunnelling and cold field emission”, Proc. R. Soc. A, 463, 2907-2927, 2007.

[18] Y. Xiong and X. Lu, "Metallic nanostructures: from controlled synthesis to applications", Springer, 258, 2015.

[19] E. Gagyi Palffy, P. Starzewski, A. Labani and A. Fontana, "Electrochemical reduction of polyaromatic compounds”, J. Appl. Electrochem., 24, 337-343, 1994. 


\section{SUPPORTING INFORMATION}

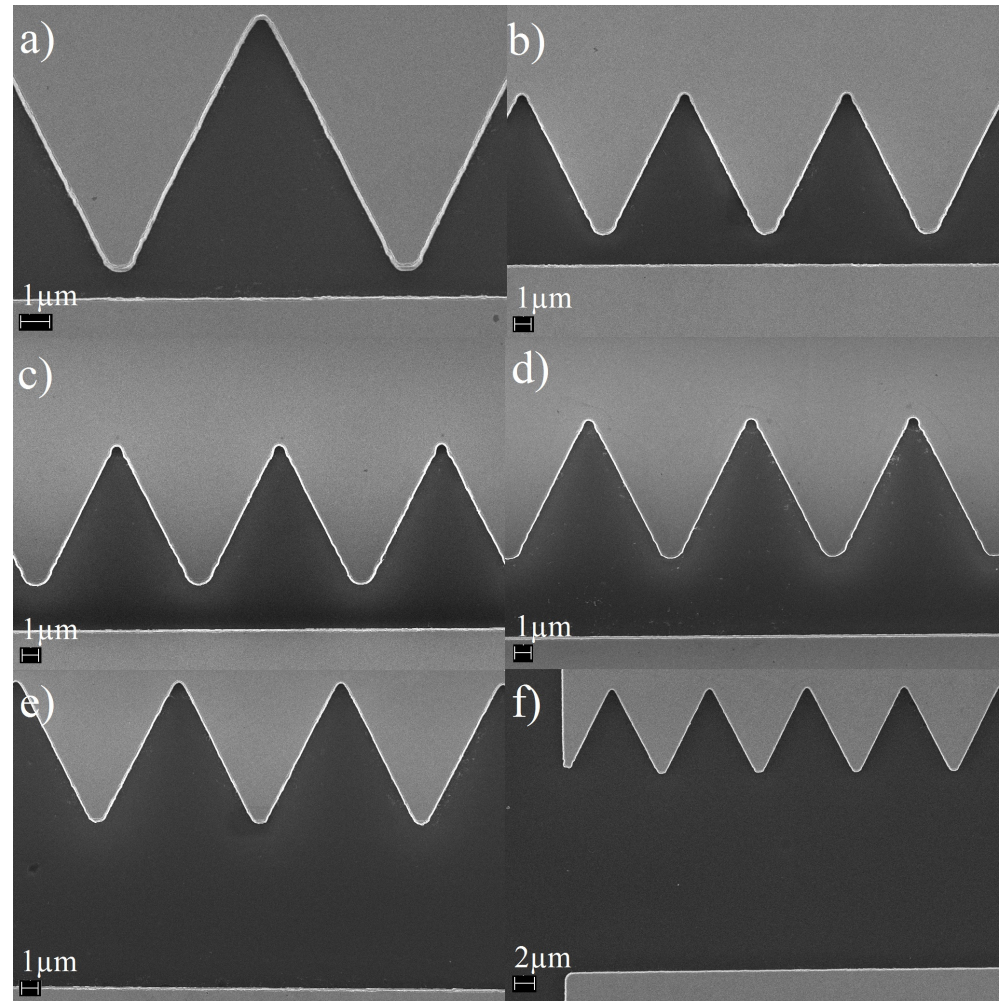

Figure SI-1: SEM images of shapes of microtip for various gaps: a) $1 \mu \mathrm{m}, \mathrm{b}) 2$, c) $3 \mu \mathrm{m}$, d) $5 \mu \mathrm{m}$, e) $10 \mu \mathrm{m}, \mathrm{f}) 20$ $\mu \mathrm{m}$.

\section{Mass Spectrometry Data}

9-ethyl-2-methyl-9,10-dihydroanthracene and 9-ethyl-3-methyl-9,10-dihydroanthracene $(\mathrm{m} / \mathrm{z}$, intensity): 17.000,197.000; 18.100,796.000; 28.000,619.000; 31.900,366.000; 165.000,286.000; $176.000,137.000 ; \quad 178.000,569.000 ; \quad 179.000,458.000 ; \quad 192.900,710.000 ; \quad 194.100,542.000 ;$ $195.100,392.000 ; 222.100,732.000 ; 223.000,160.000$

9-ethyl-10-anthrone (m/z, intensity): 17.000,260.000; 18.000,809.000; 28.000,557.000; $31.900,285.000 ; \quad 82.800,118.000 ; \quad 87.800,113.000 ; \quad 138.900,187.000 ; \quad 150.100,118.000 ;$ $163.000,531.000 ; \quad 164.000,408.000 ; \quad 165.000,2064.000 ; \quad 166.000,240.000 ; \quad 176.100,173.000$; $178.000,137.000 ; \quad 193.000,3759.000 ; \quad 194.000,1668.000 ; \quad 194.900,201.000 ; \quad 206.900,119.000 ;$ 207.900,103.000; 222.000,1633.000; 223.100,286.000. 
Chapter 4 


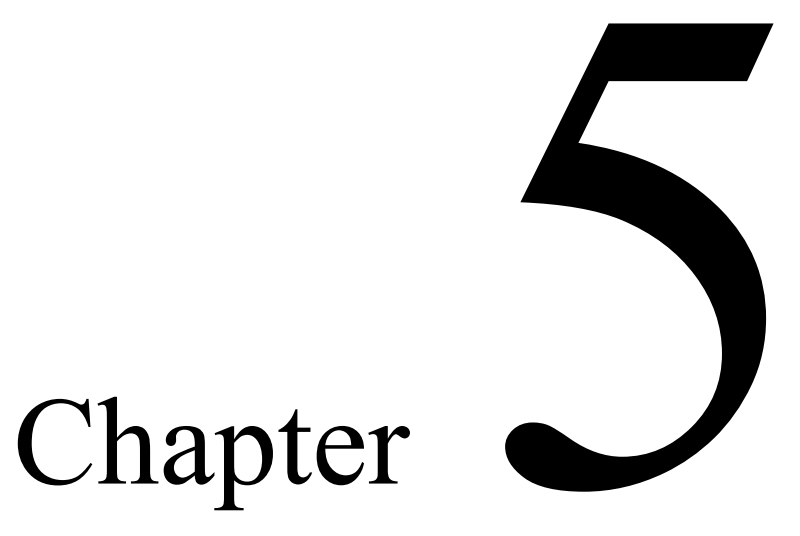

\section{Flow chemistry using field electron emission from silicon nanowires integrated into a microreactor}




\title{
Chapter 5
}

\begin{abstract}
Field emission of electrons into liquids offers the prospect of electrochemical reactions without the addition of electrolytes in solutions, thereby creating greener and more sustainable processes. As a novel microreactor concept we present low voltage charge injection from a field emitter array integrated in a microchannel, into a flow of apolar (n-hexane, 1-hexene and cyclohexane) and polar solvents (N,N-dimethylformamide, ethanol and 1-propanol) under ambient conditions. The cathode of the microreactor is formed by a dense array of micromachined silicon nanowires of which the sharp tips are positioned a few micrometers from the anode. The resulting emission currents follow FowlerNordheim behavior. The microdevice was successfully tested as a flow reactor for the partial reduction of anthracene. Although due to re-oxidation side-reactions the yields in these preliminary tests are relatively low, this method opens a new route for performing partial reduction of aromatic hydrocarbons, similar to Birch reduction.
\end{abstract}

Keywords: electron field emission, aromatic reduction, polar organic solvents, apolar organic solvents 


\subsection{Introduction}

Field Emission (FE) permits the injection of a high current into a liquid by applying an electrostatic field on an element with a small radius of curvature. This phenomenon has been used several decades ago to study electron mobility in and work function of liquids, as well as the effects of high currents to liquids ${ }^{[1,2]}$. The electric field necessary to promote electron transfer at the metal/liquid interface was obtained by using sharp metal electrodes such as tungsten tips, razor blades and brass cylinders, immersed in a dielectric liquid, at a distance of few millimeters from a typically flat counter electrode. The intensified electric field at a sharp tip increases the possibility of an electron passing the potential barrier through either Schottky or Fowler-Nordheim emission.

Nanostructures, such as silicon nanowires (SiNWs), carbon nanofibers (CNFs) and carbon nanotubes (CNTs), exhibit excellent field emission properties due to both their high length to diameter aspect ratio as well as their small radius of curvature tips ${ }^{[3,4,5]}$. The use of carbon nanostructures or SiNWs for field emission in organic liquids has hardly been investigated, except for the work carried out with CNT and CNF arrays in hexamethylphosphortriamide (HMPA) and n-hexane ${ }^{[6,7]}$. In this contribution we will extend this research by using silicon nanowires, fabricated with a Metal-Assisted Chemical Etching (MACE) process, as field emitters of excess electrons in several organic liquids.

Excess electrons can be generated in an insulating liquid by irradiating that liquid, or by dissolving a metal like $\mathrm{Na}$ or $\mathrm{Li}$ which will ionize the liquid ${ }^{[8]}$. The most well-known example of the latter is the dissolution of alkali metals in liquid ammonia, in which these excess electrons have exceptionally long lifetimes, of up to days. The color of the obtained solution becomes blue and it has been demonstrated that the reason for this is the generation of solvated electrons in the solution ${ }^{9}$. Solvated electrons have also been shown to exist in liquids such as water, hydrocarbons and alcohols ${ }^{[10,11,12]}$, but with relatively short lifetime. In synthetic organic chemistry solvated electrons are often used for the partial reduction of aromatic hydrocarbons, known as "Birch reduction",[13], which is typically carried out with the alkali metal-liquid ammonia combination mentioned above. Several attempts have been made to perform the reaction with less harmful substances than alkali metals and liquid ammonia. Most of the proposed alternatives utilize an electrochemical approach which relies on electrical activation of the alkali salts or by the formation of an amalgam between the electrolyte and the electrode to achieve the reduction ${ }^{[14,15]}$.

The demand for a greener process that can be performed at ambient temperatures inspired us to investigate the potential of direct electron injection into a solvent for partial reduction of aromatic hydrocarbons. We integrated a dense array of nanowires on a wall surface opposite of a planar electrode in a rectangular microreactor channel. This configuration not only allows a high emission current density, but also gives the possibility to perform synthetic reactions in continuous flow, by which residence time, and therewith hopefully product selectivity, may be tuned. The example reaction that was chosen is the partial reduction of anthracene. 


\subsection{Experimental}

\subsubsection{Microreactor fabrication}

The developed microreactor for injection of electrons in liquids consists of two electrodes positioned face-to-face. The cathode contains a dense array of SiNWs that are formed by using an electroless metal deposition (EMD) method on highly doped p-type silicon. Around the wire array an insulating layer of $250 \mathrm{~nm}$ of low-stress silicon-rich silicon nitride (SiRN) is deposited using low pressure chemical vapor deposition (LPCVD). This layer is needed to separate the silicon substrate from the anode, a $100 \mathrm{~nm}$ platinum (Pt) layer deposited on a glass substrate via sputtering (Figure 5.1a).
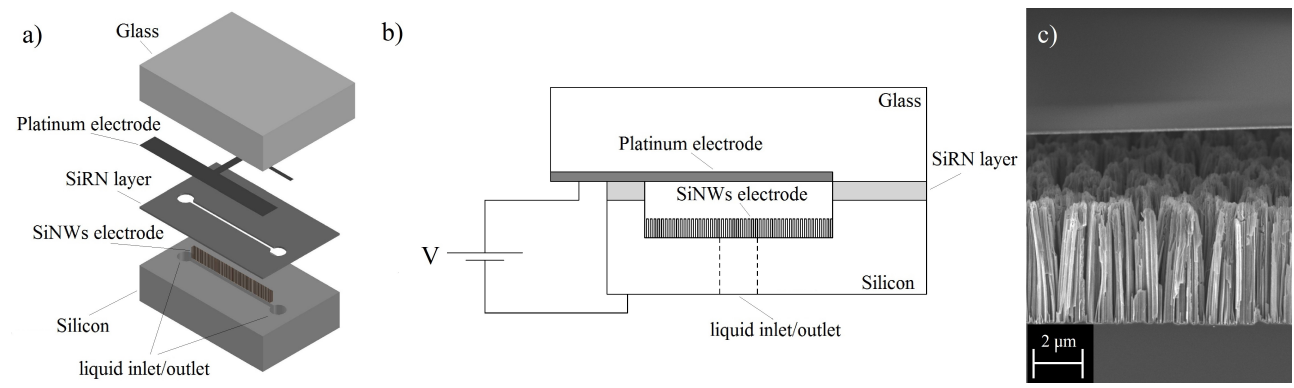

Figure 5.1. Microreactor with an embedded array of silicon nanowires which act as field emission electrodes: (a) $3 \mathrm{D}$ concept drawing of the microreactor. The channel is $0.1 \mathrm{~mm}$ wide, $15 \mathrm{~mm}$ long and $3.5 \mu \mathrm{m}$ height, the Pt electrode is $80 \mu \mathrm{m}$ wide, $12 \mathrm{~mm}$ long and $100 \mathrm{~nm}$ thick, the nanowires are $5 \mu \mathrm{m}$ long; (b) Cross section scheme of the microreactor (c) SEM cross section image of the microreactor channel showing the silicon nanowires.

Silicon substrates (p+-type boron doped, (100)-orientation, resistivity 0.01-0.024 $\Omega \mathrm{cm}, 100 \mathrm{~mm}$ diameter, thickness $525 \mu \mathrm{m}$, single side polished; Okmetic, Finland) were cleaned by immersion in fuming 100\% nitric acid (UN2031 OM Group) for $10 \mathrm{~min}$ and boiling 69\% nitric acid (BASF, 51153574) for $15 \mathrm{~min}$, rinsing in demineralized water, immersion for $1 \mathrm{~min}$. in $1 \%$ hydrofluoric acid (D252M Honeywell), and finally rinsing in demineralized water followed by spin drying. The silicon substrates were placed in a furnace and $250 \mathrm{~nm}$ of SiRN was deposited using LPCVD (Tempress, $\mathrm{SiH}_{2} \mathrm{Cl}_{2}$ flow: $77.5 \mathrm{sccm}, \mathrm{NH}_{3}$ flow $20 \mathrm{sccm}, \mathrm{N}_{2}$ flow $250 \mathrm{sccm}$, at a pressure of $150 \mathrm{mTorr}$ and a temperature of $\left.850^{\circ} \mathrm{C}\right)$. Straight microreactor flow channels $(15 \mathrm{~mm}$ long and $0.1 \mathrm{~mm}$ wide) were lithographically defined in photoresist (standard UV-lithography, photoresist Olin 907-17), centered with respect to a microreactor footprint-size of $20 \times 15 \mathrm{~mm}$. After removal of the SiRN in the lithographically defined areas by dry etching (Adixen DE, 20/15/150 sccm flow of $\mathrm{C}_{4} \mathrm{~F}_{8} / \mathrm{CH}_{4} / \mathrm{He}$, $8.510^{-3}$ mbar, $2800 \mathrm{~W}$ ICP, $350 \mathrm{~W}$ CCP) the substrates were cleaned from photoresist and fluorocarbon traces (originating from the dry etching process) in an $\mathrm{O}_{2}$ plasma (TePla 300E, $30 \mathrm{~min}$. $500 \mathrm{~W})$ and cleaned in Piranha solution $\left(4: 1 \mathrm{H}_{2} \mathrm{SO}_{4} / \mathrm{H}_{2} \mathrm{O}_{2}, \mathrm{H}_{2} \mathrm{SO}_{4}\right.$ BASF 51151507, $\mathrm{H}_{2} \mathrm{O}_{2}$ BASF 55316830) for $20 \mathrm{~min}$. At this point the silicon substrates were ready for the formation of SiNWs using a MACE process, which is based on the electroless metal deposition (EMD) protocol of Peng et 
$\mathrm{al}^{[16]}$ (for details see Supporting Information). After the deposition of silver nanoparticles in a solution of $5 \mathrm{mM} \mathrm{AgNO}_{3}$ (Sigma-Aldrich) in 20\% $\%_{\mathrm{vol}}$ aqueous HF (BASF, 51151083) for 1 min. the substrates were immersed in a solution of $20 \%$ vol $\mathrm{HF}$ and $0.1 \%_{\mathrm{vol}} \mathrm{H}_{2} \mathrm{O}_{2}$ for $10 \mathrm{~min}$. This results in the creation of SiNWs due to the formation of a localized short-circuited electrochemical cell between the silver nanoparticles and the silicon areas surrounding these nuclei. The Ag and the Si will work as cathode and anode, facilitating the oxidation of $\mathrm{Si}$ and its dissolution ${ }^{[17]}$, which proceeds faster under the nanoparticles than at the surface of uncovered silicon, and hence the remaining silicon is shaped as SiNWs. The remaining Ag particles were removed by immersion in $69 \% \mathrm{HNO}_{3}$ (BASF, 51153574) for $30 \mathrm{~min}$, followed by rinsing in demineralized water and spin drying. On the backside of the silicon substrate fluidic access holes to the flow channel were created via plasma etching (Adixen SE, T=$40^{\circ} \mathrm{C}, 175 / 500 \mathrm{sccm}$ flow rate $\mathrm{C}_{4} \mathrm{~F}_{8} / \mathrm{SF}_{6}, 2500 \mathrm{~W}$ ICP, $20 \mathrm{~W} \mathrm{CCP}$ ) after standard UV-lithography (photoresist Olin 908-35). The remaining photoresist was removed with an $\mathrm{O}_{2}$ plasma (Tepla 300).

On glass substrates (Mempax, $100 \mathrm{~mm}$ diameter, thickness $500 \mu \mathrm{m}$, Mark Optics, USA) the anode of each microreactor was lithographically defined in photoresist (standard UV-lithography, photoresist Olin 907-17) and, after treatment with UV/Ozone (Surf Ozone UV PRS 100 reactor, 5 min.) and immersion for $5 \mathrm{~min}$. in buffered hydrofluoric acid solution (BHF) (Honeywell, 10188624) for etching $110 \mathrm{~nm}$ deep into the glass surface in order to have a flat surface after Pt/Ta deposition to avoid bonding problems, a layer of $100 \mathrm{~nm}$ of Pt and $10 \mathrm{~nm}$ of tantalum (Ta) as adhesion layer was sputtered on the surface (homemade machine, 6.66 $10^{-3} \mathrm{mbar}, 145 \mathrm{sccm}$ Ar flow rate, $200 \mathrm{~W}$ DC). After sputtering, ultrasonic lift-off of the photoresist layer was performed in acetone $(20 \mathrm{~min}$; VLSI 51150924, BASF) followed by immersion in isopropanol (10 min; VLSI 51152037, BASF), rinsing in de-mineralized water (10 min) and spin drying.

Silicon and glass wafers, after cleaning in piranha solution for $30 \mathrm{~min}$., were anodically bonded (EVG $501,400^{\circ} \mathrm{C} ; 1000 \mathrm{~V}$ for $10 \mathrm{~min}$.). Subsequently, the obtained stack was immersed in $1 \% \mathrm{HF}$ for 1 min., after closure of the fluidic access holes by foil to avoid leakage of HF into the flow channels, followed by rinsing in demineralized water and sputtering of $\mathrm{Pt} / \mathrm{Ta}(100 \mathrm{~nm} / 10 \mathrm{~nm})$ on the silicon surface. Finally, individual microreactors of $20 \times 15 \mathrm{~mm}$ were cut (Disco DAD-321 dicing machine) from the wafer stack. After a pre-cut on both sides of $200 \mu \mathrm{m}$ with the dicing machine, a number of microreactors were broken and cross-sectional images were acquired using high resolution scanning electron microscopy (HR-SEM; Zeiss, Merlin) in order to check the interior appearance of the flow channel (Figure 5.1c). The gap between the two electrodes in the fabricated microdevice is about 3.5 $\mu \mathrm{m}$, which equals the height of the flow channel. The distance between the tips of the SiNWs and the counter electrode is larger than the thickness of the insulating layer ( $\mathrm{SiRN})$, which is due to the fact that during the MACE process with the chosen conditions (see above) not only SiNWs are formed by dissolution of $\mathrm{Si}$ underneath the $\mathrm{Ag}$ nanoparticles (dissolution rate ca. $500 \mathrm{~nm} \min ^{-1}$ ), but also $\mathrm{Si}$ uncovered with Ag slowly etches, approximately half as fast (dissolution rate ca. $270 \mathrm{~nm} \mathrm{~min}^{-1}$ ). 


\subsubsection{Electrical measurements}

Field emission in the microreactor was studied for 3 main categories of solvents: (i) nonpolar aprotic solvents (n-hexane 95\%, 1-hexene 99\% and cyclohexane 99.5\% from Sigma-Aldrich); (ii) polar aprotic solvents (N,N-dimethylformamide 99.8\% from Sigma-Aldrich) ; and (iii) polar protic solvents (1-propanol 99.7\% and absolute ethanol 99.8\% from Sigma-Aldrich). A source measurement unit (Keithley, 2410), connected via spring connectors (Ganter Griff, 615.3-M3-KN) to the two electrodes of the microreactor, was used to provide the desired electric field. Data were recorded by a custom Labview program. Before and after each measurement, the microreactor was washed with fresh solvent using a syringe (Hamilton gastight $2.5 \mathrm{cc}$ ) and a Harvard syringe pump (Harvard Apparatus, PHD 2000). Recorded characteristic current-voltage curves obtained by applying a negative potential to the SiNWs cathode are shown in Figure 5.2. Electrical measurements were repeated at least 3 times in 3 different microreactors for each solvent type and all show identical behavior.

\subsubsection{Chemical reactions}

For each of the chosen solvents, a solution containing $5 \mathrm{mM}$ of anthracene (Sigma-Aldrich) was continuously pumped at a flow rate of $10 \mu \mathrm{l} / \mathrm{min}$ into the microdevice, under the application of an electric field between the electrodes. In order to prevent the breakdown of the insulating layer during the reaction the maximum applied voltage was set at $50 \mathrm{~V}$ and the maximum current at $1 \mathrm{~mA}^{[18]}$. Solvents and reaction conditions are listed in Table 5.1. A total of $3 \mathrm{ml}$ of reactant was collected in a vial and analyzed via GC-MS (Agilent Technologies, GC 7890A MS 5975C). Reactions were carried out at the same conditions at least 3 times. 
Table 5.1: GC-MS analysis of solutions containing $5 \mathrm{mM}$ of anthracene after reaction at ambient temperature in continuous flow $(10 \mu \mathrm{l} / \mathrm{min})$ by applying a potential of $25 \mathrm{~V}$ for polar solvents and $50 \mathrm{~V}$ for apolar solvents (amount of product $<1 \%$ indicated as Traces).

\begin{tabular}{|c|c|c|c|c|}
\hline Solvent type & $\begin{array}{c}9,10- \\
\text { dihydroanthracene } \\
\%\end{array}$ & $\begin{array}{c}\text { anthraquinone } \\
\%\end{array}$ & $\begin{array}{l}\text { 10-propyl-9- } \\
\text { anthranol \% }\end{array}$ & $\begin{array}{l}\text { 9-ethyl-2-methyl-9,10- } \\
\text { dihydroanthracene } \\
\text { and } \\
\text { 9-ethyl-3-methyl-9,10- } \\
\text { dihydroanthracene \% }\end{array}$ \\
\hline \multicolumn{5}{|c|}{ Apolar (with or without proton donator) } \\
\hline n-hexane & None & None & None & None \\
\hline $\begin{array}{l}\text { n-hexane }+ \\
5 \% \text { vol ethanol }\end{array}$ & None & None & None & None \\
\hline $\begin{array}{l}\text { n-hexane }+ \\
10 \%_{\mathrm{vol}} \text { ethanol }\end{array}$ & None & 1.2 & None & 1.2 \\
\hline $\begin{array}{l}\text { n-hexane }+ \\
25 \%_{\text {vol }} \text { ethanol }\end{array}$ & None & 4.3 & None & 1.5 \\
\hline \multicolumn{5}{|c|}{ Aprotic polar (with or without proton donator) } \\
\hline DMF & None & None & None & None \\
\hline $\begin{array}{l}\text { DMF + } \\
25 \% \mathrm{vol} \\
\text { ethanol }\end{array}$ & 1.2 & Traces & None & None \\
\hline \multicolumn{5}{|l|}{ Protic polar } \\
\hline 1-propanol & 1.3 & 2.8 & 3.5 & None \\
\hline ethanol & 1.4 & Traces & None & 2.1 \\
\hline
\end{tabular}




\subsection{Results and Discussion}

\subsubsection{Apolar solvents}

The current-voltage curves shown in Figure 5.2a at first increase linearly as a function of the applied voltage, and change to exponential behavior when the voltage reaches approx. $40 \mathrm{~V}$.
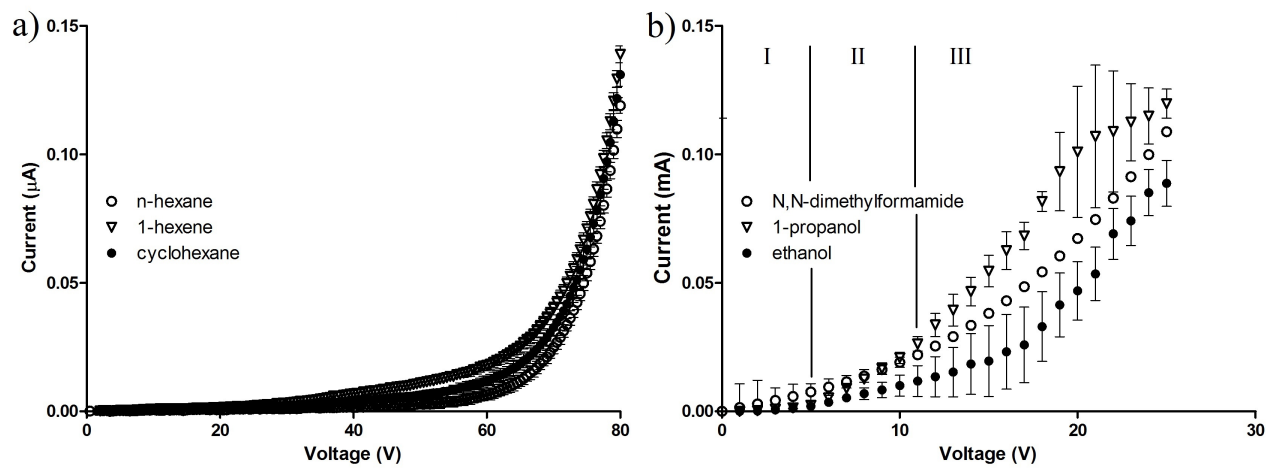

Figure 5.2: (a) current-voltage curves as measured in microreactors with silicon nanowires as cathodes, for apolar solvents 1-hexene, cyclohexane and n-hexane; (b) current-voltage curves for polar solvents N,Ndimethylformamide (DMF), 1-propanol and ethanol.

The curve shapes are characteristic for field emission in apolar liquids. Halpern et al. and Forbes et al. have demonstrated that the relation between field emission current and electric field strength, originally derived by Fowler and Nordheim for an emitter surface in vacuum, can be made valid for field emission in dielectric liquids by the addition of a correction factor ${ }^{[1,19]}$ :

$I=A a \emptyset^{-1} F^{2} \exp \left\{-b \emptyset^{1.5} / F\right\} \equiv R^{e l} F^{2} \exp \left\{S^{e l} / F\right\}$

where $A$ is the area of emission, $\mathrm{F}$ is the local electric field strength, $\emptyset$ is the local work function, and $a$ and $b$ are constants ( $a \equiv e^{3} / 8 \pi h_{p}=1.541434 \times 10^{-6} \mathrm{AeV} \mathrm{V}^{-2}$, $b \equiv \frac{4}{3}\left(2 m_{e}\right)^{\frac{1}{2}} / e \hbar_{p}=6.830888 \times 10^{9} e V m^{-1}$ where $m_{e}$ is the electron mass, $e$ is the elementary positive charge, and $\hbar_{p}$ is the Plank's constant divided by $\left.2 \pi\left(\hbar_{p}=h_{p} / 2 \pi\right)\right)$.

By introducing the parameters $R^{e l}$ and $S^{e l}$ which are defined as $R^{e l} \equiv A a \emptyset^{-1}$ and $S^{e l} \equiv-b \emptyset^{1.5}$ equation (1) can be rewritten as:

$\ln \left\{1 / F^{2}\right\}=\ln \left\{R^{e l}\right\}+S^{e l} / F$

$R^{e l}$ and $S^{e l}$ are constants for a surface with a given work function and size. It should be noted that $R^{e l}$ is related to the area of emission and $S^{e l}$ to the barrier strength. The local electrical field $F$ at the tips of SiNWs is often higher than the macroscopic applied electric field $\left(F_{m}\right)$, the ratio of these two fields is defined as the field-enhancement factor $\gamma\left(\gamma=F / F_{m}\right)$. Replacing $F$ with $F_{m}$ in equation (2) leads to the following expression:

$\ln \left\{1 / F_{m}{ }^{2}\right\}=\ln \left\{R^{e l} \gamma^{2}\right\}+\left\{S^{e l} / \gamma\right\} / F_{m}$ 
In case of field emission in dielectric liquids or gases the Fowler-Nordheim equation was demonstrated to be valid if the local work function is replaced by $\emptyset^{*}$

$\emptyset^{*}=\varnothing-\Delta \emptyset$

where $\Delta \emptyset=1 / \varepsilon_{r}$ and $\varepsilon_{r}$ is the dielectric constant of the liquid ${ }^{[19]}$. For our SiNWs we will use the work function of crystalline silicon $(4.85 \mathrm{eV})$.

The observed current-voltage curves are re-plotted as Fowler-Nordheim plots in Figure 5.3 and exhibit a linear relation at high electric fields. The slope $\left(S^{e l} / \gamma\right)$ of the linear part of the different curves is found to be slightly dependent on the solvent type, where 1-hexene, n-hexane and cyclohexane show fairly similar slopes. The small differences are caused by the difference in dielectric constants of the solvents (see Table 5.2).

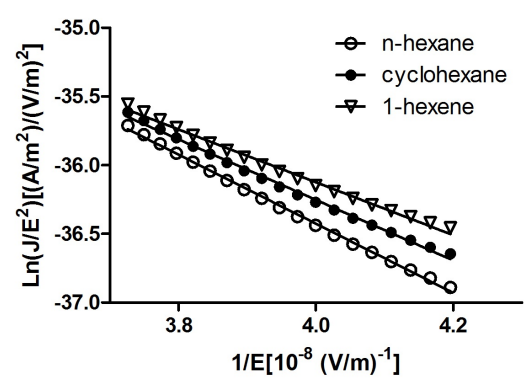

Figure 5.3: Fowler-Nordheim plot of investigated apolar solvents $\left(\mathrm{R}^{2} \geq 0.99\right.$, plot range 71-80V).

Considering a length of the SiNWs of approx. $5 \mu \mathrm{m}$ and a diameter of approx. $190 \mathrm{~nm} \pm 60 \mathrm{~nm}$ and by applying the "hemi-ellipsoid on plane" model for ideal vacuum conditions, the field-enhancement factor $\gamma$ for the fabricated microdevices can be calculated ${ }^{[20]}$. For high aspect ratio nanostructures, where $L$ is the length and $\rho$ is the radius of the wire at its base, the equations $v=L / \rho$ and $\xi=$ $\left(v^{2}-1\right)^{0.5}$ are valid for $v>1$, and the field enhancement factor $\gamma$ at the apex of a single SiNWs is:

$\gamma=\xi^{3} /[\{v \ln (v+\xi)\}-\xi]$ 
Table 5.2: Enhancement factors, as experimentally determined and theoretically calculated, for field emission from SiNWs in apolar solvents.

\begin{tabular}{lccc}
\hline Solvent type & $\begin{array}{c}\text { dielectric constant } \\
\left(\boldsymbol{\varepsilon}_{\mathbf{r}}\right)\end{array}$ & $\begin{array}{c}\text { experimental } \\
\text { enhancement factor }\end{array}$ & $\begin{array}{c}\text { theoretical } \\
\text { enhancement factor in } \\
\text { vacuum }\end{array}$ \\
\hline 1-hexene & 2.07 & 324 & \\
cyclohexane & 2.02 & 281 & $757 \pm 315$ \\
n-hexane & 1.88 & 243 & \\
\end{tabular}

In Table 5.2 the calculated value for $\gamma$ is compared with the experimental values, obtained from the slope of fitting curves. The calculated enhancement factor is approx. 2-3 times higher than the experimental values obtained for hexane, 1-hexene and cyclohexane. The mismatch between theoretical and experimental values may be due to the tip shape approximation used in the model with respect to the real structure of the SiNW or the presence of (polar) impurities in the solvents used in the experiments.

\subsubsection{Polar solvents}

Current-voltage curves for polar solvents show a different behavior than apolar solvents (Figure 5.2b). Three different regions characterize the current-voltage plots. The first two regions (I and II) of the curves are normally attributed to an electrochemical process in which the ions are in equilibrium between the dissociation and recombination states ${ }^{[21]}$. The origin of the third region (III) of the curve is not well understood. Some research groups attribute it to electron emission, while others propose charge-carrier injection from the electrode into the liquid, although field emission cannot be distinguished in the case of sufficiently high electric fields ${ }^{[22,23]}$. Considering the electrode configuration and the results of the chemical reactions carried out in our microreactors, we belive that in polar solvents field emission takes place, for the reasons given in the next section.

\subsubsection{Aromatic reduction}

GC analyses of the solutions obtained after the reaction in the microdevices (see Table 5.1) clearly indicate that pure apolar liquids are inactive during the partial reduction of anthracene. The two main reasons for this are: (i) the low currents $(\leq 0.1 \mu \mathrm{A})$ that pass through the liquids are insufficient to reduce a significant number of molecules such that detection by GC-MS analysis is not possible; (ii) after the first addition of an electron to the aromatic ring the resulting radical species loses an electron due to the absence of a proton donator which is necessary to continue the reduction and to maintain an equilibrium between the anthracene and its radical anion. Addition of ethanol to n-hexane confirms 
that the absence of a proton donator is the main reason for the absence of reduction of aromatic hydrocarbons during the reaction in pure n-hexane, although the reduction of anthracene to 9,10 dihydroanthracene is impeded by secondary reactions that are observed for polar solvents as well.

Also in the case of N,N-dimethylformamide the addition of a proton donator is necessary to partially reduce anthracene. 9,10-dihydroanthracente and traces of anthraquinone are the obtained products if $25 \%$ vol of ethanol is added to the solution. The same products are also obtained by using ethanol and 1-propanol as solvents, with the addition of 9-ethyl-2-methyl-9,10-dihydroanthracene, 9-ethyl-3methyl-9,10-dihydroanthracene and 10-propyl-9-anthranol in the case of ethanol and 1-propanol, respectively.

From these results, we hypothesize that the reduction of anthracene is impeded by 3 competitive reactions: (i) oxidation of the formed dihydroanthracene to anthracene, which returns the reaction to its starting condition; (ii) oxidation of 9,10-dihydroanthracene to anthraquinone, this reaction occurs at the anode; and (iii) addition of cations during the reduction of anthracene. Re-oxidation of the desired product at the anode negatively affects the selectivity of the reaction in 1-propanol, N,Ndimethylformamide and ethanol. A similar effect is reported by Fontana et. al. using an undivided electrochemical cell and tetrabutylammonium hydroxide (TBAOH) as electrolyte ${ }^{[24]}$. In the case of ethanol, 1-propanol and n-hexane/ethanol mixtures, another side reaction occurs: a cation can be added to the anthracene radical anion, instead of a proton, forming 9-ethyl-9,10-dihydroanthracene or 10-propyl-9-anthranol depending on the alcohol type (Figure 5.4).

The formation of 9-ethyl-9,10-dihydroanthracene is followed by the addition of a methyl group to one of the aromatic rings and the removal of a proton by a hydroxide anion forming in this way 9-ethyl-2methyl-9,10-dihydroanthracene or 9-ethyl-3-methyl-9,10-dihydroanthracene. We hypothesize that for the applied electrical fields during the reaction, electron emission at the cathode is not the only phenomenon that takes place, but that also charge carrier injection occurs in proximity of the electrodes thereby forming cations and anions. The relatively low reaction yield obtained by using field emission instead of an electrochemical method are due to 3 reasons ${ }^{[13,25,26]}$ : (i) the presence of contaminants in the solvent reduces the lifetime of the excess of electrons in the solution, thereby decreasing the amount of aromatic radical anions formed during the reaction; (ii) the reaction is performed in continuous flow, with a quite low residence time of ca. $0.25 \mathrm{sec}$; (iii) during the reaction hydrogen evolution can occur at the electrodes decreasing the proton donator source. Indeed, in some cases bubbles were observed at the outlet of the microreactor, but it was not possible to distinguish the origin (dissolved ambient gas, $\mathrm{H}_{2}, \mathrm{O}_{2}$ or solvent evaporation). 


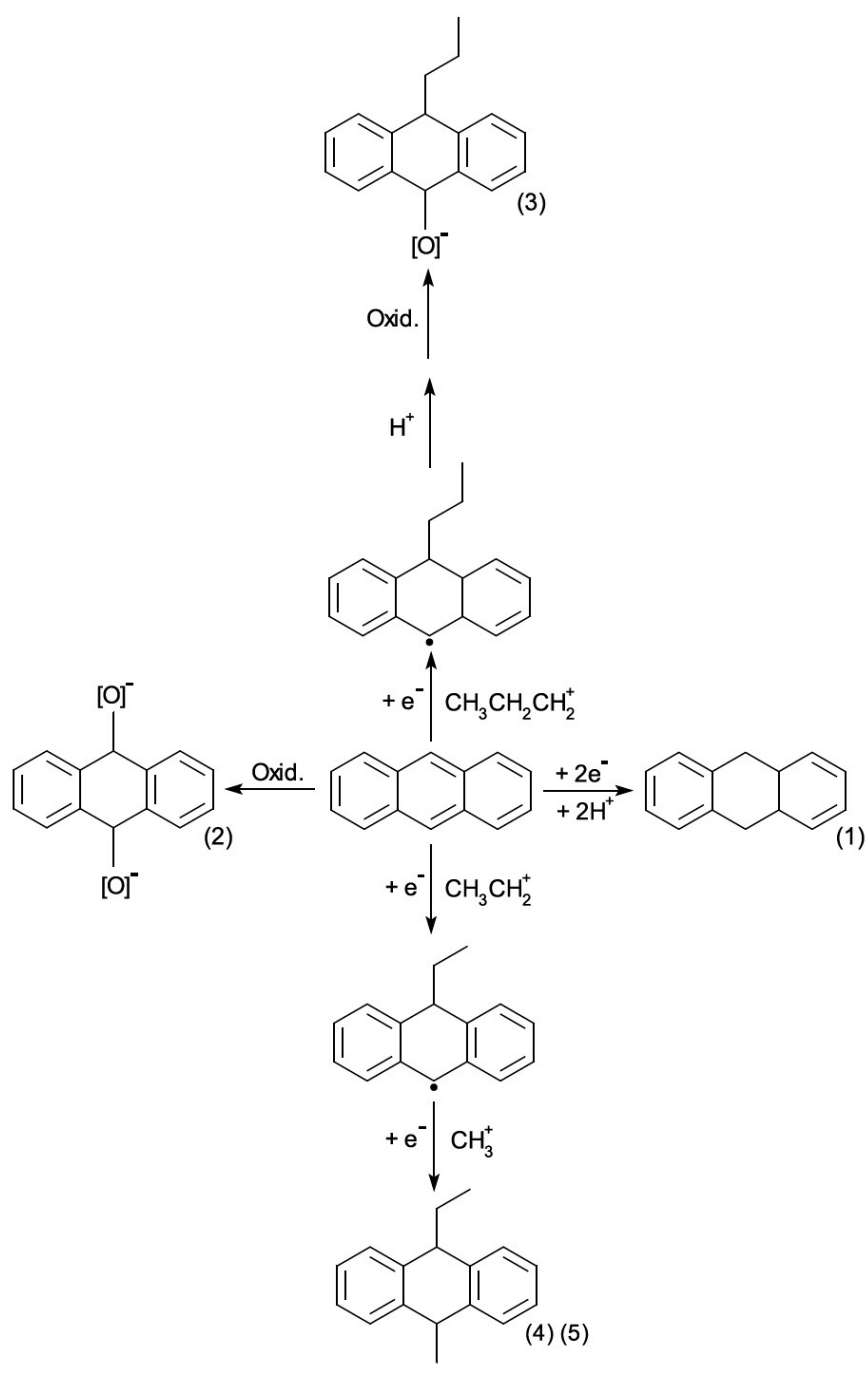

Figure 5.4: Proposed reaction scheme for anthracene reduction in microreactors using field electron emission: (1) 9,10-dihydroanthracene, (2) anthraquinone, (3) 10-propyl-9-anthranol, (4) 9-ethyl-2-methyl-9,10dihydroanthracene and (5) 9-ethyl-3-methyl-9,10-dihydroanthracene. 


\subsection{Conclusions}

Proof-of-principle is shown of a microreactor for flow chemistry based on electron emission into liquids. Electron emission is possible at low potentials due to the electric field enhancement at the tips of integrated SiNWs emitters. If the electric field is sufficiently high, both in polar and in apolar solvents electron emission becomes predominant with respect to electrochemical conduction. Field emission into pure aprotic liquids seems to be irrelevant for the reduction of aromatic hydrocarbons, due to the absence of a proton donator. Field emission in liquids containing a proton donator was experimentally proven to partially reduce aromatic hydrocarbons, in our configuration with relatively low reaction yield. We consider field electron emission a promising innovative method to perform chemistry based on radical formation, such as Birch-type reductions, in a greener and more sustainable manner than currently existing procedures. 


\subsection{References}

[1] B. Halpern and R. Gomer, "Field emission in liquids", J. Chem. Phys., 51, 1031-1047, 1969.

[2] K. Dotoku, H. Yamada, S. Sakamoto, S. Noda and H. Yoshida, "Field emission into nonpolar organic liquids”, J. Chem. Phys., 69, 1121-1125, 1978.

[3] S. Fan, M. G. Chapline, N. R. Franklin, T. W. Tombler, A. M. Cassell and H. Dai, "SelfOriented Regular Arrays of Carbon Nanotubes and Their Field Emission Properties", Science, 283, 512-514, 1999.

[4] P. G. Collins and A. Zettl, "A simple and robust electron beam source from carbon nanotubes”, Appl. Phys. Lett., 69, 1969-1971, 1996.

[5] F. C. K. Au, K. W. Wong, Y. H. Tang, Y. F. Zhang, I. Bello, and S. T. Lee, "Electron field emission from silicon nanowires", Appl. Phys. Lett., 75, 1700-1702, 1999.

[6] A.G. Krivenko, N.S. Komarova and N. P. Piven, "Electrochemical generation of solvated electrons from nanostructurated carbon”, Electrochem. Commun., 9, 2364-2369, 2007.

[7] A. Agiral, H. B. Eral, D. van den Ende and J. G. E. Gardeniers, "Charge injection from carbon nanofibers into hexane under ambient conditions", IEEE Trans. Electron Devices, $58,3514-3518,2011$.

[8] D. Chandler and K. Leung "Excess electrons in liquids: Geometrical prospectives", Annu. Rev. Phys. Chem., 45, 557-591, 1994.

[9] C. A. Kraus, "Solutions of metals in non-metallic solvents; iv. 1. Material effects accompanying the passage of an electrical current through solutions of metals in liquid ammonia. Migration experiments”, J. Am. Chem. Soc., 30, 1323-1344, 1908.

[10] M. J. Bronskill, R. K. Wolff and J. DW. Hunt, "Picosecond pulse radiolysis studies. The solvated electron in aqueous and alcohol solutions”, J. Appl. Phys., 53, 4201-4210, 1970.

[11] J. R. Brandon and R. F. Firestone, "Solvated electrons in alcohol-alkane and alcohol-amine solutions", J. Phys. Chem., 78, 792-796, 1974.

[12] J. H. Baxendale, "A pulse radiolysis study of solvated electrons in diluted solutions of polar liquids in nonpolar solvents", Can. J. Chem., 55, 1991-2002, 1977. 
[13] J. A. Birch, "Reduction by dissolving metals Part I", J. Chem. Soc., 430-436, 1944.

[14] T. Asahara, M. Seno and H. Kaneko, "Electrolytic reduction of naphthalene in various alcohol-hexamethylphosphoramide systems”, Bul. Chem. Soc. Jpn., 41, 2985-2989, 1968.

[15] E. Kariv-Miller, K. E. Swenson, G. K. Lehman and R. Andruzzi, "Selective cathodic Birch reductions", J. Org. Chem., 50, 556-560, 1985.

[16] K. Peng, Y. Yan, S. Gao and J. Zhu, "Dendrite-assisted growth of silicon nanowires in electroless metal deposition”, Adv. Funct. Mater., 13, 127-132, 2003.

[17] Z. Huang, N. Geyer, P. Werner, J. de Boor and U. Gösele, "Metal-assisted chemical etching of silicon: a review”, Adv. Mater., 23, 141-308, 2011.

[18] R. M. Tiggelaar, A. W. Groenland, R. G. P. Sanders and J. G. E. Gardeniers, "Electrical properties of low pressure chemical vapor deposited silicon nitride thin films for temperatures up to $650{ }^{\circ} \mathrm{C}$ ", J. Appl. Phys., 105, 033714, 2009.

[19] R. G. Forbes and J. H. B. Deane, "Reformulation of the standard theory of FowlerNordheim: tunnelling and cold field emission”, Proc. R. Soc. A, 463, 2907-2927, 2007.

20] R. G. Forbes, C. J. Edgcombe and U. Valdrè, "Some comments on models for field enhancement", Ultramicroscopy, 95, 57-65, 2003.

[21] M. Zhan, S. Voldman and T. Takada, "Charge injection and transport in high voltage water/glycol capacitors”, J. Appl. Phys., 54 (1), 315-325, 1983.

[22] N. Felci, "High-field conduction in dielectric liquids revisited", Trans. Electr. Insul., 20 (2), 233-238, 1985.

[23] S. Theoleyre and R. Tobazeon, "Ion injection by metallic electrodes in highly polar liquids of controlled conductivity”, Trans. Electr. Insul., 20 (2), 213-220, 1985.

[24] E. Gagyi Palffy, P. Starzewski, A. Labani and A. Fontana, "Electrochemical reduction of polyaromatic compounds”, J. Appl. Electrochem., 24, 337-343, 1994.

[25] H. W. Sternberg, R. Markby and I. Wender, "Electrochemical reduction of benzene ring", J. Electrochem. Soc.,110, 425, 1963.

[26] E. Karvin-Miller, K.E. Swenson and D. Zemach, "Cathodic Birch reduction of methoxyaromatics and steroids in aqueous solution”, J. Org. Chem., 48, 4210-4214, 1983. 


\section{SUPPORTING INFORMATION}

\section{Introduction}

The development of nanostructures has become an active research topic in the last years and in particular the synthesis of silicon nanowires (SiNWs) attracted the attention of various research groups ${ }^{[1,2]}$. One of the recent methods to create dense arrays of SiNWs is based on metal assisted chemical etching (MACE). The MACE technique is a top-bottom approach based on redox reactions occurring between a silicon ( $\mathrm{Si}$ ) substrate and a noble metal (such as silver and gold) deposited on it. Nowadays, the MACE technique permits to create SiNWs avoiding the use of high temperatures and hazardous silicon precursors (commonly required for the vapor-liquid-solid (VLS) technique) ${ }^{[3,4,5]}$. In this work an overview is given of important parameters affecting the fabrication of SiNWs based on this MACE technique as well as possible formation mechanisms, with the aim to provide background information.

\section{Synthesis of SiNWs}

In a typical 2-step MACE process for creation of SiNWs, a Si substrate is firstly covered with silver (Ag) particles and subsequently immersed in an etching solution containing hydrofluoric acid (HF) and an oxidizing agent such as hydrogen peroxide $\left(\mathrm{H}_{2} \mathrm{O}_{2}\right)$. It is also possible to fabricate SiNWs via a single step MACE process, by immersing the Si substrate in a solution containing an Ag salt (such as silver nitrate, $\mathrm{AgNO}_{3}$ ) and $\mathrm{HF}$ : in this case silver particles are deposited on the substrate and immediately etch into the Si. Both methods have been explored with the aim to create dense arrays of vertically aligned SiNWs. The SiNWs formed with these two methods are analyzed by using scanning electron microscopy (SEM, Zeiss Merlin).

\section{Single step MACE process}

In the single step process, the $\mathrm{Si}$ substrate is immersed for $25 \mathrm{~min}$. in a $25 \mathrm{mM}$ solution of $\mathrm{AgNO}_{3}$ (Sigma-Aldrich, 99\%) containing $20 \% \%_{\mathrm{vol}}$ of $50 \%$ HF (BASF, 51151083) followed by rinsing in demineralized water and spin drying (SiNWs formation rate ca. $200 \mathrm{~nm} / \mathrm{min}$ ).

\section{Two step MACE process}

In the two step process, the $\mathrm{Si}$ substrate is immersed for $1 \mathrm{~min}$. in a $5 \mathrm{mM}$ solution of $\mathrm{AgNO}_{3}$ containing $20 \%$ vol of $50 \% \mathrm{HF}$ (in order to deposit Ag particles on the Si substrate) and afterwards directly placed in a solution containing $20 \% \%_{\mathrm{vol}}$ of $50 \% \mathrm{HF}$ and $2.5 \% \%_{\mathrm{vol}}$ of $\mathrm{H}_{2} \mathrm{O}_{2}$ (BASF, 55316830). Post to this 10 min. etching step the substrate is rinsed with demineralized water and dried with a nitrogen $\left(\mathrm{N}_{2}\right)$ flow (SiNWs formation rate approx. $500 \mathrm{~nm} / \mathrm{min}$ ). 


\section{Results and Discussion}

Single step vs. two step MACE process

The SiNWs formed with the single step process contain a dense layer of Ag rods, elongated particles with lengths of 1-2 $\mu \mathrm{m}$ and a diameter of a few hundred nanometers, on the silicon substrate after water rinsing. The metallic particles are due to the continuous formation of $\mathrm{Ag}$ dendrites during the SiNW formation process and lead to the generation of indents in the upper surface of the SiNW array, due to bending of some SiNWs (Figure SI-1a).

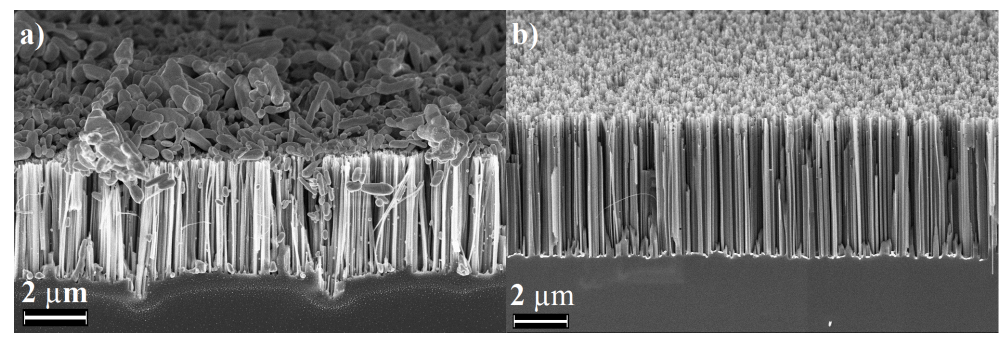

Figure SI-1: SEM images of SiNWs formed by using a) single step or b) two step MACE process.

In the two step process Ag dendrite formation does not occur during the SiNW formation, due to the absence of Ag cations in the etching solution. For this reason the SiNWs formed in the two-step MACE process are straighter and more vertically aligned compared to the SiNWs resulting from the single step method.

\section{Fabrication mechanisms for SiNWs: Single step MACE process}

Various possible mechanisms for the formation of SiNWs have been proposed. In 2003, for the single step process Peng et al. proposed a mechanism based on the formation of local electrochemical cells composed by an anode (Si substrate) and a cathode (Ag particle $)^{[6]}$. The reactions of the two half cells are:

- At the cathode: $\mathrm{Ag}^{+}+\mathrm{e}^{-} \rightarrow \mathrm{Ag}\left(\mathrm{E}_{(\mathrm{Ag}+/ \mathrm{Ag})}^{0}=0.779 \mathrm{~V}\right)$

- At the anode: $\mathrm{Si}+6 \mathrm{~F}^{-} \rightarrow \mathrm{SiF}_{6}{ }^{2-}+4 \mathrm{e}^{-}\left(\mathrm{E}^{0}{ }_{(\mathrm{Si} 4+/ \mathrm{Si})}=-1.24 \mathrm{~V}\right)$

The overall reaction obtained by combining the two half reactions is:

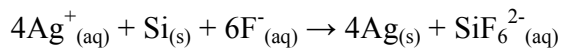

The proposed reactions explain the simultaneous formation of $\mathrm{Ag}$ dendrites and the Si etching during the single step fabrication process. Our experiments for different reaction times (the concentration of $\mathrm{AgNO}_{3}$ in the solution was decreased in order to slow down the SiNWs formation and permit the analysis of the samples) show that an increase of the $\mathrm{Ag}$ dendrites is correlated to an increase in length of the formed SiNWs (Figure SI-2), which confirms the validity of the proposed mechanism. 


\section{Chapter 5}

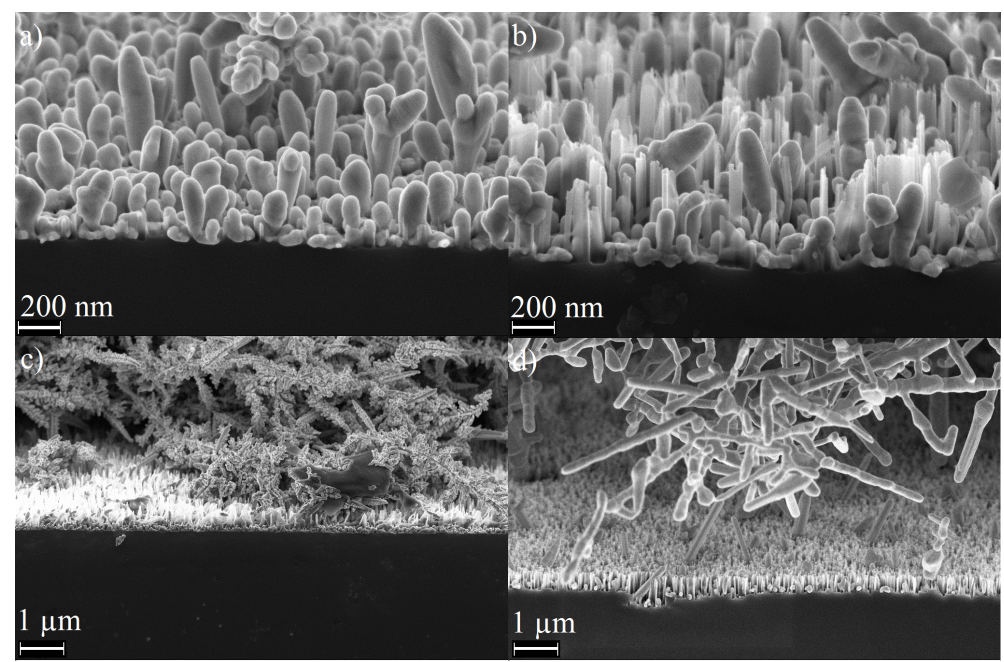

Figure SI-2: SEM images of SiNWs formed by using the single step method after a) 5 min. b) 15 min. c) 25 min. and d) 30 min. of reaction in a $0.01 \mathrm{M}$ solution of $\mathrm{AgNO}_{3}$ in $20 \% \mathrm{vol}_{\mathrm{vol}} \mathrm{HF}$.

\section{Fabrication mechanisms for SiNWs: Two step MACE process}

The model given in the previous subscription is not valid for the formation of SiNWs by the two-step method. For this MACE process three different reaction models have been proposed, to describe the dissolution of $\mathrm{Si}$ under the $\mathrm{Ag}$ particles (anodic reaction):

i) direct dissolution of $\mathrm{Si}$ in tetravalent state $\mathrm{e}^{[7,8]}$

- $\mathrm{Si}+4 \mathrm{HF} \rightarrow \mathrm{SiF}_{4}+\mathrm{H}^{+}+4 \mathrm{e}^{-}$

ii) direct dissolution of $\mathrm{Si}$ in divalent state ${ }^{[9,10]}$

- $\mathrm{Si}+6 \mathrm{~F}^{-} \rightarrow \mathrm{SiF}_{6}{ }^{2-}+4 \mathrm{e}^{-}$

iii) silicon oxide formation followed by dissolution of silicon oxide ${ }^{[11,12]}$

- $\mathrm{Si}+\mathrm{H}_{2} \mathrm{O} \rightarrow \mathrm{SiO}_{2}+4 \mathrm{H}^{+}+4 \mathrm{e}^{-}$followed by: $\mathrm{SiO}_{2}+6 \mathrm{HF} \rightarrow \mathrm{H}_{2} \mathrm{SiF}_{6}+2 \mathrm{H}_{2} \mathrm{O}$

In case of the last model, the formation of an oxide layer under the Ag particle prior to dissolution of $\mathrm{Si}$ is still under debate in literature. In order to have some additional information on the validity of this hypothesis regarding the formation of an oxide layer under the Ag particle, experiments have been carried out in which deliberately an oxide layer is created after forming the SiNWs, followed by re-immersion of the substrate in the etching solution. The procedure was as follows: a Si substrate is immersed for $1 \mathrm{~min}$ in a $5 \mathrm{mM}$ solution of $\mathrm{AgNO}_{3}$ containing $20 \%$ vol of $50 \%$ HF immediately followed by etching for $10 \mathrm{~min}$ in a solution containing $20 \% \%_{\mathrm{vol}}$ of $50 \% \mathrm{HF}$ and $2.5 \%_{\mathrm{vol}}$ of $\mathrm{H}_{2} \mathrm{O}_{2}$, water rinsing and drying. Afterwards the substrate with the SiNWs is loaded in a furnace (Tempress, $\mathrm{O}_{2}$ flow $4 \mathrm{slm}, 1 \mathrm{~h}$ at $700{ }^{\circ} \mathrm{C}$ ) and oxidized in a dry $\mathrm{O}_{2}$ flow during which an oxide layer of approx. $10 \mathrm{~nm}$ is grown. The substrate is re-immersed in the etching solution for $10 \mathrm{~min}$. to continue SiNW etching. 
Figure SI-3 shows the obtained results before (a) and after (b) the second etching cycle. The SiNWs formed during the first etching cycle, i.e. before oxidation in the furnace, are etched away due to the complete oxidation of the SiNWs, and only a few Ag particles are able to continue the Si etching during the second etch cycle. We believe that the formation of a thin $\mathrm{SiO}_{2}$ film under the $\mathrm{Ag}$ particles yields an electrical insulating layer which terminates the reaction because the involved charge carriers cannot be transported from the silicon to the Ag and vice versa. Unfortunately we were not able to monitor $\mathrm{SiO}_{2}$ formation in-situ during the reaction.

If reduction of $\mathrm{Si}$ occurs, an oxidation should occur in the proximity of the cathode (Ag particle), otherwise the dissolution of Si will not proceed. For example, in an etching solution containing only $\mathrm{HF}$ (thus without oxidizing agent) no SiNWs are formed. In the case of addition of $\mathrm{H}_{2} \mathrm{O}_{2}$ to hydrofluoric acid, the following reaction pathway is commonly accepted ${ }^{[13]}$ :

- $\mathrm{H}_{2} \mathrm{O}_{2}+2 \mathrm{H}^{+}+2 \mathrm{e}^{-} \rightarrow 2 \mathrm{H}_{2} \mathrm{O}$

If $\mathrm{H}_{2} \mathrm{O}_{2}$ is replaced with nitric acid $\left(\mathrm{HNO}_{3}\right)$ at the same concentration, the formation of SiNWs also takes place, in this case we assume that one of the following reactions occurs at the silver surface:

- $\quad \mathrm{NO}_{3}{ }^{-}+2 \mathrm{H}^{+}+\mathrm{e}^{-} \rightarrow \mathrm{NO}_{2}+\mathrm{H}_{2} \mathrm{O}\left(\mathrm{E}^{0}=0.79 \mathrm{~V}\right)$ or $\mathrm{NO}_{3}{ }^{-}+4 \mathrm{H}^{+}+3 \mathrm{e}^{-} \rightarrow \mathrm{NO}+2 \mathrm{H}_{2} \mathrm{O}\left(\mathrm{E}^{0}=0.96 \mathrm{~V}\right)$

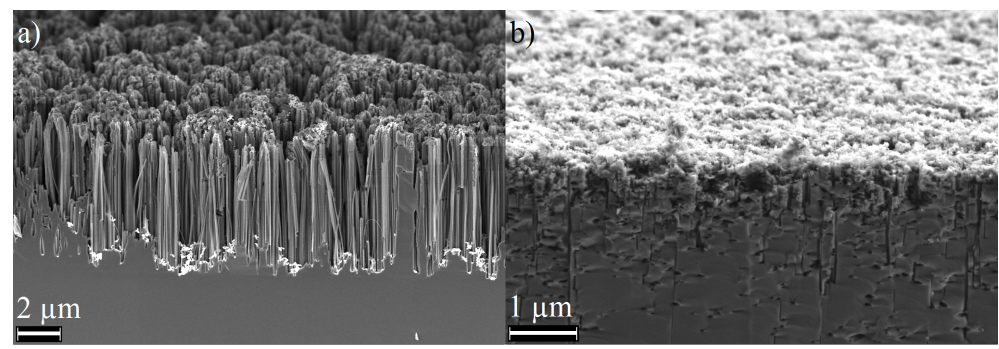

Figure SI-3: SEM images of Si substrate with SiNWs a) after etching for $10 \mathrm{~min}$. in a solution containing $20 \%$ vol of $\mathrm{HF}$ and $2.5 \%$ vol of $\mathrm{H}_{2} \mathrm{O}_{2}$ (prior to dry oxidation) and b) after dry $\mathrm{SiO}_{2}$ formation and a second etching cycle of 10 $\min$.

SiNW formation using $\mathrm{HNO}_{3}$ and $\mathrm{H}_{2} \mathrm{O}_{2}$ as oxidizing agents has been carried out (Figure SI-4). In the case of the use of $\mathrm{H}_{2} \mathrm{O}_{2}$ the formed $\mathrm{SiNWs}$ are longer, thinner and with smaller spacing, compared to the use of $\mathrm{HF} / \mathrm{HNO}_{3}$ as etchant. 


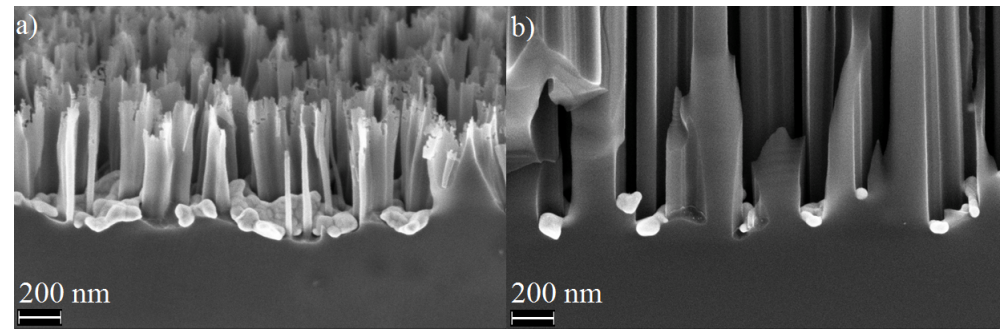

Figure SI-4: SEM images of SiNWs formed by using a etching solution a) $25 \mathrm{mM}$ of $\mathrm{HNO}_{3}$ and $20 \% \mathrm{vol}_{\text {vol }} 50 \% \mathrm{HF}$ b) $25 \mathrm{mM}$ of $\mathrm{H}_{2} \mathrm{O}_{2}$ and $20 \%$ vol $50 \% \mathrm{HF}$.

This is due to the presence of more Ag particles during the etching phase when nitric acid is used as oxidizing agent. The Ag particles in a solution containing $\mathrm{H}_{2} \mathrm{O}_{2}$ are reoxidized, thereby yielding smaller particles and decreased interspaces between the SiNWs with respect to formation performed with $\mathrm{HNO}_{3}$. The following reaction can describe the observed phenomenon at the cathode ${ }^{[14]}$ :

$\mathrm{H}_{2} \mathrm{O}_{2}+\mathrm{Ag}+\mathrm{H}^{+} \rightarrow 2 \mathrm{Ag}^{+}+2 \mathrm{H}_{2} \mathrm{O}$

\section{Conclusions}

In conclusion, by means of a MACE technique vertical aligned SiNWs arrays can be realized. The fabricated SiNWs are more straight and better vertically aligned if a 2-step process is used instead of a single step process. If $\mathrm{H}_{2} \mathrm{O}_{2}$ is added as oxidizing agent to the HF-based etching solution a more dense array of SiNWs is obtained compared to use of $\mathrm{HNO}_{3}$. During this brief study a conclusive reaction mechanism could not be determined, although based on experimental data it is hypothesized that the formation of a silicon oxide layer under the Ag particle during the etching phase is unlikely. 


\section{References}

[1] C. M. Lieber, "One dimensional nanostructures: Chemistry, physics \& applications", Solid State Commun., 107, 607-616, 1998.

[2] Y. Cui and C. M. Lieber, "Functional nanoscale electronic devices assembled using silicon nanowires building blocks", Science, 291, 851-853, 2001.

[3] D. Dimova-Malinovska, M. Sendova-Vassileva, N. Tzenov and M. Kamenova, "Preparation of thin porous silicon layers by stain etching”, Thin Solid Films, 297, 9-12, 1997.

[4] X. Li and P. W. Bohn, "Metal-assisted chemical etching in $\mathrm{HF} / \mathrm{H} 2 \mathrm{O} 2$ produces porous silicon", Appl. Phys. Lett., 77, 2571-2574, 2000.

[5] S. Schmidt, S. Senz and U. Gösele, "Diameter-dependent growth direction of epitaxial silicon nanowires", Nano Lett., 5, 931-935, 2005.

[6] K. Q. Peng, Y. J. Yan, S. P. Gao and J. Zhu, "Dendrite-assisted growth of silicon nanowires in electroless metal deposition", Adv. Funct. Mater., 2, 127-131, 2003.

[7] S. Chattopadhyay, X. L. Li and P. W. Bohn, "In-plane control of morphology and tunable photoluminescence in porous silicon produced by metal-assisted electroless chemical etching", J. App. Phys., 91, 6134-6140, 2002.

[8] C. Y. Chen, C. S. Wu, C. J. Chou and T. J. Yen, "Morphological control of singlecrystalline silicon nanowire arrays near room temperature", Adv. Mater., 20, 3811-3815, 2008 .

[9] K. Q. Peng, H. Fang, J. J. Hu, Y. Wu, J. Zhu, Y. J. Yan and S. Lee, "Metal-particle-induced, highly localized site-specific etching of $\mathrm{Si}$ and formation of single-crystalline Si nanowires in aqueous fluoride solution”, Chem.-Eur. J., 12, 7942-7947, 2006.

[10] C. Chartier, S. Bastide and C. Levy-Clement, "Metal-assisted chemical etching of silicon in HF-H2O2", Electrochimica Acta, 53, 5509-5516, 2008.

[11] K. Peng, A. Lu, R. Zhang and S. T. Lee, "Mobility of metal nanoparticles in silicon and induced anisotropic silicon etching”, Adv. Funct. Mater., 18, 3026-3035, 2008.

[12] X. H. Xia, C. M. A. Ashruf, P. J. French and J. J. Kelly, "Galvanic cell formation in silicon/metal contacts: the effect on silicon surface morphology", Chem. Mater., 12, 16711678, 2000. 
[13] Y. Harada, X. L. Li, P. W. Bohn and R. G. Nuzzo, "Catalytic amplification of the soft lithographic patterning of $\mathrm{Si}$. Nanoelectrochemical orthogonal fabrication of photoluminescent porousSi pixel arrays”, J. Am. Chem. Soc., 123, 8709-8717, 2001.

[14] C. Chiappini, X. Liu, J. R. Fakloury and M. Ferrari, "Biodegradable porous silicon barcodes nanowires with defined geometry”, Adv. Funct. Mater., 20, 2231-2239, 2010. 


\section{Chapter}

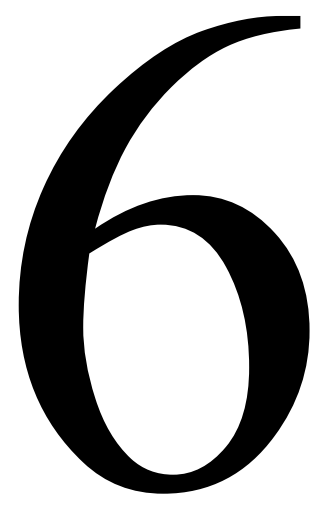

\section{Birch-type reduction of polycyclic}

aromatic hydrocarbons in alcohols using field electron emission in a microreactor

This chapter is in preparation for submission; M. Morassutto, H. Zhang, S.

Schlautmann, R.M. Tiggelaar and J.G.E. Gardeniers 


\title{
Chapter 6
}

\begin{abstract}
Hydrogenation of aromatic hydrocarbons by solvated electrons has become well-known through the groundbreaking work of Birch, who thoroughly investigated reduction reactions based on the dissolution of alkali metals in liquid ammonia. Birch reduction is one of the few available synthetic methods for the conversion of aromatic substrates into alicyclic compounds and has been applied in the synthesis of pharmaceuticals and complex natural products. Despite its great value, alternative processes that circumvent the undesirable environmental issues associated with the use of amine solvents, cryogenic conditions, and handling of alkali metals, are highly desired, to be able to extend the scope of such reduction methods and make them suitable for production on a larger scale. In this article we add several novel elements to Birch-type processes, to develop them into green processes for the reduction of polycyclic aromatic hydrocarbons. These elements are: the use of (i) integrated silicon nanowire-based field emitters to generate the required solvated electrons by cold field electron emission in (ii) simple organic liquids, such as alcohols, applied in (iii) continuous flow microreactors. The platform will be used for the reduction of anthracene, naphthalene and benzophenone in ethanol and 1-propanol. Besides with conventional GC-MS, the product mixtures will be analyzed with an optimized microfluidic stripline-based NMR system which allows highresolution spectroscopy on the very limited sample amounts that can be collected from the microreactors. Based on the obtained consistent analytical data, side products are identified and quantified, and feasible reaction pathways are proposed.
\end{abstract}

Keywords: field electron emission, alicyclic hydrocarbons, Birch-type reduction, polar solvents, microreactors, solvated electrons 


\subsection{Introduction}

Nowadays, new green processes are of economic interest for the chemical industry and therefore important research topics. The partial reduction of polycyclic aromatic hydrocarbons (PAH) can be achieved by Birch reduction, lithium aluminum hydride $\left(\mathrm{LiAlH}_{4}\right)$ or transition metal based catalysts $^{[1,2,3,4]}$. Due to the high costs of noble and alkali metals, since the beginning of the 60 's, new strategies to perform the partial reduction of PAH were proposed. Most of the alternatives are based on the electrochemical reduction of alkali salts in liquid ammonia or simple amines (such as ethylamine, diethylamine), others on the formation of amalgams by using a mercury cathode ${ }^{[5,6,7,8,9,10]}$. The generation of phenanthrene and naphthalene radical anions in non-polar solvents, such as n-hexane, tetramethylsilane and 2,2,4-trimethylpentane, was measured by pulse conductivity by Holroyd in 1977. This work initiated the possibility of performing PAH reduction in different liquid media by generating an excess of electrons with an external energy source, such as the $15 \mathrm{MeV}$ linear particle accelerator, which generates X-ray bursts, used by Holroyd ${ }^{[11]}$. Agiral et al. were the first to suggest the possibility to generate an excess of electrons in liquid n-hexane by using cold field emission $(\mathrm{CFE})^{[12]}$. CFE permits to inject high currents into liquids by applying an electrostatic field. The presence of sharp tips or needles on the electrode surface, due to their small radius of curvature and their high length-to-diameter aspect ratio, locally increases the applied electric field, thereby facilitating the possibility to discharge an electron from the surface. Using this method, we demonstrated in the previous chapter the possibility to inject electrons in polar and non-polar liquids and to partially reduce $\mathrm{PAH}$.

In this study we will analyze the performance of a continuous flow CFE microreactor for the partial reduction of PAH without the use of toxic or harmful solvents. Specifically, the hydrogenation of anthracene, naphthalene and benzophenone in ethanol and 1-propanol will be used as model reactions in a proof-of-principle of CFE activity.

\subsection{Experimental}

Details of the microreactor have been described elsewhere (see chapter 5). In brief, the device consists of two electrodes oriented in a vertical configuration and separated by an insulating layer of $250 \mathrm{~nm}$ of low stress silicon-rich silicon nitride (SiRN). Silicon nanowires (SiNWs), arranged in a dense array on the cathode surface, act as emitters for the injection of electrons into the solution. The SiNWs are formed by metal assisted chemical etching of highly doped silicon (details can be found in the appendix of chapter 5). The anode is a $100 \mathrm{~nm}$ platinum (Pt) layer deposited on a glass surface positioned opposite to the SiNWs. The microreactor (total volume $15 \mathrm{~nL}$ ) has a main channel with length, width and height of respectively $15 \mathrm{~mm}, 200 \mu \mathrm{m}$ and $5 \mu \mathrm{m}$. Based on the obtained results described in chapter 5 and in order to obtain a green process to partially reduce PAH, only solutions containing the aromatic hydrocarbon dissolved in an alcohol are continuously pumped in the 
microreactor by using a glass syringe (Hamilton Gastight $2.5 \mathrm{cc}$ ) and a volumetric pump (Harvard, model PHD2000). The electric field, necessary to generate solvated electrons, is created by applying a negative potential to the cathode with a source measurement unit (Keithley, model 2410) and the anode connected to ground. The chemical activity of CFE for the partial dehydrogenation of PAH is evaluated by analyzing the solutions collected from the outlet of the microreactor with a GC-MS (Agilent Technologies, GC7890A, MS5975C).

\subsection{Results and discussion}

\subsubsection{Reduction of anthracene}

In Table 6.1 an overview of product yields for the reduction of anthracene in a CFE microreactor using ethanol and 1-propanol for different voltages and residence times is shown.

Table 6.1: Product yields (in \%) for the reduction of anthracene using a microreactor with a nanostructured electrode and ethanol and 1-propanol as solvents.

\begin{tabular}{|c|c|c|c|c|c|c|c|}
\hline \multicolumn{8}{|c|}{ Reduction of anthracene in 1-propanol } \\
\hline Voltage & \multicolumn{2}{|c|}{$\begin{array}{c}\text { Flow Rate/Residence } \\
\text { Time }\end{array}$} & $\begin{array}{c}\text { Conversion } \\
(\%)\end{array}$ & \multicolumn{2}{|c|}{$\begin{array}{c}\text { 9,10-dihydroanthracene } \\
(\%)\end{array}$} & \multicolumn{2}{|c|}{$\begin{array}{c}\text { 10-propyl-9-anthranol } \\
(\%)\end{array}$} \\
\hline $10 \mathrm{~V}$ & $1 \mu \mathrm{l} / \mathrm{min} / 1 \mathrm{se}$ & & & & ne & & 64 \\
\hline $10 \mathrm{~V}$ & $10 \mu 1 / \mathrm{min} / 0.1$ & $\sec$ & & & ne & & 2 \\
\hline $25 \mathrm{~V}$ & $1 \mu \mathrm{l} / \mathrm{min} / 1 \mathrm{se}$ & & & & .2 & & 40.8 \\
\hline \multirow[t]{2}{*}{$25 \mathrm{~V}$} & $10 \mu \mathrm{l} / \mathrm{min} / 0.1$ & $\sec$ & 1 & & ne & & 11 \\
\hline & \multicolumn{7}{|c|}{ Reduction of anthracene in ethanol } \\
\hline Voltage & $\begin{array}{c}\text { Flow } \\
\text { Rate/Residence } \\
\text { Time }\end{array}$ & $\begin{array}{c}\text { Conversion } \\
(\%)\end{array}$ & dihyd & $\begin{array}{l}9,10- \\
\text { oanthracene } \\
(\%)\end{array}$ & $\begin{array}{r}\text { 9-ethyl-2-n } \\
9,10 \\
\text { dihydroant } \\
\text { and 9-eth } \\
\text { methyl- } \\
\text { dihydroant } \\
(\%)\end{array}$ & $\begin{array}{l}\text { ethyl- } \\
\text { racene } \\
\text { l-3- } \\
\text { 10- } \\
\text { racene }\end{array}$ & $\begin{array}{c}\text { Anthraquinone } \\
\text { (\%) }\end{array}$ \\
\hline $10 \mathrm{~V}$ & $1 \mu \mathrm{l} / \mathrm{min} / 1 \mathrm{sec}$ & $62 \%$ & & 2 & 38 & & 22 \\
\hline $10 \mathrm{~V}$ & $10 \mu 1 / \mathrm{min} / 0.1 \mathrm{se}$ & $\leq 1 \%$ & & None & Trace & & Traces \\
\hline
\end{tabular}


Formation of 9,10-dihydroanthracene is only obtained by flowing at $1 \mu \mathrm{L} / \mathrm{min}$ a $5 \mathrm{mM}$ solution of anthracene (Sigma-Aldrich, 97\%) in 1-propanol (Sigma-Aldrich, 99.7\%) through the microreactor upon applying a potential difference of $25 \mathrm{~V}(\mathrm{E}=50 \mathrm{kV} / \mathrm{cm})$ between the electrodes. At these reaction conditions 9,10-dihydroanthracene is not the only formed product, also a secondary product with a nominal mass of 236 uma is detected with GC-MS analysis. The mass spectrum (see MS-data) suggests the formation of 10-propyl-9-anthranol. We hypothesize that the formation of 10-propyl-9anthranol is due to the addition of a propyl group to the anthracene radical anion followed by an anodic oxidation (Fig. 6.1). Presumably an ionization process involving the 1-propanol molecules occurs in the proximity of the cathode yielding anions and cations that can be added to the anthracene radical anion instead of a proton.
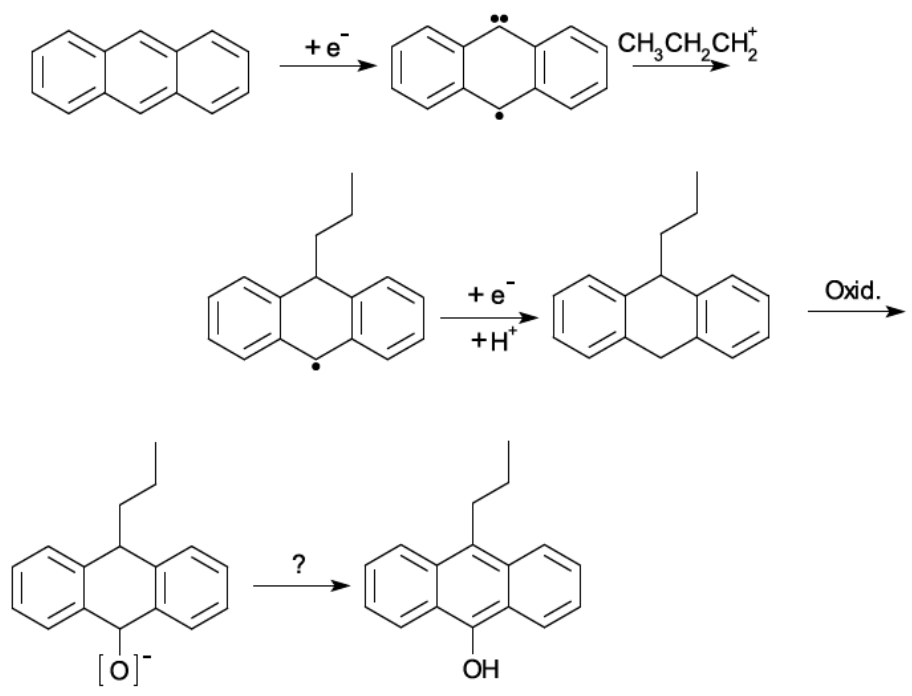

Figure 6.1: Proposed reaction pathway for the formation of 10-propyl-9-anthranol in 1-propanol.

By decreasing the residence time of the liquid in the microreactor, from 1 to 0.1 seconds (upon applying an electric field of $50 \mathrm{kV} / \mathrm{cm}$ ), the conversion of anthracene is reduced from 58 to $11 \%$, however, for this small residence time the only obtained product is 10-propyl-9-anthranol.

The formation of 10-propyl-9-anthranol is also observed upon applying a low voltage $(10 \mathrm{~V}, \mathrm{E}=20$ $\mathrm{kV} / \mathrm{cm}$ ) independent of the flow rate; for this electric field only traces of 9,10-dihydroanthracene are detected for residence times $\geq 1$ second. From these results it is clear that, for low applied potentials, most of the measured current is generated by the formation of charge carriers and that propyl cations (present due to degradation of the solvent) compete with protons in the reduction of the anthracene radical anion. 


\section{Chapter 6}

These results suggest that, at the applied electric fields $(20-50 \mathrm{kV} / \mathrm{cm})$, the current generated in the 1-propanol solution is due to an equilibrium between two different phenomena: i) direct injection of electrons from tips of the SiNWs into the liquid, generating solvated electrons (favored at high potentials, $25 \mathrm{~V}$ ), and ii) the formation of charge carriers (ions), favored at lower potentials.

In the case of ethanol as solvent, sufficiently high residence times (approx. 1 second) are required to synthesize 9,10-dihydroanthracene starting from a $5 \mathrm{mM}$ solution of anthracene in ethanol (VWR, $99.9 \%)$ upon applying a potential difference of $10 \mathrm{~V}(\mathrm{E}=20 \mathrm{kV} / \mathrm{cm})$ between the electrodes. Similar to the reduction of anthracene in 1-propanol, also in case of ethanol, side products are formed during the reaction.

From the MS data (see also Supporting Information) it follows that, in addition to the anthraquinone, a product with a methyl and an ethyl group added to the reduced anthracene molecule is formed. In order to get information on the position of the methyl and ethyl group on the molecule NMR analysis was performed. Unfortunately, the quantity of collected solution after the reaction was not sufficient to proceed with a purification step. Therefore, due to the very small volumes of product mixture that can be collected from the outlets of the microreactor, we have applied a microfluidic NMR stripline probe with a sample volume of $100 \mathrm{~nL}$. This device is an improved version of the previously reported silicon-based stripline chip ${ }^{[13]}$, and consists of a stripline structure of copper, electroplated on a fused silica substrate, on which a $250 \mu \mathrm{m}$ inner diameter fused silica capillary is aligned, which contains the sample as a liquid slug embedded in Fluorinert ${ }^{\circledR}$ FC-40 liquid (Sigma-Aldrich), as previously described by Bart et $\mathrm{al}^{[14]}$. Full details of this probe, which has a spectral resolution of ca. $2 \mathrm{~Hz}$ at a $1 \mathrm{H}$ resonance frequency of $600 \mathrm{MHz}$, are reported elsewhere. Although the NMR data (shown in the Supporting Information) shows the signals from all the different types of molecules present in the solution we can obtain some information on the molecular structure of the product. In detail, the $2 \mathrm{D}$ COSY experiment shows a strong interaction between the signals positioned at $0.9,1.5$, and $3.4 \mathrm{ppm}$. These signals are attributed to the interactions between a $-\mathrm{CH}_{3}(0.9 \mathrm{ppm}),-\mathrm{CH}_{2}(1.5 \mathrm{ppm})$ and $-\mathrm{CH}$ $(3.4 \mathrm{ppm})$ groups and suggest the interaction between the ethyl group with a proton in the ring of the molecule. The methyl group (signal at $2.7 \mathrm{ppm}$ ) doesn't show any interaction with other protons suggesting its addition to a carbon atom of the aromatic ring. Combining the information obtained from the 2D NMR and the GC-MS spectra we hypothesize the formation of 9-ethyl-2-methyl-9,10dihydroanthracene and 9-ethyl-3-methyl-9,10-dihydroanthracene. Most of the signals in the NMR spectra were identified, unfortunately, due to the analysis conditions (a mixture of products) the origin of some of the signals remain unclear, probably due to the formation of new molecules from the solvent degradation and recombination that are not visible in the GC-MS analysis.

Considering the formed molecule types and the applied potential in the microreactor, we propose the initial formation of an anthracene radical anion, followed by an addition of the ethyl cation instead of a proton, forming 9-ethyl-9,10-dihydroanthracene. Then, the formation of 9-ethyl-9,10- 
dihydroanthracene is followed by the addition of a methyl group to one of the aromatic rings and the removal of a proton by a hydroxide anion forming in this way 9-ethyl-2-methyl-9,10dihydroanthracene or 9-ethyl-3-methyl-9,10-dihydroanthracene (Figure 6.2).

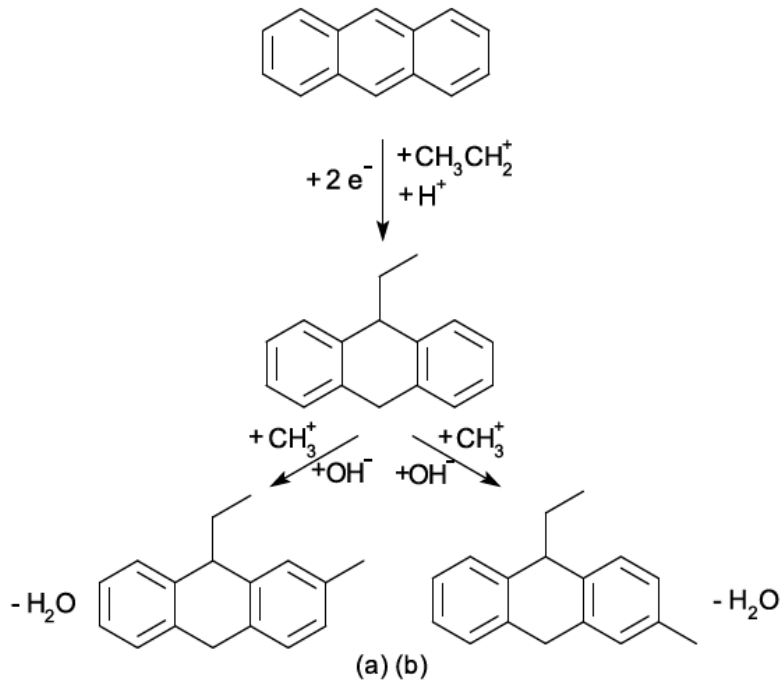

Figure 6.2: Proposed reaction pathway for the formation of (a) 9-ethyl-2-methyl-9,10-dihydroanthracene and (b) 9-ethyl-3-methyl-9,10-dihydroanthracene in ethanol.

The formation of anthraquinone in the partial reduction of anthracene was also observed by Fontana et $\mathrm{al}^{[15]}$, for experiments in an undivided electrochemical cell, and they state that this is due to a reoxidation of some of the formed 9,10-dihydroanthracene at the counter electrode (anode).

The obtained results for the partial reduction of anthracene suggest that applying a high electric field between two electrodes $(E=20$ or $50 \mathrm{kV} / \mathrm{cm})$ generates solvated electrons in parallel with charge carriers. Considering the different structure of the molecules obtained using ethanol or 1-propanol, we hypothesize that the charge carriers consist of cations and anions originating from a degradation process of the solvent. The ratio between current formed by injection of charges and solvated electrons depends on the applied electric field: at an electric field of $50 \mathrm{kV} / \mathrm{cm}$ the electron injection mechanism is favored. This is confirmed by the conversion data of anthracene during the reaction in 1-propanol (at a flow rate of $1 \mu \mathrm{l} / \mathrm{min}$ ): at both electric fields, 20 and $50 \mathrm{kV} / \mathrm{cm}$, the conversion is ca. $60 \%$ but only in the case of an electric field of $50 \mathrm{kV} / \mathrm{cm} \mathrm{9,10-dihydroanthracene} \mathrm{is} \mathrm{formed,}$ suggesting a relatively low amount of propyl cations in the reaction environment with respect to the case of a reaction carried out at an electric field of $20 \mathrm{kV} / \mathrm{cm}$. 


\subsubsection{Reduction of naphthalene}

The partial reduction of naphthalene (Sigma-Aldrich, 99\%) in both alcohols, ethanol and 1-propanol, is also studied in the CFE microreactors. $50 \mathrm{mM}$ solutions of naphthalene are continuously flowed in the microreactor. For flow rates higher than $1 \mu \mathrm{l} / \mathrm{min}$ no product is detected in the collected solution. 1,4-dihydronaphthalene is formed when a potential difference of $10 \mathrm{~V}(\mathrm{E}=20 \mathrm{kV} / \mathrm{cm})$ is applied between the electrodes and the residence time of the fluid inside the microreactor is $\geq 1 \mathrm{sec}$. By increasing the potential to $20 \mathrm{~V}(\mathrm{E}=40 \mathrm{kV} / \mathrm{cm})$ a consecutive reduction occurs, yielding $1,2,3,4-$ tetrahydronaphtalene (Table 6.2). Hydrogenation of naphthalene proceeds through a sequential pathway (Figure 6.3):

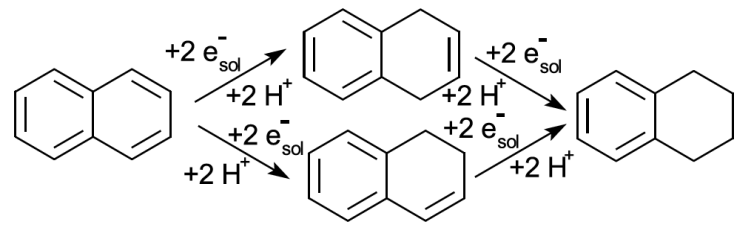

Figure 6.3: Hydrogenation pathway for the formation of 1,2-dihydronaphthalene, 1,4-dihydronaphthalene and 1,2,3,4-tetrahydronaphthalene.

Table 6.2. Product yields (in \%) for the reduction of naphthalene using a microreactor with a nanostructured electrode and ethanol and 1-propanol as solvents.

\begin{tabular}{|c|c|c|c|c|c|}
\hline \multicolumn{6}{|c|}{ Reduction of naphthalene in 1-propanol } \\
\hline Voltage & $\begin{array}{c}\text { Flow } \\
\text { Rate/Residence } \\
\text { Time }\end{array}$ & $\begin{array}{c}\text { Conversion } \\
(\%)\end{array}$ & $\begin{array}{c}1,4- \\
\text { dihydronaphthalene } \\
(\%)\end{array}$ & $\begin{array}{c}1,2- \\
\text { dihydronaphthalene } \\
(\%)\end{array}$ & $\begin{array}{c}, 2,3,4- \\
\text { tetrahydro } \\
\text { naphthalene } \\
(\%)\end{array}$ \\
\hline $10 \mathrm{~V}$ & $1 \mu \mathrm{l} / \mathrm{min} / 1 \mathrm{sec}$ & $0.1 \%$ & 0.1 & None & None \\
\hline $20 \mathrm{~V}$ & $1 \mu \mathrm{l} / \mathrm{min} / 1 \mathrm{sec}$ & $2.9 \%$ & 2.5 & 0.1 & 0.3 \\
\hline \multicolumn{6}{|c|}{ Reduction of naphthalene in ethanol } \\
\hline Voltage & $\begin{array}{c}\text { Flow } \\
\text { Rate/Residence } \\
\text { Time }\end{array}$ & $\begin{array}{c}\text { Conversion } \\
(\%)\end{array}$ & $\begin{array}{c}1,4- \\
\text { dihydronaphthalene } \\
(\%)\end{array}$ & $\begin{array}{c}1,2- \\
\text { dihydronaphthalene } \\
(\%)\end{array}$ & $\begin{array}{c}1,2,3,4- \\
\text { tetrahydro } \\
\text { naphthalene } \\
(\%)\end{array}$ \\
\hline $20 \mathrm{~V}$ & $1 \mu 1 / \mathrm{min} / 1 \mathrm{sec}$ & $1.7 \%$ & 0.9 & None & 0.8 \\
\hline
\end{tabular}


First one of the double bonds of the aromatic ring is reduced by two solvated electrons and two protons (giving 1,4-dihydronaphthalene, or the less stable product 1,2-dihydronaphthalene) and secondly another two solvated electrons in combination with two protons reduce the other double bond, which yields 1,2,3,4-tetrahydromaphtalene. Considering our results and the studies carried out by Kaiser ${ }^{[16]}$ on the Birch reduction of naphthalene, who reports that an excess of metal in the solution shifts the reduction from 1,4-dihydronaphtalene to 1,2,3,4-tetrahydronaphtalene, we can state that only upon formation of a sufficient amount of solvated electrons in the solution (an electric field of at least $40 \mathrm{kV} / \mathrm{cm}$ ), the reaction can proceed to form 1,2,3,4-tetrahydronaphtalene. The overall conversion of naphthalene to the di-hydro and tetra-hydro products is quite low in comparison to the results obtained by Rabideau et al. using alkali metals in liquid ammonia, where almost complete conversion of naphthalene to di-hydro and tetra-hydro products was achieved. This is due to the longer reaction time of $30 \mathrm{~min}$. in the batch reactor used by Rabideau et al. ${ }^{[17]}$, compared to a residence time of $1 \mathrm{sec}$. in our CFE continuous flow microreactor.

\subsubsection{Reduction of benzophenone}

Finally, the selectivity of CFE in a microreactor for the reduction of a PAH containing more than one reducible group is verified by flowing a $5 \mathrm{mM}$ solution of benzophenone (Sigma-Aldrich, 99\%) in ethanol at $1 \mu \mathrm{l} / \mathrm{min}$ upon applying a potential difference of $20 \mathrm{~V}$ between the electrodes. At these reaction conditions, only the reduction of the ketone to an alcohol is obtained. Kariv-Miller et al. achieved a similar result for the reduction of estrone 3-methyl ether, namely only a reduction of the ketone to the aromatic alcohol for low currents. Upon increasing the current and completing the hydrogenation of the ketone, it was possible to reduce the aromatic ring ${ }^{[8]}$. This indicates that the reduction of the ketone is favored with respect to the reduction of the aromatic ring, which is also the case with solvated electrons generated in the CFE microreactor. At the applied reaction conditions, the reduction of the aromatic ring is not achieved. Probably a significant increase of the residence time is required to obtain the aromatic ring reduction. 


\subsection{Conclusions}

We have demonstrated the chemical performance of a microreactor, developed to generate solvated electrons by using CFE, for the partial reduction of PAHs in a continuous flow process. The conversion of the PAHs to the dihydro-products is relatively low, which is mainly due to the small residence times attainable in the current CFE microreactor. In the case of anthracene hydrogenation, the synthesis is affected by the formation of side products that are not formed with other reported methods. This is due to the nature of the CFE method, where, upon applying high electric fields between two electrodes, solvated electrons are generated in parallel with charge carriers originating from a degradation process of the solvent. The ratio between the current formed by injection of charges and solvated electrons depends on the applied electric field, and influences the outcome of the partial reduction of anthracene in ethanol/1-propanol, for which a new pathway is proposed. On the contrary, the reductions of naphthalene and benzophenone in CFE microreactors follow a known pathway for this type of reaction. Further in-depth investigations on the reaction mechanism should be performed to clearly understand the potential of these CFE microreactors. 


\subsection{References}

[1] A. J. Birch, "Reduction by dissolving metals. Part 1", J.Chem. Soc., 0, 430-436, 1944.

[2] F. L. Ortiz, M. J. Iglesias, I. Fernandez, C. M .A. Sanchez and G. R. Gomez, "Nucleophilic dearomatizing (DNAr) reactions of aromatic $\mathrm{C}, \mathrm{H}$-systems. a mature paradigm in organic synthesis", Chem. Rev., 107, 1580-1691, 2007.

[3] W. D. Harman, W. P. Schaefer and H. Taube, "The regio- and stereospecific selective hydrogenation of $\eta 2$-coordinated arenes”, J. Am. Chem. Soc., 112, 2682-2685, 1990.

[4] J. J. Eisch, S. R. Sexsmith and M. Singh, "Lewis acid catalyzed hydrogen shuttling between aromatic and hydroaromatic hydrocarbons", Energy Fuels, 3, 762-764, 1989.

[5] H. W. Sternberg, R. Markby and I. Wender, "Electrochemical reduction of benzene ring", J. Electrochem. Soc.,110, 425-429, 1963.

[6] A. Demortier and A. J. Bard, "Electrochemical reactions of organic compounds in liquid ammonia. I. Reduction of benzophenone”, J. Am. Chem. Soc., 3495-3500, 1973.

[7] R. A. Benkeser, E. M. Kaiser and R. F. Lambert, "The selective reduction of aromatic compounds to dihydro or tetrahydro products by an electrochemical method", J. Am. Chem. Soc., 5272-5276, 1964.

[8] E. Kariv-Miller, K. E. Swenson, G. K. Lehman and R. Andruzzi, "Selective cathodic Birch reduction”, J. Org. Chem., 556-560, 1985.

[9] Y. Segawa and D. W. Stephan, "Metal-free hydrogenation of polycyclic aromatic hydrocarbons", Chem. Commun., 11963-11965, 2012.

[10] N. Na, Y. Xia, Z. Zhu, X. Zhang and R. G. Cooks, "Birch reduction of benzene in a lowtemperature plasma”, Angew. Chem. Int. Ed., 48, 2017-2019, 2009.

[11] R. A. Holroyd, "Equilibrium reactions of excess electrons with aromatics in non-polar solvents”, Berichte der Bunsen-Gesellschaft, 298-304, 1977.

[12] A. Agiral, H. B. Eral, D. van den Ende, J. G. E. Gardeniers, "Charge injection from carbon nanofibers into a dielectric liquid under ambient conditions", IEEE Trans. Electron Devices, 58, 3514-3518, 2011. 


\section{Chapter 6}

[13] J. Bart, A. J. Kolkman, A. J. O. Vries, K. Koch, P. J. Nieuwland, H. Janssen, J. van Bentum, K. A. M. Ampt, F. P. J. T. Rutjes, S. S. Wijmenga, H. Gardeniers and A. P. M. Kentgens, “A microfluidic high-resolution NMR flow probe", J. Am. Chem. Soc., 131, 5014-5015, 2009.

[14] J. Bart, J. W. G. Janssen, P. J. M. van Bentum, A. P. M. Kentgens and J. G. E. Gardeniers, "Optimization of stripline-based microfluidic chips for high-resolution NMR", J. Magn. Reson., 201, 175-185, 2009.

[15] E. Gagyi Palffy, P. Starzewski, A. Labani and A. Fontana, "Electrochemical reduction of polyaromatic compounds”, J. Appl. Electrochem., 24, 337-343, 1994.

[16] E. M. Kaiser, "A comparison of methods using lithium/amine and Birch reduction systems", Synthesis, 391-415, 1971.

[17] P. W. Rabideau and D. L. Huser, "Protonation of anion intermediates in metal-ammonia reduction: 1,2- vs. 1,4-dihydro aromatic products”, J. Org. Chem, 48, 4266-4271, 1983. 


\section{SUPPORTING INFORMATION}

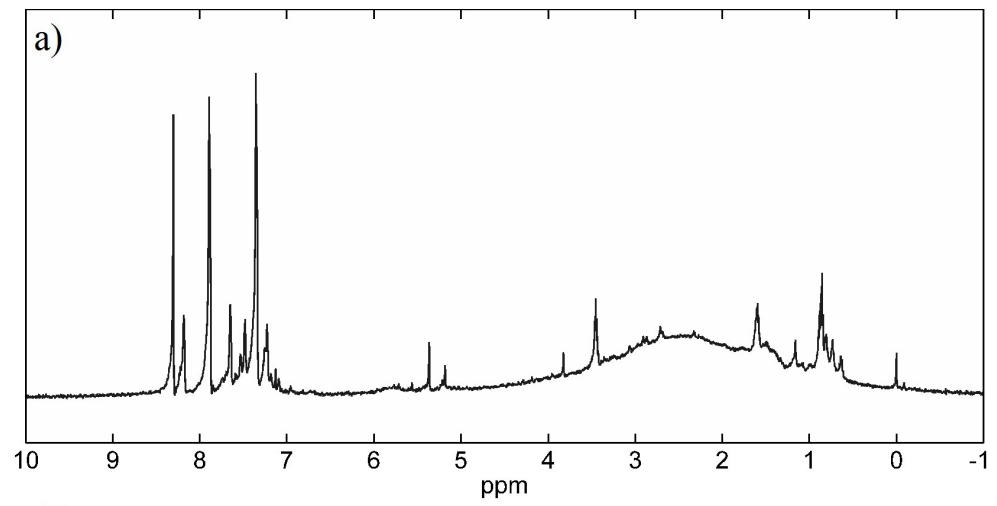

b)

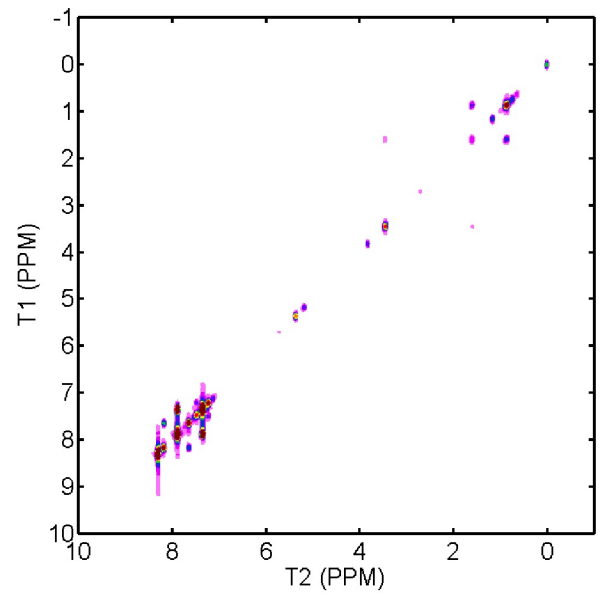

Figure SI-1: a) 1D ${ }^{1} \mathrm{H}$ NMR spectra and b) 2D COSY NMR spectra for the reduction of anthracene using a microreactor with a nanostructured electrode and ethanol.

\section{NMR spectra of the obtained products:}

9-ethyl-2-methyl-9,10-dihydroanthracene and 9-ethyl-3-methyl-9,10-dihydroanthracene ( $\delta$ ): 0.9, 1.5, 2.7, 3.4, 3.8, 7.3, 7.5.

Anthraquinone (ס): 7.6, 8.2.

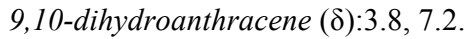

Anthracene ( $\delta$ ): 7.4, 7.9, 8.3. 


\section{Mass Spectrometry Data}

9,10-dihydroanthracene $\quad(\mathrm{m} / \mathrm{z}$, intensity): 17.000,381.000; 18.000,1564.000; 28.000,980.000; 32.100,498.000; 76.200,237.000; 87.900,178.000; 89.000,450.000; 151.000,206.000; $151.900,216.000 ; \quad 165.000,518.000 ; \quad 176.000,502.000 ; \quad 176.900,224.000 ; \quad 178.000,1681.000$; 179.000,2253.000; 180.000,2047.000; 181.100,294.000

10-propyl-9-anthranol (m/z, intensity): 17.000,249.000; 18.000,983.000; 28.000,620.000; $31.900,339.000 ; \quad 163.000,353.000 ; \quad 164.000,245.000 ; \quad 165.000,1238.000 ; \quad 165.900,180.000$; $176.000,118.000 ; \quad 193.000,1323.000 ; \quad 194.000,2909.000 ; \quad 195.000,491.000 ; \quad 206.900,128.000$; $236.100,876.000 ; 236.900,131.000$

Anthraquinone (m/z, intensity): 17.000,235.000;18.000,801.000; 28.000,546.000; 31.900,311.000; 76.000,153.000; 151.000,187.000; 151.900,261.000; $165.000,105.000 ; \quad 180.000,270.000$; 207.000,111.000;208.000,389.000

9-ethyl-2-methyl-9,10-dihydroanthracene and 9-ethyl-3-methyl-9,10-dihydroanthracene $(\mathrm{m} / \mathrm{z}$, intensity): 17.000,197.000; 18.100,796.000; 28.000,619.000; 31.900,366.000; 165.000,286.000; $176.000,137.000 ; \quad 178.000,569.000 ; \quad 179.000,458.000 ; \quad 192.900,710.000 ; \quad 194.100,542.000$; $195.100,392.000 ; 222.100,732.000 ; 223.000,160.000$

1,4-dihydronaphtalene $\quad(\mathrm{m} / \mathrm{z}, \quad$ intensity): $\quad 16.900,252.000 ; \quad 18.000,902.00 ; \quad 27.000,268.000$; 28.000,1659.000; $31.900,491.000 ; \quad 37.900,161.000 ; \quad 39.000,827.000 ; \quad 50.000,1006.000$; 51.000,2128.000; $\quad 51.900,372.000 ; \quad 53.100,118.000 ; \quad 60.800,154.000 ; \quad 61.900,490.000$; 63.000,1734.000; 64.000,2242.000; 64.800,664.000; 74.000,782.000; 75.000,885.000; 76.000,761.00; 77.000,1639.000; 78.000,807.000; 85.900,227.000; 86.900,408.000; 88.000,100.000; 89.000,592.000; 91.000,318.000; 97.900,205.000; $101.000,591.000 ; \quad 102.000,1847.000 ; \quad 103.000,557.000$; $104.000,120.000 ; \quad 114.000,131.000 ; \quad 115.000,10547.000 ; \quad 116.000,1097.000 ; \quad 126.000,1725.000$; 127.100,5445.000; 128.100,14821.000; 129.000,20824.000; 130.000,21248.000; 131.000,2353.000; $132.000,158.000$

1,2-dihydronaphtalene (m/z, intensity): 17.100,344.000; 18.000,972.000; 28.000,1653.000; 32.000,396.000; 43.900,112.000; 51.000,159.000; 63.300,113.000; 63.900,173.000; 76.900,144.000; $115.000,996.000 ; \quad 127.100,292.000 ; \quad 128.000,971.000 ; \quad 129.000,1431.000 ; \quad 130.000,1693.000$; $131.000,338.000$

1,2,3,4-tetrahydronaphtalene ( $\mathrm{m} / \mathrm{z}$, intensity): 17.000,317.000; 18.100,1000.000; 28.000,1786.000; $32.000,564.000 ; 39.100,188.000 ; 43.900,147.000 ; 50.100,119.000 ; 50.900,318.000 ; 57.700,130.000$; 63.000,244.000; 63.900,276.000; 65.100,302.000; 74.900,104.000; 76.900,378.000; 78.000,462.000; 89.000,109.000; 91.000,1758.000; 91.900,115.000; $102.000,210.000 ; \quad 103.000,619.000 ;$ $104.000,4257.000 ; \quad 105.000,433.000 ; \quad 115.000,682.000 ; \quad 116.000,333.000 ; \quad 117.100,695.000$; 
Birch-type reduction of PAH in alcohols using field electron emission

$127.000,180.000 ; \quad 128.000,494.000 ; \quad 129.100,335.000 ; \quad 130.000,180.000 ; \quad 131.000,658.000 ;$ $132.000,2576.000 ; 132.900,150.000$ 
Chapter 6 


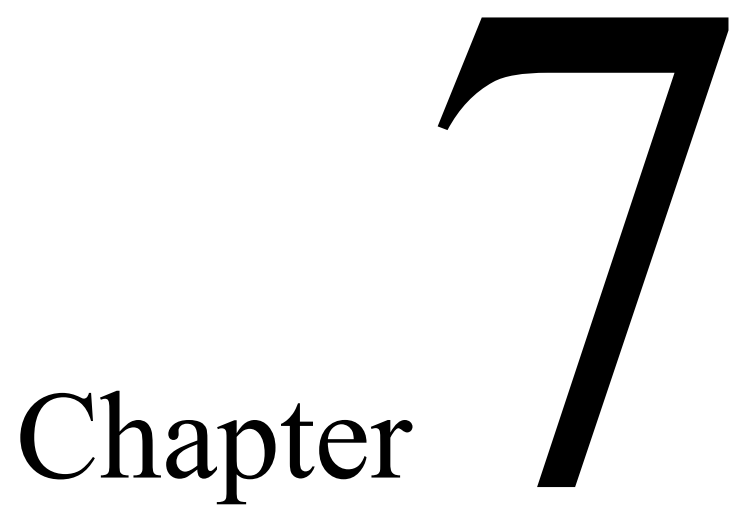

Conclusions and Outlook 


\section{Chapter 7}

\subsection{Conclusions}

A new green process to partially reduce polycyclic aromatic hydrocarbons is presented in this thesis. The proposed process is based on the generation of solvated electrons $\left(\mathrm{e}_{\text {sol }}^{-}\right)$in a continuous flow of dielectric solvents with reactants. The $\mathrm{e}_{\text {sol }}$ are generated by cold field emission (CFE) from micro- or nanotips in a microdevice and result in the reduction of for example anthracene and naphthalene.

In chapter 3 the formation of dense arrays of carbon nanotubes (CNTs) on metal layers using a thermal catalytic chemical vapor deposition method is described. The main synthesis parameters resulting in the vertical alignment of CNTs were analyzed, such as the pretreatment of the sample under hydrogen atmosphere, growth phase in absence of hydrogen and reaction time. Since the synthesis of vertical aligned CNTs is governed by steric factors, a method to form a high amount of catalyst nanoparticles on the sample surface was developed based on dewetting of an iron $(\mathrm{Fe})$ thin film $(3 \mathrm{~nm})$. In addition, samples of VACNTs with low Ohmic resistance were synthesized by introducing a gold or platinum layer of $100 \mathrm{~nm}$ between the $\mathrm{Fe} / \mathrm{Ta}$ (tantalum as adhesion layer) and the silicon support. The as such obtained samples allow field emission enhancement factors up to 2136, however, these VACNTs were not integrated into the flow channel of microfluidic devices.

The role of the distance between the electrodes during field emission in liquids is analyzed in chapter 4. To this end, microreactors were developed with photolithography defined microtips on the electrode surface positioned at different distances from the counter-electrode. These microreactors were tested for field emission of electrons into $n$-hexane and used to reduce anthracene dissolved in a mixture of n-hexane and ethanol. The gathered results indicate that field emission is the prevalent way to introduce charges in $n$-hexane for distances between the electrodes $<3 \mu \mathrm{m}$. In contrast, direct charge exchange at the electrode surface occurs in case of electrode spacing above $3 \mu \mathrm{m}$. For small gaps $(<3 \mu \mathrm{m})$ 9-ethyl,2-methyl-9,10-dihydroanthracene, 9-ethyl,3-methyl-9,10-dihydroanthracene and 9-ethyl-anthrone are formed during the reduction of anthracene in a solution of n-hexane and ethanol.

In chapter 5 another microreactor suitable to induce field emission in liquids is presented. The cathode, consisting of a dense array of vertically aligned silicon nanowires (SiNWs), was placed at approximatively $5 \mu \mathrm{m}$ from the anode, represented by a platinum layer. After the electrical characterization using different solvents (polar and apolar), the microreactor was used for the reduction of anthracene dissolved in n-hexane, N,N-dimethylformamide, ethanol and 1-propanol. Upon the presence of a proton donor the reduction of anthracene was achieved, while the use of pure aprotic solvents did not trigger any product formation.

The reaction performances of the SiNW-based microreactor are described in chapter 6. The microreactor was tested for the reduction of anthracene, naphthalene and benzophenone in ethanol and 1-propanol. Dihydro and tetrahydro-products were obtained only for anthracene and naphthalene. The reduction of anthracene is affected by the formation of side reactions, due to either the addition of 
cations generated by degradation of the solvent or oxidation of anthracene at the anode. A possible reaction pathway is proposed based on product analysis by GC-MS and $\mu$ NMR. In contrast, the reduction of naphthalene and benzophenone follows the known pathways for this type of reaction.

\subsection{Outlook}

The use of CFE to activate radical reactions represents a green alternative to the "conventional developed" processes. CFE in a microreactor allows both the formation of electrons with high energies (upon applying low potentials between the electrodes), as well as the generation of currents in pure dielectric liquids without the addition of electrolytes. However, further research and optimization is required to develop an alternative process for Birch-type reactions to make it of "industrial interest".

The low conversion obtained for the reduction of naphthalene and anthracene could be improved by increasing the residence time of fluid inside the microreactor. To this end, both an increase of the footprint of the nanowire electrode in the microfluidic device or the use of the stop-flow concept represent feasible options. Another option is a different layout/design of the flow channel, for example parallelization of flow channels. In the case of a scale-up of the process the distance between the electrodes is one of the limiting factors. During scaling-up the distance between the electrodes should be maintained to the order of a few micrometers, since otherwise significantly higher voltages have to be applied to the system in order to reach the electric field needed to obtain CFE of electrons. The selectivity of the shown CFE-based method is another issue that has to be improved to avoid consecutive purification. Studies focused on the reaction mechanism (e.g. isotopic labeling) and a better stability of the solvents involved in CFE potentially allow to overcome this issue.

The development of new nanostructured materials as electrodes, for example substitution of the metallic electrodes by carbon-derived materials (such as graphene or carbon nanotubes), can potentially benefit selectivity or conversion of the reactions. Moreover, it is also believed that periodic reversal of polarity of the electrodes during the reaction can increase the efficiency of the proposed process. 
Chapter 7 


\section{Summary}

This thesis describes the development of a novel process to partially reduce aromatic hydrocarbons by combining microreactor technology and cold field emission (CFE) of electrons in liquids.

In the first and second chapter, the project goal and a review of literature on solvated electrons and their application in organic chemistry are given.

In the third chapter the synthesis of vertically aligned carbon nanotubes (VACNTs) on various substrates and their application as electron emitters is considered. Vertically aligned carbon nanotubes were obtained by thermal catalytic chemical vapor deposition using iron $(\mathrm{Fe})$ catalyst dispersed on a thin tantalum (Ta) layer, on silicon or fused silica support wafers. The effect of the original Fe layer thickness, the Fe dewetting pretreatment and synthesis conditions on the topography and electrical properties of the nanotubes were analyzed. Either randomly oriented or vertically aligned carbon nanotubes were obtained by varying the catalyst thickness from 2 to $6 \mathrm{~nm}$ or the synthesis temperature between 680 and $740^{\circ} \mathrm{C}$. The nature of the substrate under the Ta layer had an important effect on catalyst dewetting during pretreatment. Introduction of an $\mathrm{Au}$ or Pt metal layer between the silicon and the Ta significantly improved the overall conductivity of a sample. The optimal settings to grow VACNTs on silicon and fused silica, with or without the introduction of a metal layer between the adhesion layer and the support, were found by adjusting the pretreatment time for a fixed catalyst layer thickness $(3 \mathrm{~nm})$, and fixed temperature $\left(720{ }^{\circ} \mathrm{C}\right)$ and gas mixture composition during pretreatment (4:1 vol\% $\left.\mathrm{N}_{2} / \mathrm{H}_{2}\right)$ and growth $\left(2: 1 \mathrm{vol} \% \mathrm{~N}_{2} / \mathrm{C}_{2} \mathrm{H}_{4}\right)$ phases. This method permitted to create VACNTs with a low Ohmic resistance, suitable for field emission applications. Field enhancement factors up to 2136 were found for VACNTs synthesized on Fe/Ta.

A novel microreactor with photolithographically defined integrated electrodes, one of them containing micro- tips that serve as emission points for solvated electrons into liquids, is described in chapter 4 . After a computational analysis of the electric field distribution in the gap between a linear microtip array and a flat electrode, electrical characterization of these microdevices was carried out. By varying the distance between the electrodes in commercially pure grade n-hexane, for tip-to-flat-electrode distances of less than $3 \mu \mathrm{m}$ field emission was identified as the prevalent way to introduce charges in liquid n-hexane, whereas for distances higher than $3 \mu \mathrm{m}$ direct charge exchange at the electrode surfaces became the prevalent way. With this microreactor field emission in pure n-hexane did not directly reduce aromatic hydrocarbons, for that the addition of a proton donator was necessary. In solutions of n-hexane and ethanol, a mixture of products identified as 9-ethyl-2-methyl-9,10dihydroanthracene, 9-ethyl-3-methyl-9,10-dihydroanthracene and 9-ethyl-anthrone was formed, due to the presence of methyl and ethyl cations formed by electrochemical degradation of the alcohol. 
In chapter 5 a microreactor is described with nanostructured electrodes consisting of two electrodes oriented in a vertical configuration and separated by an insulating layer of $250 \mathrm{~nm}$ of low stress silicon-rich silicon nitride. One of the electrodes, the cathode, contained a dense array of silicon nanowires created with an electroless metal deposition method on highly doped p-type silicon; the other electrode, the anode, was a $100 \mathrm{~nm}$ platinum layer deposited on a glass wafer. Low voltage charge injection from a field emitter array integrated in a microchannel into a flow of apolar (nhexane, 1-hexene and cyclohexane) or polar (N,N-dimethylformamide, ethanol and 1-propanol) solvents under ambient conditions was studied in this microreactor. In the case of a sufficiently high electric field, in both polar and apolar solvents electron emission became predominant with respect to electrochemical conduction. For this microreactor field emission in liquids containing a proton donator was experimentally proven to partially reduce aromatic hydrocarbons, although with relatively low reaction yield.

In chapter 6 a study on the partial hydrogenation of polycyclic aromatic hydrocarbons, using the microreactor described in chapter 5 , is reported. In detail, the reduction of anthracene, naphthalene and benzophenone in ethanol and 1-propanol upon applying a potential difference between the electrodes from $10 \mathrm{~V}$ to $25 \mathrm{~V}$ was performed. The conversion of these polycyclic aromatic hydrocarbons to their dihydro-products was relatively low, which was mainly due to the small residence times attainable in the microreactor. In the case of anthracene hydrogenation, the synthesis was affected by the formation of side products that are not formed in case of 'conventional' methods as found in literature. This was due to the nature of the CFE method, where, upon applying high electric fields between two electrodes, solvated electrons were generated in parallel with charge carriers originating from a degradation process of the solvent. In contrast to anthracene, the reductions of naphthalene and benzophenone followed a known pathway for this type of reaction.

Finally, in chapter 7 an outlook and recommendations for future work are given. 


\section{Samenvatting}

Dit proefschrift beschrijft de ontwikkeling van een nieuw proces voor de partiële reductie van aromatische koolwaterstoffen, welke gebaseerd is op een combinatie van microreactortechnologie en koud-veld emissie van elektronen in vloeistoffen.

In het eerste en tweede hoofdstuk worden het doel van het project beschreven, alsmede een literatuuroverzicht van gesolvateerde elektronen en de toepassingen hiervan in organische chemie.

In het derde hoofdstuk wordt de synthese van verticaal geörienteerde koolstof nanobuisjes op verschillende dragers besproken en de applicatie hiervan als elektron-emissie punten. Verticaal geörienteerde koolstof nanobuisjes zijn gemaakt door thermo-katalytische gas fase depositie op ijzerdeeltjes (Fe) die verdeeld zijn over een dunne tantaal (Ta) film, op zowel silicium en silica glas als drager. De effecten van de begindikte van de ijzer film, het opbreekproces van deze dunne continue ijzer film in losse deeltjes en synthese condities op de topografie en elektrische eigenschappen van de koolstof nanobuisjes zijn geanalyseerd. Zowel willekeurig als verticaal geörienteerde koolstof nanobuisjes zijn verkregen voor variërende diktes van de ijzer film ( $2 \mathrm{~nm}$ tot 6 $\mathrm{nm})$ of synthese temperaturen $\left(680^{\circ} \mathrm{C}\right.$ tot $\left.740{ }^{\circ} \mathrm{C}\right)$. Tevens is gebleken dat het type drager onder de tantaal film grote invloed heeft op het opbreekproces van de ijzer film. Inclusie van een laagje goud $(\mathrm{Au})$ of platina $(\mathrm{Pt})$ tussen de drager en de tantaal film leidt tot een sterke toename in elektrische geleiding van de film van koolstof nanobuisjes. De optimale condities om verticaal geörienteerde koolstof nanobuisjes te fabriceren op silicium en silica glas, met of zonder metallische laag tussen het tantaal en de drager, betreft het aanpassen van de tijd van het opbreekproces voor een vaste dikte van de ijzer film $(3 \mathrm{~nm})$, een gelijke temperatuur voor het opbreekproces en de synthese stap $\left(720^{\circ} \mathrm{C}\right)$ en gegeven composities van de gasmengels tijdens het opbreekproces $\left(4: 1 \mathrm{vol} \% \mathrm{~N}_{2} / \mathrm{H}_{2}\right)$ en de synthese stap (2:1 vol\% $\mathrm{N}_{2} / \mathrm{C}_{2} \mathrm{H}_{4}$ ). Op deze manier zijn laag-ohmige verticaal geörienteerde koolstof nanobuisjes gemaakt die zeer geschikt zijn voor veld emissie. Voor dergelijke nanobuisjes op Fe/Ta zijn veldversterkingsfactoren tot 2136 vastgesteld.

Hoofdstuk 4 gaat over een microreactor met foto lithografisch gedefinieerde geïntegreerde elektrodes, waarbij één elektrode micropunten bevat die leiden tot emissie van gesolvateerde elektronen in vloeistoffen. Na een computer-analyse van de elektrische veldverdeling in de ruimte tussen een lineaire array van micropunten en een vlakke elektrode is een elektrische karakterisatie van deze microreactoren uitgevoerd. Door het variëren van de afstand tussen deze elektrodes is in geval van commercieel puur n-hexaan vastgesteld dat i) voor elektrode ruimtes van $3 \mu \mathrm{m}$ (en kleiner) veld emissie het dominante mechanisme is om ladingen in vloeibaar n-hexaan te introduceren, ii) voor elektrode afstanden groter dan $3 \mu \mathrm{m}$ direct ladingsoverdracht aan het elektrode oppervlak het bepalende mechanisme is. In deze microreactor leidt veld emissie in puur n-hexaan niet direct tot 
reductie van aromatische koolwaterstoffen: hiervoor is het toevoegen van een proton-donor vereist. In oplossingen van $\mathrm{n}$-hexaan en ethanol is het mengsel van producten geanalyseerd en bleken 9-ethyl-2methyl-9,10-dihydroantraceen, 9-ethyl-3-methyl-9,10-dihydroantraceen en 9-ethyl-antron te zijn gevormd, vanwege de aanwezigheid van methyl en ethyl kationen ten gevolge van elektrochemische degradatie van de alcohol.

Hoofdstuk 5 beschrijft de ontwikkeling van een microreactor met nano-gestructureerde elektrodes welke in een verticale configuratie geplaatst zijn en gescheiden zijn door een isolerende laag van stress arm silicium-rijk silicium nitride. Één van de elektrodes, de kathode, bevat een array van silicium nanodraden die zijn gemaakt met behulp van een stroomloze metaal depositie methode op hooggedoteerd p-type silicium; de andere elektrode, de anode, is een $100 \mathrm{~nm}$ dikke platina film op een glas drager. In deze microreactor is lage spanning ladingsinjectie vanaf een array van silicium nanodraden bestudeerd, voor arrays die geïntegreerd zijn in een microkanaal waardoor apolaire (nhexaan, 1-hexeen en cyclohexaan) of polaire (N,N-dimethylformamide, ethanol en 1-propanol) oplosmiddelen stromen. In geval van een voldoende hoog elektrisch veld is zowel voor polaire als apolaire oplosmiddelen elektron emissie dominant ten opzichte van elektrochemische geleiding. Met deze microreactor is experimenteel bewezen dat veld emissie in vloeistoffen waaraan een protondonor is toegevoegd daadwerkelijk tot partiële reductie van aromatische koolwaterstoffen leidt, zij het met een relatief lage reactie opbrengst.

Hoofdstuk 6 omvat een studie naar de partiele hydrogenering van polycyclische aromatische koolwaterstoffen met behulp van de microreactor met daarin arrays van silicium nanodraden voor elektron emissie. Meer specifiek, er is onderzoek gedaan naar de reductie van antraceen, naftaleen en benzofenon in ethanol en 1-proponal voor elektrode-potentialen van $10 \mathrm{~V}$ tot $25 \mathrm{~V}$. De omzetting van deze polycyclische aromatische koolwaterstoffen tot hun dihydro-producten was relatief laag, wat in hoofdzaak een gevolg is van de kleine verblijftijden van stoffen in de microreactor. In het geval van antraceen hydrogenering wordt de omzetting beïnvloedt door het ontstaan van bijproducten welke niet gevormd worden in 'conventionele' methodes zoals gerapporteerd in de literatuur. Dit is een gevolg van de koud-veld emissie methode waar, na het aanbrengen van hoge elektrische velden tussen twee elektrodes, tegelijkertijd gesolvateerde elektronen gegenereerd worden als ook ladingsdragers ten gevolge van een degradatie proces van het oplosmiddel. De reducties van naftaleen en benzofenon verlopen daarentegen volgens bekende wegen voor dit type reactie.

Tenslotte worden in hoofdstuk 7 een vooruitblik en aanbevelingen gegeven voor toekomstig onderzoek. 